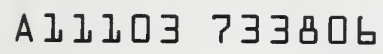

\title{
Data for Fire Hazard Assessment of Selected Non-halogenated and Halogenated Fire Retardants; Report of Test FR 3983
}

Richard H. Harris, Jr., Vytenis Babrauskas, Barbara C. Levin, and Maya Paabo 



\section{Data for Fire Hazard Assessment of Selected Non-halogenated and Halogenated Fire Retardants; Report of Test FR 3983}

Richard H. Harris, Jr., Vytenis Babrauskas, Barbara C. Levin, and Maya Paabo

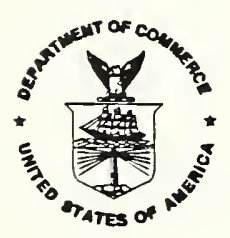

U.S. Department of Commerce Robert A. Mosbacher, Secretary National Institute of Standards and Technology John W. Lyons, Director

Building and Fire Research Laboratory
Sponsored by:

J. M. Huber Corporation/Solem Division 4940 Peachtree Industrial Blvd.

Norcross, GA 30071

Aluminum Company of America

Alcoa Technical Center

Alcoa Center, PA 15069 

LIST OF TABLES . . . . . . . . . . . . . . . . . . . . . . . . . . iv

LIST OF FIGURES . . . . . . . . . . . . . . . . . . . . . . . . . . . v

ABSTRACT . . . . . . . . . . . . . . . . . . . . . . . . . 1

1. INTRODUCTION . . . . . . . . . . . . . . . . . . . . . 2

2. MATERIALS . . . . . . . . . . . . . . . . . . . . . . 3

3. EXPERIMENTAL . . . . . . . . . . . . . . . . . . . . . . 4 4

3.1 Cone Calorimeter . . . . . . . . . . . . . . . . . . . . . . 4

3.1.1 Combustion Technique .. . . . . . . . . . . . . 4

3.1.2 Gas Sampling Through Impingers . . . . . . . . . . . . 5

3.1.3 Test Conditions . . . . . . . . . . . . . . . . . . . 5

3.1.4 Data Collected . . . . . . . . . . . . . . . . 6

3.1.5 Test Results . . . . . . . . . . . . . . . 6

3.2 Cup Furnace Smoke Toxicity Method . . . . . . . . . . . . 15

3.2.1 Discussion . . . . . . . . . . . . . . 15

3.2.2 Animals................... . 16

3.2.3 Toxicity Test System . . . . . . . . . . . 16

3.2.4 Gas Analysis .. . . . . . . . . . . . . . . . 17

3.2.5 Results ................... . 17

4. SUMMARY AND CONCLUSIONS . . . . . . . . . . . . . . . . . . . . . 20

5. ACKNOWLEDGEMENTS . . . . . . . . . . . . . . . . . . . . . . . . . 21

6. REFERENCES . . . . . . . . . . . . . . . . . . . . . 23

APPENDIX A. ION CHROMATOGRAPHY PROCEDURE . . . . . . . . . . . . . . . 49 


\section{LIST OF TABLES}

Page

Table 1. Materials Studied . . . . . . . . . . . . . . . . . 25

Table 2. Cone Calorimeter Data Summary -. $30 \mathrm{~kW} / \mathrm{m}^{2}$ Irradiance Tests without Spark Igniter . . . . . . . . . . . . . . . . . 26

Table 3. Cone Calorimeter Data Summary - Test Average Data at $30 \mathrm{~kW} / \mathrm{m}^{2}$ Irradiance without Spark Igniter . . . . . . . . . 28

Table 4. Cone Calorimeter Data Summary - $30 \mathrm{~kW} / \mathrm{m}^{2}$ Irradiance Tests with Spark Igniter . . . . . . . . . . . . . . . . 29

Table 5. Cone Calorimeter Data Summary - Test Average Data at 30 $\mathrm{kW} / \mathrm{m}^{2}$ Irradiance with Spark Igniter . . . . . . . . . . . . 31

Table 6. Cone Calorimeter Data Summary - $100 \mathrm{~kW} / \mathrm{m}^{2}$ Irradiance Tests without Spark Igniter . . . . . . . . . . . . . . . . . . 33

Table 7. Cone Calorimeter Data Summary - Test Average Data at $100 \mathrm{~kW} / \mathrm{m}^{2}$ Irradiance without Spark Igniter . . . . . . . . . . 34

Table 8. Chemical and Toxicological Results from Material 5-VV . . . 35

Table 9. Chemical and Toxicological Results from Material 6-HH . . . 36

Table 10. Chemical and Toxicological Results from Material 7-BB . . . 37

Table 11. Chemical and Toxicological Results from Material 8-EE . . . 38

Table 12. Chemical and Toxicological Results from Material 11-PP . . . 39

Table 13. Summary of Chemical and Toxicological Results - Non-flaming . 40

Table 14. Summary of Chemical and Toxicological Results - Flaming . . 41

Table 15. Estimated Toxic Potency from High Density Polyethylene

with and without Fire Retardants . . . . . . . . . . . . 42 


\section{LIST OF FIGURES}

Page

Figure 1. Conceptual view of the Cone Calorimeter . . . . . . . . . . . 43

Figure 2. Smoke measurement system used on the Cone Calorimeter . . . . 44

Figure 3. Impinger gas sampling in the Cone Calorimeter . . . . . . . . 45

Figure 4. Animal exposure system . . . . . . . . . . . . . . . . . . . . 46

Figure 5. Post-exposure animal weight change, material 5-VV, $30 \mathrm{~min}$ flaming exposure, $39 \mathrm{~g} / \mathrm{m}^{3}$ mass loading . . . . . . . . . . . 47

Figure 6. Post-exposure animal weight change, material 5-VV, 30 min flaming exposure, $40 \mathrm{~g} / \mathrm{m}^{3}$ mass loading . . . . . . . . . . 48 



\title{
DATA FOR FIRE HAZARD ASSESSMENT OF SELECTED NON-HALOGENATED AND HALOGENATED FIRE RETARDANTS; REPORT OF TEST 3983
}

\author{
Richard H. Harris, Jr., Vytenis Babrauskas, \\ Barbara C. Levin, Maya Paabo \\ Building and Fire Research Laboratory \\ National Institute of Standards and Technology \\ Gaithersburg, Maryland 20899
}

\begin{abstract}
Five plastic materials, with and without fire retardants, were studied to compare the fire hazards of non-halogenated fire retardant additives with halogenated flame retardants. The plastic materials were identified by the sponsors as unsaturated polyesters, thermoplastic high density, low density and cross-linked low density polyethylenes, polypropylene, flexible and rigid poly(vinyl chlorides), and cross-linked and thermoplastic ethylene-vinyl acetate copolymers. The non-halogenated fire retardants tested were aluminum hydroxide $\left(\mathrm{Al}(\mathrm{OH})_{3}\right)$, also known as alumina trihydrate (ATH), sodium aluminocarbonate, and magnesium hydroxide. The halogenated flame retardants were chlorine or bromine/antimony oxides. The plastics were studied using the Cone Calorimeter and the cup furnace smoke toxicity method (high density polyethylene only). The Cone Calorimeter provided data on mass consumed, time to ignition, peak rate and peak time of heat release, total heat released, effective heat of combustion, average yields of $\mathrm{CO}, \mathrm{CO}_{2}, \mathrm{HCl}$, and $\mathrm{HBr}$, and average smoke obscuration. The concentrations of toxic gases generated in the cup furnace smoke toxicity method were used to predict the toxic potency of the mixed thermal decomposition products. The data from the Cone Calorimeter indicate that the non-halogenated fire retardants were, in most of the tested plastic formulations, more effective than the halogenated flame retardants in increasing the time to ignition. The non-halogenated fire retardants were also more effective in reducing the mass consumed, peak rate of heat release, total heat released, and effective heat of combustion, and in reducing the amount of smoke produced. The use of halogenated flame retardants increased smoke production and $\mathrm{CO}$ yields and, additionally, produced the known acid gases and toxic irritants, $\mathrm{HCl}$ and $\mathrm{HBr}$, in measurable quantities. The chemical analytical data for the high density polyethylene samples decomposed via the cup furnace smoke toxicity method in the non-flaming mode indicated that the levels of $\mathrm{CO}$ and $\mathrm{CO}_{2}$ were insufficient to cause death of the test animals (rats), but deaths did occur with all samples except the one containing the halogenated flame retardant. In the flaming mode deaths occurred during exposure to the combustion products from the non-fire retarded control and from the halogenated sample; only in the latter case were the $\mathrm{CO}$ and $\mathrm{CO}_{2}$ concentrations high enough to cause the within exposure deaths. These toxicity results are unusual, but do not indicate a need for concern, since the $\mathrm{LC}_{50}$ values are in the range typical of many common materials.
\end{abstract}




\section{INTRODUCTION}

Fire retardants are most frequently added to plastics to reduce their ease of ignition. Historically, this has meant increasing a material's resistance to a variety of Bunsen burner type exposures $[1]^{1}$. These simple, visual tests have resulted in the modification of many of the most obviously flammable materials, and an accordant increase in fire safety.

In recent years, the fire safety engineers and code officials have perceived a broader concept of product fire safety. This advanced view has caused the examination of other flammability and toxicity characteristics of materials such as:

- Rate of fire growth. This is measured as the rate of heat release from the burning material and the resulting increased temperatures near and away from the fire.

- Smoke obscuration. The time-variant yield of soot and the nature of that soot affect both the spread of alarm and the ability of alerted people to escape.

- Smoke toxicity. Inhalation of the fire products can result in a variety of $i l l$ effects ranging from disorientation to death.

This new understanding has led to a more comprehensive way of evaluating the overall fire safety of commercial building and furnishing materials. For fire-retardant (FR) products in particular, the questions have been raised as to 1. does the FR product result in an improved overall fire hazard performance, compared to the non-retarded one; or 2. are there fire performance areas where a particular hazard component is made worse? These are then areas for future improvement.

During the past several years, the National Institute of Standards and Technology's Building and Fire Research Laboratory (NIST-BFRL) (formerly the Center for Fire Research) has been developing the methodology to determine the overall fire hazard of commercial products. This includes the use of advanced bench-scale measurement-methods, confirmatory real-scale tests, and computer modeling of fires and their impact [2]. Similarly, in comparing different fire retardants intended for the same application, a fire hazard evaluation should also be performed on each.

J. M. Huber Corporation/Solem Division (SOLEM) and The Aluminum Company of America (ALCOA), manufacturers of alumina trihydrate (ATH) fire and smoke retardants, therefore, asked NIST-BFRL to obtain fire property data for hazard analysis on a series of plastics treated with various FR materials and assess if any of the products posed notable differences from that which could be considered "ordinary". The test materials supplied and identified by the sponsor were in the following categories:

1 Numbers in brackets refer to literature references listed in Section 6 at the end of this report. 
1. not flame retarded;

2. not flame retarded, but filled with inert fillers such as calcium carbonate;

3. flame retarded with $\mathrm{ATH}$;

4. flame retarded with magnesium hydroxide and sodium aluminocarbonate; and

5. flame retarded with halogenated/antimony oxides.

In general, $\mathrm{ATH}$ and $\mathrm{Mg}(\mathrm{OH})_{2}$ act as flame retardants and smoke suppressants because of their thermodynamic properties $[3,4,5]$. Sodium aluminocarbonate is thought to act in the same manner as the $\mathrm{ATH}$ and $\mathrm{Mg}(\mathrm{OH})_{2}$, but $\mathrm{CO}_{2}$ is evolved rather than $\mathrm{H}_{2} \mathrm{O}$. Halogenated flame retardants operate in the vapor phase (interfering with oxidation) and synergize with antimony oxide, also interfering with oxidation [6]. $\mathrm{CaCO}_{3}$ acts as an inert filler thereby reducing the total amount of flammable material.

The plastics were to be studied using the Cone Calorimeter (to monitor rate of heat release, effective heat of combustion, smoke production, and the production of several different gas species) and the cup furnace smoke toxicity method.

The cup furnace smoke toxicity method [7] and the $\mathrm{N}$-gas model $[8,9,10,11]$ were used to evaluate the smoke from burning materials for their toxic potency and any unusual toxic gas generation.

\section{MATERIALS}

The materials used in the study were provided by SOLEM and ALCOA. They consisted of five plastics, which were generically designated as unsaturated polyester (PES); thermoplastic high density polyethylene (HDPE), low density polyethylene (LDPE), and cross-linked low density polyethylene (XLPE); polypropylene (PP); flexible and rigid poly(vinyl chloride) (F-PVC and R-PVC); and cross-linked and thermoplastic ethylene-vinyl acetate (XL-EVA and TP-EVA). The materials were supplied with and without flame retardants or fillers. The formulations were not verified by NIST-BFRL.

Table 1 is a summary of the materials studied and the amount of flame retarding elements or additives contained therein. With respect to the unsaturated polyesters, there are two sets in the study. Both sets contain $25 \%$ glass fiber. In the first set, sample $1-C C$ is the reference sample. In both sets, the halogen is introduced by a bromine or chlorine substitution on the aromatic ring of the resin. Sample 35 contains nepheline syenite (NPS), an inert filler which is a variety of rock that contains albite and microcline feldspars and nepheline, a mineral with the composition ( $\mathrm{Na}, \mathrm{K}) \mathrm{AlSiO}_{4}$.

Also of note in Table 1 is that the bromine in samples 8-EE, 30-AH, and 15-UU was introduced from a brominated organic additive not specifically identified by the sponsor. The chlorine in samples 31-AJ, 42, and 46 was introduced from Dechlorane Plus (formulation: 8 weight, Dechlorane Plus 25, antimony oxide 5, 
talc 20, Fe compound 0.2, peroxide curing agent 1.4, and antioxidant (1076) 0.7 ).

The ATH used in the specimens was of a commercial, flame retarded grade of either the ground or precipitated variety $[3,12]$.

There are two sets of rigid poly(vinyl chloride) samples (16 to 18 and 36 to 39). It is not known whether the resin is the same in both sets.

Finally, the flexible PVC samples 19 to 21 all contain $8 \%$ clay as well as about 48 of a phthalate ester plasticizer in addition to the other additives listed.

\section{EXPERIMENTAL}

\subsection{Cone Calorimeter}

\subsubsection{Combustion Technique}

The Cone Calorimeter (Figure 1) was initially presented in 1982 as an improved technique for measuring rate of heat release of bench-scale specimens [13]. Its operation involves an application of the oxygen consumption principle. Earlier instruments for measuring rates of heat release were based on either a concept of a well-insulated box, which led to some very serious measurement errors, or on substitution type schemes, which were cumbersome and difficult to operate [14].

The oxygen consumption principle [15] states that for most combustibles there is a unique constant, $13.1 \mathrm{MJ} / \mathrm{kg} \mathrm{O}$, relating the amount of heat released during a combustion reaction and the amount of oxygen consumed from the air. Thus, using this principle it is only necessary to measure the concentration of oxygen in the flow of the exhaust stream.

In the Cone Calorimeter, specimens of a material or product to be tested are cut into a 100 by $100 \mathrm{~mm}$ size. The thickness depends on the type of product tested, and can range from 6 to $50 \mathrm{~mm}$. All specimens, as the final step of specimen preparation, are wrapped in aluminum foil on the bottom and sides to protect the specimen edges from burning. Edge frames and wire grids were used for some of the samples in this test series. The specimen can be oriented either horizontally or vertically. In this test series, all specimens were tested horizontally.

The specimen is irradiated by an electric heater in the shape of a truncated cone, hence the name Cone Calorimeter. The irradiance can be set to any desired value from zero to $110 \mathrm{~kW} / \mathrm{m}^{2}$. If required, external ignition of the specimen is provided by an electric spark. Since a uniform, controlled irradiance is provided, the ignition times themselves, as measured, constitute a suitable test for ignitability.

The specimen is mounted on a load cell and its mass, along with all other instrument data, is recorded every $5 \mathrm{~s}$.

A few years ago, when shortcomings of existing smoke measuring tests were becoming evident, a smoke measuring system (Figure 2) was evolved for the Cone 
Calorimeter. This comprises a He-Ne laser beam projected across the exhaust duct. The monochromatic light is monitored by a solid-state detector. A second detector serves as a reference, to guard against effects of drift and of laser power fluctuations. The optical system is designed to be selfpurging, and does not use optical windows. Further details of the smoke measuring system have been given in a recent publication [16].

An overview of the design features, along with the specifications and limitations of the Cone Calorimeter has recently been published [14].

\subsubsection{Gas Sampling Through Impingers}

Since the Cone Calorimeter represents a well-controlled combustion environment to which specimens can be exposed, it can also be used for the measurement of gaseous species yields. Thus, fixed gas analyzers for $\mathrm{O}_{2}, \mathrm{CO}, \mathrm{CO}_{2}$, total hydrocarbons, and $\mathrm{H}_{2} \mathrm{O}$ vapor are routinely used. However, it was also necessary to characterize the yields of certain acid gases - - $\mathrm{HCl}, \mathrm{HBr}$, and HCN. For these, commercial on-line gas analyzers with a fast enough response time for the Cone Calorimeter test method were not available. Thus a batch sampling technique needed to be employed.

For the batch sampling technique, a portion of the gaseous products and soot in the main exhaust duct of the Cone Calorimeter was collected and analyzed for

$\mathrm{HCl}, \mathrm{HBr}$, and $\mathrm{HCN}$ by replacing the soot collection filter with a gas sampling apparatus. Figure 3 shows a diagram of the gas sampling apparatus. The gaseous products were collected in tared 125 or $250 \mathrm{~mL}$ glass impinger bottles containing approximately $125 \mathrm{~mL}$ of $5 \mathrm{mM} \mathrm{KOH}$. A $45 \mathrm{~mm}$ diameter PTFE filter (0.45 $\mathrm{m}$ nominal porosity) was placed after the impinger bottle to break the gaseous aerosol and allow maximum collection. The flow of gases through the impinger was controlled by the existing mass flow controller used for soot collection. The ratio of gases collected to gases exhausted was nominally 1:1000; however, the exact value for each test was recorded and used in computations. Sample collection started when the specimen was placed on the load cell of the calorimeter; the collection was stopped when the specimen stopped burning and no more smoke was being evolved.

After the tests were completed, the impinger was weighed and the contents transferred to a plastic container. Before analysis, the filter containing the soot was placed into the solution from the impinger. If HCN was present, the $\mathrm{pH}$ of the unknown solutions was determined to make sure that it had not dropped below the $\mathrm{pK}_{\mathrm{a}}$ of $\mathrm{HCN}$. The samples were then analyzed for the expected anion(s) by the procedure described in Appendix A.

\section{1 .3 Test Conditions}

The tests were conducted according to the ASTM (American Society for Testing and Materials) method E 1354-90a [17]. To describe fully the test conditions requires specifying not only the specimen orientation (horizontal, face-up) and the use of spark ignition, but also the test irradiance and any special specimen preparation techniques.

Three different irradiance values were used in the test program: 


$$
\begin{aligned}
& \text { - } \quad 10 \mathrm{~kW} / \mathrm{m}^{2} \text { (with spark ignition) } \\
& \text { - } \quad 30 \mathrm{~kW} / \mathrm{m}^{2} \text { (with and without spark ignition) } \\
& 100 \mathrm{~kW} / \mathrm{m}^{2} \text { (without spark ignition) }
\end{aligned}
$$

The lowest irradiance value, $10 \mathrm{~kW} / \mathrm{m}^{2}$, would not be expected to cause ignition in most specimens; specimens which are unusually ignition-prone would, however, ignite. The intermediate value, $30 \mathrm{~kW} / \mathrm{m}^{2}$, represents an irradiative heating value that can readily be imposed by one free-burning item on another. Many bench-scale tests impose heating levels in the range of $30 \mathrm{~kW} / \mathrm{m}^{2}$ on test specimens. The high value, $100 \mathrm{~kW} / \mathrm{m}^{2}$, was selected in order to determine if any unusual combustion phenomena become manifest at high irradiances, which are not evident during normal testing. Such high irradiances are typical of the upper ranges of heating values imposed on materials in a fully involved (flashed over) room fire.

\subsubsection{Data Collected}

The data to be derived from the bench-scale tests in the Cone Calorimeter constitute a very large set, and can be analyzed in a multitude of ways. The most important variables which are presented include the following:

$$
\begin{aligned}
& \text { - mass consumed }(\%), \\
& \text { - time to ignition }(\mathrm{s}) \text {, } \\
& \text { - } \quad \text { total heat released }\left(\mathrm{MJ} / \mathrm{m}^{2}\right) \text {. } \\
& \text { - } \text { average yields of each of the measured gas species }(\mathrm{kg} / \mathrm{kg}) \text {, } \\
& \text { average smoke obscuration }\left(\mathrm{m}^{2} / \mathrm{kg}\right) \text {, and } \\
& \text { - effective heat of combustion }(\mathrm{MJ} / \mathrm{kg}) .
\end{aligned}
$$

The effective heat of combustion as determined in the Cone Calorimeter will be less than the oxygen-bomb value of the heat of combustion, since the combustion is incomplete.

In this report we will not be performing any fire hazard evaluations; this is not possible since only bench-scale materials, not full-scale products, were examined. Thus, we will not interpret the test variables to reflect on expected actual fire performance. An example of how such evaluations can be performed once sufficient data are available, is given in [18].

\section{1 .5 Test Results}

The Cone Calorimeter results are summarized in Tables 2 through 7 . The values reported, as noted in the sample ID column, are for one test value, or the average of two or three test values. Measures of data uncertainty are thus unknown for all of the specimens. For a discussion of measurement uncertainty see Appendix X2 of [17]. However, for those unsaturated polyester (sample ID 
32-35), rigid PVC (sample ID 36), and cross-linked ethylene-vinyl acetate (sample ID 40-43) and thermoplastic ethylene vinyl-acetate (sample ID 44-46) samples run in triplicate, a standard deviation was obtained to determine the repeatability. It should be noted that the runs were not done consecutively for any given set.

Twelve of the specimens which were tested in triplicate were analyzed for repeatability of ignition time, peak rate of heat release, total heat release, effective heat of combustion, and specific smoke extinction area. Although, the data is not formally presented in a table, the following information was obtained. Of the 180 values analyzed, only 6 (3.3\%) were outside the $95 \%$ confidence limits for repeatability established for the method [17]. Three of the values outside the range were for ignition time, two were for total heat release, and one was for effective heat of combustion. Thus, the repeatability of the data was extremely good for all of the samples that burned to completion.

It should be noted that for the second set of rigid PVC samples (sample ID 3639), only the reference sample with no FR additive burned to completion in all three replicate tests; at least one sample in each of $37-39$ extinguished early in the test and gave questionable data that was not used in the averages reported.

For the $10 \mathrm{~kW} / \mathrm{m}^{2}$ irradiance, even though the spark igniter was used, none of the three selected HDPE test specimens (5-VV, 7-BB, and 8-EE) ignited. Since the easily ignitable, non-FR HDPE (5-VV) did not ignite at this low flux, none of the other samples were tested at the low flux level. Thus, detailed data at $10 \mathrm{~kW} / \mathrm{m}^{2}$ were not obtained and no further discussion is made.

At $30 \mathrm{~kW} / \mathrm{m}^{2}$ irradiance with spark ignition, detailed data for all specimens are presented. For certain specimens, detailed data sets were collected at 30 $\mathrm{kW} / \mathrm{m}^{2}$ and $100 \mathrm{~kW} / \mathrm{m}^{2}$ irradiance, both without spark ignition.

The remaining data analysis focuses mainly on the $30 \mathrm{~kW} / \mathrm{m}^{2}$ results with an occasional reference to the HDPE samples run at $100 \mathrm{~kW} / \mathrm{m}^{2}$.

In some cases, we will be comparing the various low density polyethylene samples (sample ID 25-27) against sample 5-VV, the HDPE sample containing no additive.

\section{Mass consumed and time to ignition}

If the mass consumed of a product is reduced, the resulting toxic potency should also be reduced simply because there is less smoke produced. If the ignition time is delayed, then more time is available for a safe exit from a fire scenario. An effective $F R$ should then reduce the amount of sample consumed in a fire and/or increase the time to ignition.

With respect to the mass consumed data, the percentages listed in Tables 2,4 , and 6 reflect the fact that some of the inert additives and fillers are not consumed. Others, such as the ATH, lose a specific amount of water but also leave a certain amount of residual $\mathrm{Al}_{2} \mathrm{O}_{3}$. Also to be considered is the 
difference in the mass of the chlorine and bromine elements. Therefore, the mass consumed data are strongly influenced by these factors, but should give an indication of the effectiveness of the FR additive.

With respect to sample ignition, at $30 \mathrm{~kW} / \mathrm{m}^{2}$, only about one half of the samples ignited in the absence of a spark igniter (Table 2), whereas in the presence of a spark igniter, all of the samples ignited at $30 \mathrm{~kW} / \mathrm{m}^{2}$ irradiance (Table 4).

Details on mass consumed and sample ignition for each resin system are presented in the following discussion.

\section{Without spark ignition}

Ignition data for the $30 \mathrm{~kW} / \mathrm{m}^{2}$ irradiance tests without the spark igniter (Table 2) show that, generally, for those samples that did ignite, the ignition delay times of those specimens containing an additive were increased over the untreated samples.

Specifically, for the unsaturated polyester series, the only sample to ignite was the reference ( $\mathrm{I}-\mathrm{CC}$ ) containing the inert filler, $\mathrm{CaCO}_{3}$, and only about a fourth of the sample was consumed.

In the high density polyethylene series shown in Table 2, the reference (5-VV) ignited and $88 \%$ of the sample was consumed. Sample $6-\mathrm{HH}$ with $\mathrm{CaCO}_{3}$ filler ignited, but lost only about $38 \%$ of its weight. There was no ignition of 7-BB which contained $\mathrm{ATH}$ and $11-\mathrm{PP}$ which contained $\mathrm{Mg}(\mathrm{OH})_{2}$. Sample 9-MM with sodium aluminocarbonate lost 48 percent of its weight. Sample 8 -EE with the $\mathrm{Br} / \mathrm{Sb}_{2} \mathrm{O}_{3}$ additive had no significant reduction in mass consumed. For those samples that did ignite, the ignition time was increased.

Furthermore, data in Table 6 for the three HDPE samples tested at $100 \mathrm{~kW} / \mathrm{m}^{2}$, showed that ATH reduced the amount of sample consumed in 7-BB. Ignition times were not changed at this high flux for either additive.

Data in Table 1 indicate that samples 25-AC, 26-AD, and 27-AE, the LDPE, contained increasing amounts of ATH. The mass consumed data in Table 2 at 30 $\mathrm{kW} / \mathrm{m}^{2}$ show that sample $26-\mathrm{AD}$, with $50 \%$ ATH has more mass consumed than $25-\mathrm{AC}$ with only $45 \% \mathrm{ATH}$, probably a reflection of more water being driven off. Sample 27-AE, containing the highest ATH concentration (55 8 ), did not ignite. Samples 25-AC and 26-AD, with the lower ATH concentrations, ignited, but the ignition times were longer than the reference (sample 5-VV), as previously noted.

The data in Table 2 for samples 28-AF, 29-AG, 30-AH, and 31-AJ, formulated with the XLPE, show that only sample 30-AH containing 10 percent ATH and the $\mathrm{Br} / \mathrm{Sb}_{2} \mathrm{O}_{3}$ additive ignited.

The only sample in the polypropylene series presented in Table 2 that did not ignite was 14-GG with the ATH additive. Both calcium carbonate in $13-\mathrm{FF}$ and $\mathrm{Br} / \mathrm{Sb}_{2} \mathrm{O}_{3}$ in $15-\mathrm{UU}$ resulted in reduced mass consumed, with calcium carbonate more than twice as effective. No ignition time was reported for the calcium 
carbonate sample as a result of operator error. The $\mathrm{Br} / \mathrm{Sb}_{2} \mathrm{O}_{3}$ additive increased the ignition time by more than a minute.

\section{With spark ignition}

With respect to mass consumed for the tests with the spark igniter (Table 4), replacing the $\mathrm{CaCO}_{3}$ with other additives in the first set of unsaturated polyester samples ( 1 -CC to 23-II) tended to slightly increase the amount of mass consumed. For the ignition delay, sample 3-XX containing both ATH and $\mathrm{Br} / \mathrm{Sb}_{2} \mathrm{O}_{3}$ increased the ignition time by more than 2 minutes. The ATH in the acrylic-based resin (23-II) increased the ignition time by nearly 2 minutes. The remaining additives only produced small increases in ignition time.

Data in Table 4 for the second set of unsaturated polyesters show that for sample 32 (reference) and 33, formulated with a general purpose resin, the ATH additive in 33 increased the mass consumed by roughly $10 \%$ and increased the ignition time by more than two minutes over the inert filler $\mathrm{CaCO}_{3}$. With respect to the samples formulated with the brominated resin, sample 35 containing ATH and NPS showed a decrease in the mass consumed and more than a minute decrease in the ignition time over sample 34, which had the ATH alone.

The data in Table 4 for the samples in the HDPE series show that all the additives except the $\mathrm{Br} / \mathrm{Sb}_{2} \mathrm{O}_{3}$ in 8 -EE reduced the mass consumed and increased the time to ignition. The most effective additive in increasing the ignition time in this set of samples was $\mathrm{Mg}(\mathrm{OH})_{2}$ ( $\left.11-\mathrm{PP}\right)$.

In the LDPE series (25-27), the data in Table 4 indicate that the effect of the increasing ATH concentration on the mass consumed was not significant. Also, the ignition times showed a tendency to decrease instead of increase as might be expected with an increasing ATH concentration. Additionally, the ignition times were slightly less than sample 5-VV which contains no additive.

In the XLPE samples in Table 4, for the samples containing only ATH (28-AF and 29-AG), the increased ATH concentration reduced the mass consumed, but the ignition time was decreased by about a minute. Using a brominated flame retardant in sample $30-\mathrm{AH}$, as compared to $\mathrm{Cl}$ in sample $31-\mathrm{AJ}$, increased the mass consumed even though the ATH concentration was the same. This was probably a result of the higher formula weight bromine being vaporized. The ignition time was not changed.

In the polypropylene series, the data in Table 4 show that the $\mathrm{CaCO}_{3}$ additive in $13-\mathrm{FF}$ was the most effective in reducing the mass consumed (a difference ca. 50\%); the ATH in 14-GG reduced the mass consumed by roughly $30 \%$. The $\mathrm{Br} / \mathrm{Sb}_{2} \mathrm{O}_{3}$ additive ( $15-\mathrm{UU}$ ) was not effective in reducing the mass consumed. All additives were effective in increasing the ignition time; both the ATH and $\mathrm{Br} / \mathrm{Sb}_{2} \mathrm{O}_{3}$ were equally effective in providing about 70 seconds more ignition time.

The data in Table 4 indicate that the $\mathrm{CaCO}_{3}$ additive (20) and the ATH additive (21) in the flexible PVC sample only showed a slight reduction in mass consumed and a slight increase in the ignition time (less than 10 seconds with a reference that ignited in 29 seconds). 
In the first set of rigid PVC samples (16-19) shown in Table 4, the $\mathrm{CaCO}_{3}$ additive (17) and the ATH additive (18) decreased the mass consumed by roughly 13 and $10 \%$, respectively. Only the ATH additive was effective in increasing the ignition time by 90 seconds.

In the second set of rigid PVC samples (36-39) shown in Table 4, the ATH in sample 38 was very effective in decreasing the mass consumed; only 188 of the sample was consumed. The $\mathrm{Mg}(\mathrm{OH})_{2}$ in sample 39 also decreased the mass consumed by more than $30 \%$. Also the $\mathrm{ATH}$ and $\mathrm{Mg}(\mathrm{OH})_{2}$ were very effective in increasing the ignition time (ca. 8 and 3 minutes, respectively.)

All of the additives reduced the mass consumed about $20 \%$ in the cross-linked ethylene-vinyl acetate samples shown in Table 4. All of the additives except, the $\mathrm{Cl} / \mathrm{Sb}_{2} \mathrm{O}_{3}$, increased the ignition time; the ATH in sample 41 nearly doubled the ignition time and the $\mathrm{Mg}(\mathrm{OH})_{2}$ in sample 43 added more than a minute and a half to the ignition delay.

Finally in Table 4, the ATH in sample 45 of the thermoplastic ethylene-vinyl acetate sample reduced the mass consumed and was more effective in increasing the ignition time than the $\mathrm{Cl} / \mathrm{Sb}_{2} \mathrm{O}_{3}$ additive in sample 46 .

\section{Peak rate of heat release}

\section{Without spark ignition}

Generally, for the $30 \mathrm{~kW} / \mathrm{m}^{2}$ irradiance tests without the spark igniter (Table 2 ), the peak rates of heat release (peak q") for those samples that ignited were reduced considerably by the additives. Specifics for each polymer type follow.

Only the reference in the set of unsaturated polyester samples ignited.

For the HDPE samples the peak $\dot{q} "$ for the control sample $(5-\mathrm{VV})$ was $1760 \mathrm{~kW} / \mathrm{m}^{2}$. Neither sample 7-BB with ATH additive nor sample 11 -PP with $\mathrm{Mg}(\mathrm{OH})_{2}$ additive ignited in the HDPE set. Sodium aluminocarbonate ( $9-\mathrm{MM})$ and $\mathrm{CaCO}_{3}(6-\mathrm{HH})$ were also very effective in reducing peak $\dot{q} "$ in the HDPE samples. The least effective additive to the $\mathrm{HDPE}$ was the $\mathrm{Br} / \mathrm{Sb}_{2} \mathrm{O}_{3}$ in sample $8-\mathrm{EE}\left(1280 \mathrm{~kW} / \mathrm{m}^{2}\right)$. Data at $100 \mathrm{~kW} / \mathrm{m}^{2}$ (Table 6) also show the effectiveness of ATH and the brominated flame retardant in reducing the peak $\dot{q} "$. At this high flux level, reductions of approximately 2300 and $900 \mathrm{~kW} / \mathrm{m}^{2}$, respectively, were achieved.

For the three LDPE samples (25-AC, 26-AD, and 27-AE), a tendency for the peak $\dot{q} "$ to decrease as the ATH concentration increases was observed (sample 27-AE with 558 ATH failed to ignite). The peak q" values for these samples are considerably lower than the reference sample (5-VV).

In the XLPE samples, both samples containing only ATH additive (28-AF and 29AG) failed to ignite. Sample 31 -AJ which contained the chlorinated flame retardant also failed to ignite, whereas 30-AH with the brominated retardant did ignite (peak q" ca. $160 \mathrm{~kW} / \mathrm{m}^{2}$ ). 
Finally, the peak $\dot{q} "$ of the polypropylene samples was greatly affected by addition of FR additives. The peak $\dot{q} "$ for the control was $1600 \mathrm{~kW} / \mathrm{m}^{2}$. Sample 14-GG with ATH failed to ignite. The $\mathrm{CaCO}_{3}$ in sample $13-\mathrm{FF}$ reduced the peak $\dot{q} "$ to $25 \mathrm{~kW} / \mathrm{m}^{2}$ and the $\mathrm{Br} / \mathrm{Sb}_{2} \mathrm{O}_{3}$ additive in $15-\mathrm{UU}$ reduced it to $456 \mathrm{~kW} / \mathrm{m}^{2}$.

\section{With spark ignition}

For the corresponding tests with the spark igniter (Table 4), in general, all of the additives were effective in reducing the peak $\dot{q} "$.

For the first set of unsaturated polyester samples (1-CC to 23-II) in Table 4, if $1-C C$ is used as a reference, then the halogenated resins in conjunction with the $\mathrm{Sb}_{2} \mathrm{O}_{3}$ were the most effective in reducing the peak $\dot{\mathrm{q}}$ ". Samples $2-\mathrm{QQ}$ and 23-II containing only ATH also decreased the peak $\dot{q} "$ by 120 to $140 \mathrm{~kW} / \mathrm{m}^{2}$, respectively.

In the second series of unsaturated polyester samples (32-35) in Table 4, for the general purpose resin, ATH in sample 33 decreased the peak $\dot{q} "$ by nearly 80 $\mathrm{kW} / \mathrm{m}^{2}$ in comparison to the $\mathrm{CaCO}_{3}$ reference (32). For the general purpose, brominated resin set, the reference (34) containing 50 \& ATH produced a peak q" of $95 \mathrm{~kW} / \mathrm{m}^{2}$, whereas sample 35 containing only half the amount of ATH in combination with $25 \%$ nepheline syenite actually showed a slight increase in the peak $\dot{q}^{\prime \prime}\left(118 \mathrm{~kW} / \mathrm{m}^{2}\right)$ indicating that the ATH is more effective by itself.

The control ( $5-\mathrm{VV}$ ) for the HDPE samples in Table 4 had a peak $\dot{q}$ " of 1800 $\mathrm{kW} / \mathrm{m}^{2}$. None of the other samples, except $8-\mathrm{EE}$, produced a value greater than $280 \mathrm{~kW} / \mathrm{m}^{2}$, a truly significant decrease. Sample 7-BB with ATH additive was the most effective in reducing the peak $\dot{q} "$. The least effective additive was the $\mathrm{Br} / \mathrm{Sb}_{2} \mathrm{O}_{3}$ in $8-\mathrm{EE}$. It should be noted from Table 6 for the $100 \mathrm{~kW} / \mathrm{m}^{2} \mathrm{flux}$ tests, that the peak $\dot{q} "$ of sample 7-BB with ATH also was reduced from about $2600 \mathrm{~kW} / \mathrm{m}^{2}$ to just over $300 \mathrm{~kW} / \mathrm{m}^{2}$. Also at $100 \mathrm{~kW} / \mathrm{m}^{2}$, the $\mathrm{Br} / \mathrm{Sb}_{2} \mathrm{O}_{3}$ additive also reduced the peak $\dot{\mathrm{q}} "$ to just under $1800 \mathrm{~kW} / \mathrm{m}^{2}$.

In the LDPE series in Table 4, the increased ATH concentration showed a tendency to decrease the peak $\dot{q} "$ ", however, the decrease was small. Again, the peak $\dot{q} "$ values were considerably less than the reference sample (5-VV).

For the XLPE samples shown in Table 4, the increased ATH concentration in 29 AG versus $28-\mathrm{AF}, 55 \%$ and $50 \%$, respectively, resulted in a $90 \mathrm{~kW} / \mathrm{m}^{2}$ decrease in the peak $\dot{q} "$; approximately the same amount of decrease was realized for the sample containing $10 \% \mathrm{ATH}$ in addition to the $\mathrm{Br} / \mathrm{Sb}_{2} \mathrm{O}_{3}(30-\mathrm{AH}$ ). The use of chlorine in sample 31 -AJ resulted in a much smaller decrease in the peak $\dot{q} "$ compared to the $\mathrm{Br}$ flame retardant in $30-\mathrm{AH}$.

The peak $\dot{q} "$ for the reference (12-LL) for the polypropylene samples in Table 4 was nearly $1600 \mathrm{~kW} / \mathrm{m}^{2}$; no other sample was over $400 \mathrm{~kW} / \mathrm{m}^{2}$. This represents a significant decrease for all of the additives. Once again the ATH additive in 14-GG was the most effective in reducing the peak $\dot{q} "$.

Both the $\mathrm{CaCO}_{3}$ in sample 20 and the ATH in sample 21 were effective in reducing the peak $\dot{q}$ " for the flexible poly(vinyl chloride) samples shown in Table 4. The ATH additive was the most effective with a reduction in peak $\dot{q}^{\prime \prime}$ of $120 \mathrm{~kW} / \mathrm{m}^{2}$. 
For the first set of rigid PVC samples shown in Table 4, only the ATH additive in sample 18 was effective in reducing the peak $\dot{q} "$. The sample with $\mathrm{CaCO}_{3}$ (17) actually caused an increase in the peak $\dot{q} "$. However, in the second set of rigid PVC samples (36 to 38 ) shown in Table 4, all of the additives decreased the peak $\dot{q} "$ by at least $50 \mathrm{~kW} / \mathrm{m}^{2}$.

The data in Table 4 show that the peak $\dot{q} "$ was decreased by all of the additives in the cross-linked ethylene-vinyl acetate samples. The control (40) gave a peak q" of $463 \mathrm{~kW} / \mathrm{m}^{2}$; the $\mathrm{ATH}$ in sample 41 and the $\mathrm{Cl} / \mathrm{Sb}_{2} \mathrm{O}_{3}$ in sample 42 gave about a $150 \mathrm{~kW} / \mathrm{m}^{2}$ reduction in the peak $\dot{q} "$.

Finally, both the $\mathrm{ATH}$ and the $\mathrm{Cl} / \mathrm{Sb}_{2} \mathrm{O}_{3}$ additives in samples 45 and 46 , respectively, of the thermoplastic ethylene-vinyl acetate samples shown in Table 4 reduced the peak $\dot{q} "$. In this set the ATH reduced the peak $\dot{q} "$ from almost $600 \mathrm{~kW} / \mathrm{m}^{2}$ for the control (44) to less than $100 \mathrm{~kW} / \mathrm{m}^{2}$, a substantial decrease. The other additive, $\mathrm{Cl} / \mathrm{Sb}_{2} \mathrm{O}_{3}$, had more than twice the peak $\dot{\mathrm{q}}$ " of the sample with ATH.

\section{Total heat released}

\section{Without spark ignition}

The total heat released (total q") for those samples that contained an additive and ignited in the $30 \mathrm{~kW} / \mathrm{m}^{2}$ irradiance tests without the spark igniter (Table 2) was usually less than their respective reference samples. The column of total q" data indicates that samples containing ATH, alone or in combination with other additives, were those samples that failed to ignite or gave very low total q"'s compared to their controls.

Data in Table 6 for the $100 \mathrm{~kW} / \mathrm{m}^{2}$ irradiance also show a reduction in the total q" by using flame retardants. At the higher irradiance level the brominated flame retardant was more effective than ATH by roughly $30 \mathrm{MJ} / \mathrm{m}^{2}$.

\section{With spark ignition}

The same pattern of decreased total q" for samples containing an additive(s) was not seen for all of the polymers in the tests with the spark igniter (Table 4). No reduction in total q" was achieved by additives in the second series of unsaturated polyester samples, the flexible PVC samples, or the thermoplastic ethylene-vinyl acetate samples. The total q" for the first set of rigid PVC samples (16-18) was very low (2-7 $\left.\mathrm{MJ} / \mathrm{m}^{2}\right)$; the ATH sample (18) in this set gave the $2 \mathrm{MJ} / \mathrm{m}^{2}$ and both the control (16) and the $\mathrm{CaCO}_{3}$ additive sample (17) were.comparable at $7 \mathrm{MJ} / \mathrm{m}^{2}$.

For the first set of unsaturated polyester samples shown in Table 4, samples 3-XX and 4-AA formulated with the halogenated resins were the most effective in reducing the total q"; sample 4-AA with Cl was especially effective.

Samples 2-QQ and 23-II, containing only ATH, had little effect on reducing the total q".

The sample with $\mathrm{Br} / \mathrm{Sb}_{2} \mathrm{O}_{3}(8-\mathrm{EE})$ in the HDPE series shown in Table 4 was most effective in reducing the total q" (a difference of $90 \mathrm{MJ} / \mathrm{m}^{2}$ ). The sample with $\mathrm{ATH}(7-\mathrm{BB})$ was also effective with a $70 \mathrm{MJ} / \mathrm{m}^{2}$ reduction in the total $\mathrm{q}$ ". 
The samples with $\mathrm{CaCO} 3(6-\mathrm{HH})$, sodium aluminocarbonate (9-MM), and $\mathrm{Mg}(\mathrm{OH})_{2}$ (11-PP) reduced the total q" by roughly $50 \mathrm{MJ} / \mathrm{m}^{2}$.

For the LDPE samples (25-27) shown in Table 4 there was no decrease in the total q" with increasing ATH concentration as might be expected. Also, only slight reductions in the total q" are seen for the XLPE samples (28-31.) All of the additives to the polypropylene samples (12-15) shown in Table 4 reduced the total q"; a reduction of $35-42 \mathrm{MJ} / \mathrm{m}^{2}$ was achieved.

For the second set of rigid PVC samples shown in Table 4, the ATH additive (38) and the $\mathrm{Mg}(\mathrm{OH})_{2}$ additive (39) reduced the total q" from $29 \mathrm{MJ} / \mathrm{m}^{2}$ for the control (36) to $18 \mathrm{MJ} / \mathrm{m}^{2}$. The inert $\mathrm{CaCO}_{3}$ additive (37) was comparable to the control (36) with respect to total q" (a. $30 \mathrm{MJ} / \mathrm{m}^{2}$ ).

Finally in Table 4, for the cross-linked ethylene-vinyl acetate samples (4043), only a small affect on the total q" was noted. The control (40) gave a total q" of $67 \mathrm{MJ} / \mathrm{m}^{2}$. The ATH sample (41) was comparable $\left(62 \mathrm{MJ} / \mathrm{m}^{2}\right)$. The $\mathrm{Cl} / \mathrm{Sb}_{2} \mathrm{O}_{3}$ sample (42) was the most effective in reducing the total q" ( 39 $\mathrm{MJ} / \mathrm{m}^{2}$ ) and the $\mathrm{Mg}(\mathrm{OH})_{2}$ sample (43) gave a slight reduction at $53 \mathrm{MJ} / \mathrm{m}^{2}$.

\section{Effective heat of combustion}

\section{Without spark ignition}

Because of the many samples that failed to ignite in the $30 \mathrm{~kW} / \mathrm{m}^{2}$ irradiance tests without the spark igniter (Table 2), the effective heat of combustion (eff. $\Delta h_{c}$ ) for those samples that ignited was evaluated only for the high density polyethylene and polypropylene samples. For the HDPE samples, the reference sample (5-VV) gave an eff. $\Delta \mathrm{h}_{\mathrm{c}}$ of $54 \mathrm{MJ} / \mathrm{kg}$. Neither samples 7-BB with $\mathrm{ATH}$ nor $11-\mathrm{PP}$ with $\mathrm{Mg}(\mathrm{OH})_{2}$ ignited. The $\mathrm{CaCO}_{3}$ in sample $6-\mathrm{HH}$ and the $\mathrm{Br} / \mathrm{Sb}_{2} \mathrm{O}_{3}$ in sample 8 -EE were not effective in reducing the eff. $\Delta \mathrm{h}_{\mathrm{c}} . A$ reduction in eff. $\Delta h_{c}$ of about $20 \mathrm{MJ} / \mathrm{kg}$ was achieved by the sodium aluminocarbonate (9-MM) sample. At the $100 \mathrm{~kW} / \mathrm{m}^{2}$ flux (Table 6), there was essentially no difference in the eff. $\Delta h_{c}$ for this set of samples.

In the polypropylene series, the control (12-LL) produced an eff. $\Delta \mathrm{h}_{\mathrm{c}}$ of 59 $\mathrm{MJ} / \mathrm{kg}$. Sample 14-GG with ATH failed to ignite. Also, both the $\mathrm{CaCO}_{3}$ in sample $13-\mathrm{FF}$ and the $\mathrm{Br} / \mathrm{Sb}_{2} \mathrm{O}_{3}$ in sample $15-\mathrm{UU}$ were effective in reducing the eff. $\Delta \mathrm{h}_{\mathrm{c}}$ ( 7 and $18 \mathrm{MJ} / \mathrm{kg}$, respectively.)

\section{With spark ignition}

For the tests with the spark igniter (Table 4), a reduction in the eff. $\Delta h_{c}$ was realized for some of the polymer samples, but not for others. Those polymer samples that were not affected by the addition of additives were the LDPE samples with increasing ATH concentrations (25-27), the flexible PVC (1921), and both sets of rigid PVC (16-18 and 36-39).

The eff. $\Delta h_{c}$ for the reference (1-CC) in the first unsaturated polyester series shown in Table 4 was $22 \mathrm{MJ} / \mathrm{kg}$. The most effective additives in reducing the eff. $\Delta h_{c}$ were the halogens in samples $3-X X$ and $4-A A$ ( 12 and 5 
$\mathrm{MJ} / \mathrm{kg}$, respectively). Both samples containing ATH (2-QQ and 23-II) were only slightly effective in reducing the eff. $\Delta \mathrm{h}_{\mathrm{c}}$.

In the second series of general purpose polyester resins shown in Table 4, only a small reduction in the eff. $\Delta \mathrm{h}_{\mathrm{c}}$ was found. A $6 \mathrm{MJ} / \mathrm{kg}$ reduction in eff. $\Delta h_{c}$ resulted from the substitution of $A T H$ (33) for $\mathrm{CaCO}_{3}$ (32) in the first non-brominated set. No change in the eff. $\Delta \mathrm{h}_{\mathrm{c}}$ for partial substitution of ATH with nepheline syenite in the brominated resin set was seen.

Only sodium aluminocarbonate and ATH additives (9-MM and 7-BB) in the HDPE samples were effective in reducing the eff. $\Delta \mathrm{h}_{c}$. The reference sample (5-VV) had an eff. $\Delta \mathrm{h}_{\mathrm{c}}$ of $59 \mathrm{MJ} / \mathrm{kg}$. The eff. $\Delta \mathrm{h}_{\mathrm{c}}$ 's of the aforementioned samples were 31 and $43 \mathrm{MJ} / \mathrm{kg}$, respectively. The other three FR additives were not effective.

In the XLPE set of samples shown in Table 4, only $30-\mathrm{AH}$ with the $\mathrm{Br} / \mathrm{Sb}_{2} \mathrm{O}_{3} / \mathrm{ATH}$ additives showed a reduction in the eff. $\Delta \mathrm{h}_{\mathrm{c}}$.

The eff. $\Delta \mathrm{h}_{\mathrm{c}}$ for the reference $(12-\mathrm{LL})$ in the polypropylene set was $60 \mathrm{MJ} / \mathrm{kg}$. The only additive in the polypropylene samples to produce a significant reduction in the eff. $\Delta \mathrm{h}_{\mathrm{c}}$ was $\mathrm{Br} / \mathrm{Sb}_{2} \mathrm{O}_{3}$ in $15-\mathrm{UU}$, which reduced the eff. $\Delta \mathrm{h}_{\mathrm{c}}$ to $18 \mathrm{MJ} / \mathrm{kg}$. The ATH additive in sample $14-\mathrm{GG}$ reduced the eff. $\Delta \mathrm{h}_{\mathrm{c}}$ to $45 \mathrm{MJ} / \mathrm{kg}$. The inert $\mathrm{CaCO}_{3}$ additive $(13-\mathrm{FF})$ had no effect on the eff. $\Delta \mathrm{h}_{\mathrm{c}}$.

The eff. $\Delta h_{c}$ for the reference $(40)$ in the cross-linked ethylene-vinyl acetate samples was $31 \mathrm{MJ} / \mathrm{kg}$. The $\mathrm{Cl} / \mathrm{Sb}_{2} \mathrm{O}_{3}$ additive in sample 46 reduced the eff. $\Delta \mathrm{h}_{\mathrm{c}}$ to $17 \mathrm{MJ} / \mathrm{kg}$. Both the ATH in sample 41 and the $\mathrm{Mg}(\mathrm{OH})_{2}$ in sample 43 reduced the eff. $\Delta \mathrm{h}_{\mathrm{c}}$, but by only about $7 \mathrm{MJ} / \mathrm{kg}$.

Finally, the ATH in sample 45 and the $\mathrm{Cl} / \mathrm{Sb}_{2} \mathrm{O}_{3}$ in sample 46 of the thermoplastic EVA gave a small reduction in the eff. $\Delta \mathrm{h}_{\mathrm{c}}$ of about $7 \mathrm{MJ} / \mathrm{kg}$, with the control at $27 \mathrm{MJ} / \mathrm{kg}$.

\section{Average smoke obscuration and average yields of measured gases}

\section{Without spark ignition}

The data in Table 3 represent $\mathrm{CO}, \mathrm{CO}_{2}$ and smoke generation for the specimens tested at $30 \mathrm{~kW} / \mathrm{m}^{2}$ irradiance without the spark igniter. For most of the samples that ignited, the $C O$ generation was on the order of $0.01-0.03 \mathrm{~kg} / \mathrm{kg}$, with a tendency for the samples with halogen additives to be higher. Notably higher $\mathrm{CO}$ generation for $30-\mathrm{AH}$, the XLPE sample with the $\mathrm{Br} / \mathrm{Sb}_{2} \mathrm{O}_{3} / \mathrm{ATH}$ additive and 15-UU, the polypropylene sample with the $\mathrm{Br} / \mathrm{Sb}_{2} \mathrm{O}_{3}$ additive was seen. Both of these samples gave $\mathrm{CO}$ values of $0.15 \mathrm{~kg} / \mathrm{kg}$. The corresponding $\mathrm{CO}_{2}$ values were also lower than most of the other test values. For the other $\mathrm{CO}_{2}$ values, there was also a tendency for the additives to lower the $\mathrm{CO}_{2}$ generation. The very low $\mathrm{CO}_{2}$ value for $13-\mathrm{FF}$ is questionable.

Data at $100 \mathrm{~kW} / \mathrm{m}^{2}$ (Table 7) for the HDPE samples also showed a decrease in CO production with the ATH sample (7-BB) and an increase with the $\mathrm{Br} / \mathrm{Sb}_{2} \mathrm{O}_{3}$ sample $(8-E E)$, while both additives decreased the $\mathrm{CO}_{2}$ production. 
Also, the smoke generation data at $30 \mathrm{~kW} / \mathrm{m}^{2}$ irradiance without the spark igniter (Table 3 ) indicated that halogenated additives increased the smoke produced for those samples that ignited.

However, data in Table 7 for smoke generation at $100 \mathrm{~kW} / \mathrm{m}^{2}$ for the HDPE samples showed an increase over the control for both the ATH and the $\mathrm{Br} / \mathrm{Sb}_{2} \mathrm{O}_{3}$ additives.

\section{With spark ignition}

The data in Table 5 give the quantities of $\mathrm{CO}, \mathrm{CO}_{2}$ and smoke generated at 30 $\mathrm{kW} / \mathrm{m}^{2}$ irradiance with the spark igniter. Similar to the tests without the spark igniter, the $\mathrm{CO}$ increased and the $\mathrm{CO}_{2}$ decreased when the additive contained a halogen. An increase in the production of $C O$ was also noted for the ATH additive in the HDPE, the second series of rigid PVC, and the thermoplastic EVA. The LDPE samples with increasing ATH concentrations (25-27) also showed an increase in the $C O$ production with increasing ATH concentration. Similar to the tests without the spark igniter, the higher CO production resulted in a lower $\mathrm{CO}_{2}$ production. Interestingly, in the XLPE sample 30-AH containing $\mathrm{Br}$ and $\mathrm{ATH}$ as compared to sample 31 with $\mathrm{Cl}$ and $\mathrm{ATH}$, about twice the $\mathrm{CO}$ production resulted with the $\mathrm{Br}$ additive. Also of note was the high CO production of the flexible PVC samples (19-21); the control with no additive produced more than $0.11 \mathrm{~kg} / \mathrm{kg}$ of $\mathrm{CO}$.

Results similar to those for tests without spark ignition were obtained for smoke generation in the tests with the spark igniter (Table 5). The samples containing $\mathrm{Br} / \mathrm{Sb}_{2} \mathrm{O}_{3}, \mathrm{Cl} / \mathrm{Sb}_{2} \mathrm{O}_{3}$, and $\mathrm{CaCO}_{3}$ produced much more smoke than their respective references. The $\mathrm{ATH}$, sodium aluminocarbonate, and magnesium hydroxide additives were very effective in reducing smoke; samples 26 and $7-B B$ were the most effective.

In the tests with the spark igniter, for those samples containing a halogenated FR the portion of the combustion products collected in the impingers and analyzed by IC confirmed the presence of the halogen. Since the acid gases are known to be irritants and contribute to post-exposure deaths at concentrations near their $\mathrm{LC}_{50}$, a measure of their production is important. The reported results are based on the calculation of chloride and bromide ion content to the acid gases only. If other halogenated species in the combus. tion products are contributing to the anion(s), then this value might be in error with respect to acid gas generation.

\subsection{Cup Furnace Smoke Toxicity Method}

\subsubsection{Discussion}

For the smoke toxicity portion of this study, the current N-Gas model was used to predict the toxicity of the thermal decomposition products of materials based on experiments at NIST on the mixtures of toxicants. That prediction and evaluation are based on data from earlier NIST experiments on the combined toxicity of the major gases produced in fires. The N-Gas model is designed to determine whether the lethality of the thermal decomposition products of a 
material can be explained by the toxicological interaction of these major gases or if other toxic combustion products need to be considered $[8,19,20]$.

The first step in the use of the $\mathrm{N}$-Gas model is the prediction of the $\mathrm{LC}_{50}$ values based on the measured concentrations of a predetermined set of gases and knowledge of their toxicological interactions. Experiments with rats were conducted at approximately the predicted $\mathrm{LC}_{50}$ value and if the prediction is correct, some of the animals will die. Death of all the animals indicates that other toxic gases need to be included in the model. Currently, five gases, $\mathrm{CO}, \mathrm{CO}_{2}, \mathrm{HCl}, \mathrm{HCN}$, and reduced $\mathrm{O}_{2}$ have been examined both individually and in various mixtures and are included in the model [19,20,21]. As more information is obtained, more gases will be added.

In this project, toxicity experiments on a few samples were conducted to test the predictive capabilities of the N-Gas model and to check for the presence of additional unknown toxicants. The high density polyethylene samples containing no additive (5-VV), $\mathrm{CaCO}_{3}(6-\mathrm{HH}), \mathrm{ATH}(7-\mathrm{BB}), \mathrm{Br} / \mathrm{Sb}_{2} \mathrm{O}_{3}$ ( $\left.8-\mathrm{EE}\right)$, and $\mathrm{Mg}(\mathrm{OH})_{2}(11-\mathrm{PP})$ were examined under both flaming and non-flaming conditions using the cup furnace apparatus [7].

\subsubsection{Animals}

Fischer 344 male rats, weighing 200-300 grams, were obtained from the Harlan Sprague-Dawley Company ${ }^{2}$ (Walkersville, MD) or from Taconic Farms (Germantown, NY). They were allowed to acclimate to our laboratory conditions for at least 10 days before experimentation. Animal care and maintenance were performed in accordance with the procedures outlined in the National Institutes of Health's "Guide for the Care and Use of Laboratory Animals." Each rat was housed individually in suspended stainless steel cages and provided with food and water ad libitum. Twelve hours of fluorescent lighting per day were provided using an automatic timer. All animals (including the controls) were weighed daily from the day of arrival until the end of the post-exposure observation period.

\subsubsection{Toxicity Test System}

The acute inhalation toxicity of the combustion products of the above materials was assessed using the combustion system, the chemical analysis system and the animal exposure system that was designed for the cup furnace smoke toxicity method [7]. Analytical experiments without animals were conducted first under both flaming and non-flaming conditions to determine the concentrations of $\mathrm{CO}, \mathrm{CO}_{2}$, and $\mathrm{HCN}$ that would be generated from different mass loadings of each material. These values were then used to predict the $\mathrm{LC}_{50}$ values which would then be used as the mass of material to be tested in the

${ }^{2}$ Certain commercial equipment, instruments, materials or companies are identified in this paper in order to adequately specify the experimental procedure. In no case does such identification imply recommendation or endorsement by the National Institute of Standards and Technology, nor does it imply that the equipment or material identified is necessarily the best available for the purpose. 
animal exposures. If, at the highest mass loading $\left(40 \mathrm{~g} / \mathrm{m}^{3}\right)$ of material permitted by the method, the combined concentrations of these gases were still below the predicted $\mathrm{LC}_{50}$, the animals were tested at $40 \mathrm{~g} / \mathrm{m}^{3}$.

The animal exposure system (Figure 4) is a closed design in which all the gases and smoke are kept in the 200 liter rectangular chamber for the duration of the experiment. The materials are decomposed in a cup furnace located directly below the animal exposure chamber such that all the combustion products from the test materials are evolved directly into the chamber. The materials are examined under separate non-flaming and flaming conditions which are achieved by setting the furnace $25^{\circ} \mathrm{C}$ below and above each material's predetermined autoignition temperature.

In the animal exposure experiments, six rats were exposed in each experiment. Animals were placed in restrainers which were then inserted into the six portholes located along the front of the exposure chamber such that only the heads of the animals were exposed. The animals were exposed to the initial generation (usually $5 \mathrm{~min}$ ) of the test atmosphere as well as the later steadystate conditions. The toxicological endpoint was death which occurred either during the 30 minute exposures or the 14 day post-exposure observation period.

\section{2 .4 Gas Analysis}

Carbon monoxide and $\mathrm{CO}_{2}$ were measured continuously by non-dispersive infrared analyzers. Oxygen concentrations were measured continuously with either a galvanic cell or a paramagnetic analyzer. Information obtained from SOLEM/ALCOA representatives indicated that these five materials did not contain nitrogen; therefore, analysis of $\mathrm{HCN}$ was not conducted. Analysis for $\mathrm{HBr}$ in 8 -EE was not done either. The $\mathrm{CO}, \mathrm{CO}_{2}$, and $\mathrm{O}_{2}$ data were recorded by an online computer every 15 seconds. All combustion products and gases that were removed for chemical analysis were returned to the chamber. All given gas concentrations are the average integrated exposure values which were calculated by integrating the area under the instrument response curve and dividing by the exposure time.

\section{2 .5 Results}

The chemical and toxicological data for the materials designated 5-VV, 6-HH, 7-BB, 8-EE, and 11-PP are presented in Tables 8-12, summarized in Tables 1315, and discussed below.

\section{Material 5-V}

The autoignition temperature was initially determined to be $375^{\circ} \mathrm{C}$, and the flaming experiments were therefore performed $25^{\circ} \mathrm{C}$ above that temperature. The data in Table 8 indicate that no animals died within the 30 minute exposures to the flaming decomposition products from approximately $40 \mathrm{~g} / \mathrm{m}^{3}$ of Material 5-VV. However, following a flaming exposure to $39 \mathrm{~g} / \mathrm{m}^{3}$, one animal died within 24 hours and the other five animals lost considerable weight (as much as 60 grams over 4 days) before showing signs of recovery (Figure 5). In another flaming experiment at $40 \mathrm{~g} / \mathrm{m}^{3}$, one animal was sacrificed after losing 140 grams of weight over 39 days, although the other 5 animals appeared to 
recover after approximately 3 days (Figure 6). The concentrations of $\mathrm{CO}$ and $\mathrm{CO}_{2}$ were insufficient to account for the death that occurred. However, the presence of one or more additional toxic gases from the decomposition of the polyethylene resin might be responsible for the death.

The non-flaming experiments were performed at two different temperatures approximately $350^{\circ} \mathrm{C}$ and $375^{\circ} \mathrm{C}$. The temperature was increased after noting the large residue remaining in the cup furnace following the non-flaming experiments at $350^{\circ} \mathrm{C}$. The autoignition temperature was rechecked and found to be $25^{\circ} \mathrm{C}$ higher than that found previously.

At the lower temperature, two experiments at a mass loading of $40 \mathrm{~g} / \mathrm{m}^{3} \mathrm{did}$ not produce deaths either within or following the exposures. However, when the temperature was increased to $375^{\circ} \mathrm{C}$, two animals died during the 30 minute exposure to the combustion products from a mass loading of $39 \mathrm{~g} / \mathrm{m}^{3}$. Two died within 4 minutes following the exposure and the remaining two died later that afternoon. At lower mass loadings - 20 and $30 \mathrm{~g} / \mathrm{m}^{3}$ - no deaths were observed during the exposures but all the animals died within 24 hours following the exposures. In the non-flaming mode, the deaths that occurred could not be attributed to the concentrations of $\mathrm{CO}$ and $\mathrm{CO}_{2}$ generated, but additional toxic gases might have been produced. Previous studies [22, 23] have shown that oxidative pyrolysis of polyethylene at $300-400{ }^{\circ} \mathrm{C}$ produce toxic, low molecular weight organic species such as acrolein and formaldehyde. These compounds are most likely to produce post-exposure deaths.

\section{Material 6-HH}

The results from the flaming experiments performed $25^{\circ} \mathrm{C}$ above the autoignition temperature $\left(450^{\circ} \mathrm{C}\right)$ showed that no deaths occurred either during the 30 minute exposures or the post-exposure observation periods (Table 9). In the nonflaming mode, no deaths were observed during the 30 minutes of actual exposure; however, all but one of the animals died 24 to 72 hours following the tests. Based on the concentrations of $\mathrm{CO}$ and $\mathrm{CO}_{2}$ generated when material $6-\mathrm{HH}$ was decomposed in the flaming and non-flaming modes, no deaths were predicted from any of the mass loadings tested. Therefore, the post-exposure deaths that occurred following the non-flaming decomposition of Material 6-HH cannot be attributed to only $\mathrm{CO}$ and $\mathrm{CO}_{2}$, but were probably due to the presence of one or more additional toxic gases that were also produced [22, 23].

\section{Material 7-BB}

The flaming experimental results showed that no deaths occurred either during the 30 minute exposures or the post-exposure observation periods (Table 10). In the non-flaming mode, no deaths were observed during the 30 minutes of actual exposure, but deaths did occur 24 to 48 hours following the tests. In one non-flaming experiment, the material started flaming approximately 10 minutes after the start of the test. This was the only case in which one animal died during the 30 minute exposure; another animal died five days later. Based on the concentrations of $\mathrm{CO}$ and $\mathrm{CO}_{2}$ generated when material 7-BB was decomposed in the flaming and non-flaming modes, no deaths would have been predicted to occur from any of the mass loadings tested. The post-exposure deaths that occurred following the non-flaming decomposition of Material 7-BB 
were, therefore, not due to the $\mathrm{CO}$ and $\mathrm{CO}_{2}$, but were probably due to the presence of one or more additional toxic gases $[22,23]$.

\section{Material 8-EE}

One animal died within the exposure and five died post-exposure from the flaming decomposition products of Material 8-EE (Table 11). The post-exposure deaths occurred as late as 4 days after the tests. The concentrations of $\mathrm{CO}$ and $\mathrm{CO}_{2}$ were sufficient to account for the deaths that occurred up to 24 hours post-exposure, but would not have accounted for the deaths occurring later. These deaths might have been caused by additional toxic gases. In the nonflaming mode, no deaths were predicted based on the $\mathrm{CO}$ and $\mathrm{CO}_{2}$ concentrations and no deaths occurred.

\section{Material 11-PP}

No deaths were observed from the flaming decomposition products from Material 11-PP (Table 12). In the non-flaming mode, there were no deaths during the 30 minute exposures, but many of the animals died following the tests. Most of these deaths occurred during the first three days; however, one animal died as late as 24 days following the exposure. Based on the levels of $\mathrm{CO}$ and $\mathrm{CO}_{2}$, no deaths were expected. The post-exposure deaths from the non-flaming mode are not attributable to the toxicological interactions of $\mathrm{CO}$ and $\mathrm{CO}_{2}$, but are probably due to one or more additional toxic gases [22, 23].

The data from the five tests are summarized in Tables 13-15. The non-flaming test results in Table 13 indicate within and post-exposure deaths for the untreated $\mathrm{HDPE}$ at $375^{\circ} \mathrm{C}$ and mass loadings from $20-39 \mathrm{~g} / \mathrm{m}^{3}$. Deaths were also experienced for the samples containing $\mathrm{CaCO}_{3}$, ATH, and magnesium hydroxide, probably as a result of the same additional toxic gases that are being generated from the control. No deaths were experienced for the sample containing the $\mathrm{Br} / \mathrm{Sb}_{2} \mathrm{O}_{3}$ additive. Since the halogenated flame retardants function in the vapor phase, perhaps the vapor phase reactions also prevent the formation of additional toxic gases, thus reducing within and postexposure deaths.

The data in Table 14 for the flaming mode indicate that fewer deaths occur for all the samples at a loading of $30-40 \mathrm{~g} / \mathrm{m}^{3}$ than in the non-flaming mode. The only additive-containing sample that produced deaths was $8-\mathrm{EE}$ with $\mathrm{Br} / \mathrm{Sb}_{2} \mathrm{O}_{3}$. These deaths were probably a result of the higher $C O$ levels acting in conjunction with the $\mathrm{CO}_{2}[19,20]$ along with the added brominated FR.

The toxicological data for both the flaming and non-flaming modes are summarized in Table 15. The data points out the problems that arose from conducting these experiments without any knowledge of the formulations of the materials and the amounts of additives and fillers. To actually determine the degree to which the additives contributed to the toxic potency of the materials, it would be necessary to determine more precise LC $_{50}$ values based on mass consumed. 


\section{SUMMARY AND CONCLUSIONS}

Full-scale fire behavior can, at the moment, be predicted from bench-scale data only under limited circumstances. To do this, it is required that specific end-use products be identified, and that an appropriate fullscale/bench-scale correlation be available for this product category [18]. Realistic estimates of the production of smoke or toxic gases cannot be made unless either full-scale tests are conducted or such correlations are available. Thus, the results below are indicative only, and are not a quantitative estimate of the full-scale fire hazards involved.

Nonetheless, changes in the key properties measured (ignition delay, rate of heat release, total heat release, and smoke toxic potency) may well be indicators of changes in hazard.

The data obtained from the Cone Calorimeter on a limited number of samples whose formulations were not verified by NIST suggest that in most samples tested, ATH was an effective fire retardant and smoke suppressant when used at levels from 30 to $65 \%$ by weight. The samples containing halogen/antimony oxide flame retardants at levels of 2.5 to $15 \%$ by weight were also effective fire retardants, but not particularly effective as smoke suppressants. NIST has neither determined whether these are optimal additive levels for fire safety enhancement, nor assessed whether one can extrapolate these results to other loadings.

The following information is noted from the data:

- In the tests at $30 \mathrm{~kW} / \mathrm{m}^{2}$ without the spark igniter, the samples containing ATH at levels of 508 by weight or greater in all polymer formulations failed to ignite. The two samples containing the chlorine as a flame retardant, without ATH in the PES formulation or in combination with $10 \%$ ATH in the XLPE formulation, also failed to ignite. Three of the four polymer formulations containing bromine as the flame retardant ignited (the PES formulation that did not ignite also contained 508 by weight ATH).

- For tests at $30 \mathrm{~kW} / \mathrm{m}^{2}$ with the spark igniter, the ignition times were longer for samples containing ATH alone, halogenated/antimony oxide flame retardants (with the exception of the HDPE formulation) or ATH in combination with halogenated/antimony oxide flame retardants.

- For tests at $30 \mathrm{~kW} / \mathrm{m}^{2}$ with the spark igniter, a 15 -fold decrease in the peak rate of heat released for the polypropylene formulation was achieved with $57 \%$ by weight ATH. A less than 2-fold decrease was achieved with the sample containing $\mathrm{Br} / \mathrm{Sb}_{2} \mathrm{O}_{3} \quad(14 / 6 \%$ by weight).

- With respect to smoke yields, a comparison of the same two samples from above shows a more than 7 -fold decrease in the smoke generation from a sample with ATH compared to an almost 3-fold increase in smoke from the $\mathrm{Br} / \mathrm{Sb}_{2} \mathrm{O}_{3}$ flame retardant. 
- In all samples that contained only a halogenated/antimony oxide $\mathrm{FR}$, the smoke production was increased.

Also of note was the increase of $\mathrm{CO}$ production with the halogenated/antimony oxide FR additives.

- In the HDPE formulation, the sodium aluminocarbonate and magnesium hydroxide were also more effective as fire retardants than the halogen/antimony oxide combinations in increasing ignition time, reducing mass consumed, peak $\dot{q} "$, CO production, and smoke generation; they were not as effective as ATH.

- The inert filler, $\mathrm{CaCO}_{3}$, was effective in reducing the mass consumed and amount of heat released, but caused an increase in smoke production. In the PVC formulations, the $\mathrm{CaCO}_{3}$ actually decreased the ignition time.

In the toxic potency testing, only a selected sub-group of five samples of high density polyethylene was examined. In the non-flaming mode, the N-Gas Model used for analysis predicted no deaths based on the $\mathrm{CO}$ and $\mathrm{CO}_{2}$ production for any of the samples. However, deaths (mostly during the post-exposure observation period) did occur with all samples except 8 -EE with $\mathrm{Br} / \mathrm{Sb}_{2} \mathrm{O}_{3}$. These deaths might be a result of other toxic gases not analyzed. Also of note in the non-flaming mode was the much lower production of $\mathrm{CO}$ and $\mathrm{CO}_{2}$ for sample 8-EE.

In the flaming mode, there were two cases in which deaths occurred during or immediately following the 30 minute exposures and they were specimen $5 \cdot \mathrm{VV}$ without additive at the highest mass loading - $39 \mathrm{~g} / \mathrm{m}^{3}$ and sample 8 -EE with $\mathrm{Br} / \mathrm{Sb}_{2} \mathrm{O}_{3}$ at a comparable mass loading. In only one case (sample 8 -EE) was the predicted concentration of $\mathrm{CO}$ and $\mathrm{CO}_{2}$ high enough to cause within-exposure deaths. Also, samples 5-VV and $8-\mathrm{EE}$ were the only samples to be completely consumed.

In the non-flaming mode, for sample 5-VV, the high density polyethylene without additives, 70 to 858 of the material was consumed when the material was decomposed at $375^{\circ} \mathrm{C}$; for samples $6-\mathrm{HH}, 7-\mathrm{BB}$ and $11-\mathrm{PP}$ only 40 to $60 \%$ of the samples were consumed and may be the reason that fewer deaths occurred during the 30 minute flaming exposures. The possibility of deaths at higher mass loadings of material was not examined since the cup furnace smoke toxicity method specifies a maximum mass loading of $40 \mathrm{~g} / \mathrm{m}^{3}$ (materials not toxic at this loading are considered to have a low toxic potency).

The observed deaths, which were not predicted by combined interactions of $\mathrm{CO}$ and $\mathrm{CO}_{2}$, were probably due to the additional toxic effects of unmeasured gases. However, the predicted toxic potency values all fall into a range typical of many comnon materials.

\section{ACKNOWLEDGEMENTS}

The authors thank Dr. Richard G. Gann for his valuable editing and technical advice, Dr. Joshua L. Gurman for his help and advice in setting up the 
experiments, and Ms. Helene Clark, Ms. Margaret Yoklavich, Ms. Carmen Davis and Messrs. W. H. Twilley and J. R. Shields for their technical assistance in performing the experiments. Ms. Helene Clarke and Ms. Margaret Yoklavich were guest workers under the auspices of the University of Pittsburgh Graduate School of Public Health, Pittsburgh, PA. 


\section{REFERENCES}

[1] Test for Flammability of Plastic Materials for Parts in Devices and Appliances, UL 94, Underwriter's Laboratory, Northbrook, Illinois, 1990.

[2] Bukowski, R. W., Peacock, R. D., Jones, W. W., Forney, C. L., Software User's Guide for the HAZARD I Fire Hazard Assessment, Vol. 1, National Institute of Standards and Technology, NIST HB-146/I, 1989.

[3] Keating, J. Z., Alumina Trihydrate: Flame-retarding, Smoke-suppressing Filler, Plastics Compounding, July/August, 1980.

[4] Gal, E., Pal, A., Rychly, J., Tarapcikova, K., Mechanism of Aluminum and Magnesium Hydroxide Action in Halogen-Free Fire Retardant Polymer Composites, Flame Retardants 1990, International Conference, 1990, Elsevier Applied Science, New York, 134-143 pp, 1990.

[5] Agnew, A., Aspects of the se of Aluminum Hydroxide as a Fire Retardant Filler for Polymeric Materials, Fire Retardants: Proceedings of 1978 Conference on Flammability and Fire Retardants, July 1978, Technomic Publishing Co., Connecticut, Bhatnager, V. M., editor, 1-14 pp, 1978

[6] Lyons, J. W., The Chemistry and Uses of Fire Retardants, P. 14-24, Wiley-Interscience, New York, (1970).

[7] Levin, B. C., Fowel1, A. J., Birky, M. M., Paabo, M., Stolte, A., and Malek, D., Further Development of a Test Method for the Assessment of the Acute Inhalation Toxicity of Combustion Products. NBSIR 82-2532, National Bureau of Standards, Gaithersburg, MD, 1982.

[8] Levin, B.C. and Gann, R.G.. Toxic Potency of Fire Smoke:Measurement and Use, Fire and Polymers:Hazards Identification and Prevention, Ed. by G.L. Nelson, ACS Symposium Series 425, American Chemical Society, Washington, DC, pp.3-11, 1990.

[9] Braun, E., Levin, B. C., Paabo, M., Gurman, J., Holt, T., Steel, J. S., Fire Toxicity Scaling (NBSIR 87-3510). [U.S.] Nat. Bur. Stand. (1987).

[10] Babrauskas, V., Levin, B. C., and Gann, R. G., A New Approach to Fire Toxicity Data for Hazard Evaluation. ASTM Standardization News. 14, 28 33 (1986).

[11] Levin, B.C., Paabo, M., Bailey, C., Harris, S.E., and Gurman, J.L., Toxicological Effects of the Interactions of Fire Gases and Their Use in a Toxic Hazard Assessment Computer Model, The Toxicologist, ㅁ:리 (1985).

[12] Levendusky, T. L. and Musselman, L. L., Precipated Alumina Trihydrate for Polymers, presented at 1984 RETEC, Society of Plastics Engineers, Georgia Institute of Technology, Atlanta, Ga, 1984. 
[13] Babrauskas, V., Development of the Cone Calorimeter - A Bench-Scale Heat Release Rate Apparatus Based on Oxygen Consumption (NBSIR 82-2611). [U.S.] Nat. Bur. Stand. (1982).

[14] Babrauskas, V., The Cone Calorimeter - - A Versatile Bench-Scale Tool for the Evaluation of Fire Properties, pp. 78-87 in New Technology to Reduce Fire Losses \& Costs, S.J. Grayson and D.A. Smith, eds., Elsevier Applied Science Publishers, London (1986).

[15] Huggett, C., Estimation of Rate of Heat Release by Means of Oxygen Consumption Measurements. Fire and Materials. 4, 61-65 (1980).

[16] Babrauskas, V., and Mulholland, G., Smoke and Soot Data Determinations in the Cone Calorimeter, pp. 83-104 in Mathematical Modeling of Fires (ASTM STP 983), American Society for Testing and Materials, Philadelphia (1987).

[17] Standard Test Method for Heat and Visible Smoke Release Rates for Materials and Products using an Oxygen Consumption Calorimeter (E 1354 90a). Annual Book of ASTM Standards, Vol. 04.07, American Society for Testing and Materials (1991).

[18] Babrauskas, V., Harris, R.H., Jr., Gann, R.G., Levin, B.C., Lee, B.T., Peacock, R.D., Paabo, M., Twilley, W., Yoklavich, M.F., and Clark, H.M., Fire Hazard Comparison of Fire-Retarded and Non-Fire-Retarded Products (NBS Special Publication SP 749). [U.S.] Natl. Bur. Stand. (1988).

[19] Levin, B. C., Paabo, M., Gurman, J. L. and Harris, S. E., Effects of Exposure to Single or Multiple Combinations of the Predominant Toxic Gases and Low Oxygen Atmospheres Produced in Fires, Fundam. Appl. Tox. 9: $236-250(1987)$.

[20] Levin, B. C., Paabo, M., Gurman, J. L., Harris, S. E., and Braun, E., Toxicological Interactions between Carbon Monoxide and Carbon Dioxide. Toxicology 47:135-164 1987 .

[21] Babrauskas, V., Harris, Jr., R. H., Braun, E., Levin, B., Paabo, M. and Gann, R. G., The Role of Bench-Scale Test Data in Assessing Real-Scale Fire Toxicity, NIST TN 1284, National Institute of Standards and Technology, 1991.

[22] Paabo, M. and Levin, B.C., A Literature Review of the Chemical Nature and Toxicity of the Thermal Decomposition Products of Polyethylenes. Fire and Matls. 11:55-70 (1987).

[23] Levin, B.C., A Summary of the NBS Literature Reviews on the Chemical Nature and Toxicity of the Pyrolysis and Combustion Products from Seven Plastics:Acrylonitrile-Butadiene Styrenes (ABS), Nylons, Polyesters, Polyethylenes, Polystyrenes, Poly(vinyl chlorides), and Rigid Polyurethane Foams. Fire and Matls. 11:143-157 (1987). 
Table 1. Materials Studied

\begin{tabular}{|c|c|c|c|c|}
\hline $\begin{array}{l}\text { Sample } \\
\text { No. }\end{array}$ & Code & Polymer Type/Fillers & Additive & $\begin{array}{l}\text { Additive } \\
\text { conc. } \\
(z \text { by wt. })\end{array}$ \\
\hline 1 & $\mathrm{CC}$ & Isophthalic acid $\mathrm{PES}^{\mathrm{a}} /$ styrene/glass & $\mathrm{CaCO}_{3}$ & 55 \\
\hline 2 & Q & Isophthalic acid PES/styrene/glass & ATH & 54 \\
\hline 3 & $x x$ & Brominated PES/styrene/glass & $\mathrm{Br} / \mathrm{Sb}_{2} \mathrm{O}_{3} / \mathrm{ATH}$ & $4 / 1 / 50$ \\
\hline 4 & AA & Chlorinated PES/styrene/glass & $\mathrm{Cl} / \mathrm{Sb}_{2} \mathrm{O}_{3}$ & $8 / 1.5$ \\
\hline 23 & II & Acrylic-based PES/styrene/glass & ATH 23 & 43 \\
\hline 32 & -- & $G P^{b}$ unsaturated PES/glass & $\mathrm{CaCO}_{3}$ & 50 \\
\hline 33. & -- & GP unsaturated PES/glass & ATH $^{3}$ & 50 \\
\hline 34 & -- & $\mathrm{GP} / \mathrm{Br}$ unsaturated $\mathrm{PES} / \mathrm{glass}$ & $\mathrm{Br} / \mathrm{Sb}_{2} \mathrm{O}_{3} / \mathrm{ATH}$ & $2.5 / 0.5 / 48$ \\
\hline 35 & -- & GP/Br unsaturated PES/glass & $\mathrm{Br} / \mathrm{Sb}_{2} \mathrm{O}_{3} / \mathrm{ATH} / \mathrm{NPS}$ & $2.5 / 0.5 / 24 / 24$ \\
\hline 5 & VV & High Density Polyethylene & None & -- \\
\hline 6 & $\mathrm{HH}$ & High Density Polyethylene & $\mathrm{CaCO}_{3}$ & 60 \\
\hline 7 & $\mathrm{BB}$ & High Density Polyethylene & $\mathrm{ATH}^{3}$ & 60 \\
\hline 8 & $E E$ & High Density Polyethylene & $\mathrm{Br} / \mathrm{Sb}_{2} \mathrm{O}_{3}$ & $13 / 6$ \\
\hline 9 & $\mathbf{M}$ & High Density Polyethylene & Na aluminocarbonate & 58 \\
\hline 11 & PP & High Density Polyethylene & $\mathrm{Mg}(\mathrm{OH})_{2}$ & 60 \\
\hline 25 & $A C$ & Low Density Polyethylene & ATH & 45 \\
\hline 26 & $A D$ & Low Density Polyethylene & ATH & 50 \\
\hline 27 & $\mathrm{AE}$ & Low Density Polyethylene & ATH & 55 \\
\hline 28 & $\mathrm{AF}$ & $\mathrm{XL}^{\mathrm{C}}$ Low Density Polyethylene & ATH & 50 \\
\hline 29 & $A G$ & XL Low Density Polyethylene & ATH & 55 \\
\hline 30 & $\mathrm{AH}$ & XL Low Density Polyethylene & $\mathrm{Br} / \mathrm{Sb}_{2} \mathrm{O}_{3} / \mathrm{ATH}$ & $11 / 5 / 10$ \\
\hline 31 & $A J$ & XL Low Density Polyethylene & $\mathrm{Cl} / \mathrm{Sb}_{2} \mathrm{O}_{3} / \mathrm{ATH}$ & $10 / 5 / 10$ \\
\hline 12 & $\mathrm{LL}$ & Polypropylene & None & -- \\
\hline 13 & FF & Polypropy lene & $\mathrm{CaCO}_{3}$ & 58 \\
\hline 14 & GG & Polypropylene & ATH & 57 \\
\hline 15 & UU & Polypropy lene & $\mathrm{Br} / \mathrm{Sb}_{2} \mathrm{O}_{3}$ & $14 / 6$ \\
\hline 19 & $201-65,66$ & Flexible poly(vinyl chloride)/clay & None & -- \\
\hline 20 & $201-63,64$ & Flexible poly(vinyl chloride)/clay & $\mathrm{CaCO}_{3}$ & 15 \\
\hline 21 & $201-61,62$ & Flexible poly(vinyl chloride)/clay & ATH & 15 \\
\hline 16 & $201-67$ & Rigid poly(vinyl chloride) & None & -- \\
\hline 17 & $\begin{array}{l}A B, 201- \\
611-613\end{array}$ & Rigid poly(vinyl chloride) & $\mathrm{CaCO}_{3}$ & 30 \\
\hline 18 & $\begin{array}{l}201-68,69 \\
201-610\end{array}$ & Rigid poly(vinyl chloride) & ATH & 30 \\
\hline 36 & -- & Rigid poly(vinyl chloride) & None & -- \\
\hline 37 & -- & Rigid poly(vinyl chloride) & $\mathrm{CaCO}_{3}$ & 30 \\
\hline 38 & -- & Rigid poly(vinyl chloride) & ATH & 30 \\
\hline 39 & -- & Rigid poly(vinyl chloride & $\mathrm{Mg}(\mathrm{OH})_{2}$ & 30 \\
\hline 40 & -- & XI Ethylene-vinyl acetate & None & -- \\
\hline 41 & -- & XI Ethylene-vinyl acetate & ATH & 65 \\
\hline 42 & -- & XL Ethylene-vinyl acetate & $\mathrm{Cl} / \mathrm{Sb}_{2} \mathrm{O}_{3}$ & $15 / 4$ \\
\hline 43 & -- & XI Ethylene-vinyl acetate & $\mathrm{Mg}(\mathrm{OH})_{2}$ & 65 \\
\hline 44 & -- & $\mathrm{TP}^{\mathrm{d}}$ Ethylene-vinyl acetate & None & -- \\
\hline 45 & -- & TP Ethylene-vinyl acetate & ATH & 65 \\
\hline 46 & -- & TP Ethylene-vinyl acetate & $\mathrm{Cl} / \mathrm{Sb}_{2} \mathrm{O}_{3}$ & $15 / 4$ \\
\hline$\overline{a:}$ & Polyester & & & \\
\hline $\mathrm{b}:$ & General $\mathrm{F}$ & & & \\
\hline c: & $\mathrm{XI}=$ cross & inked & & \\
\hline d: & $T P=$ Them & lastic formulation & & \\
\hline
\end{tabular}


蚄

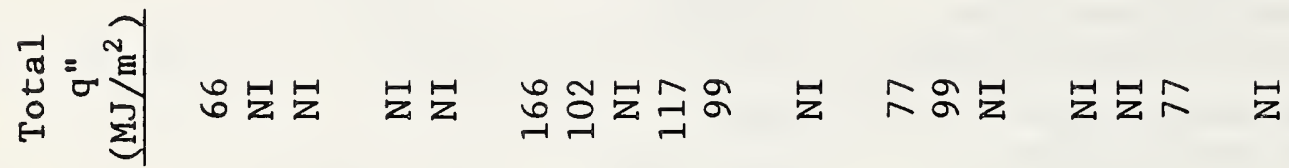
光

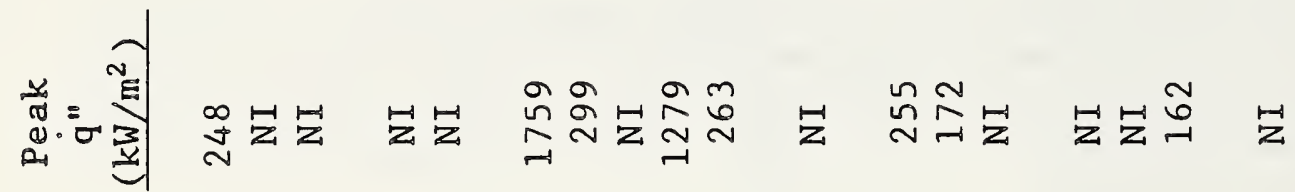

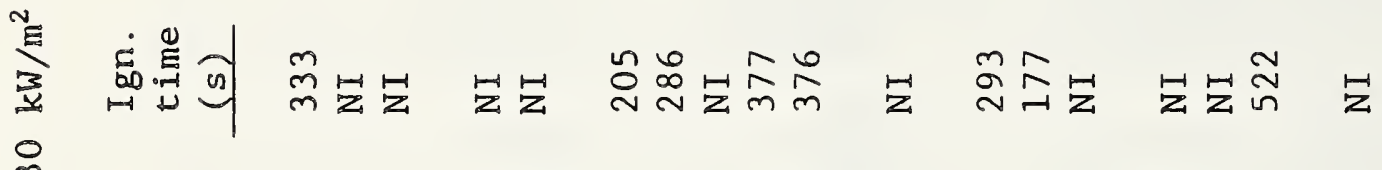

旁

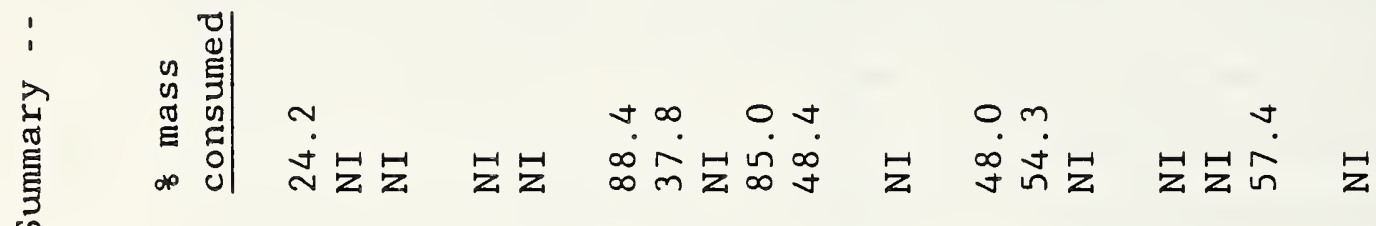
烍

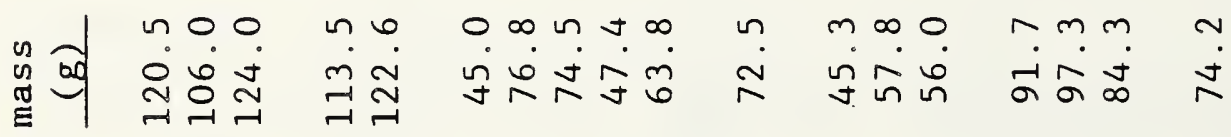

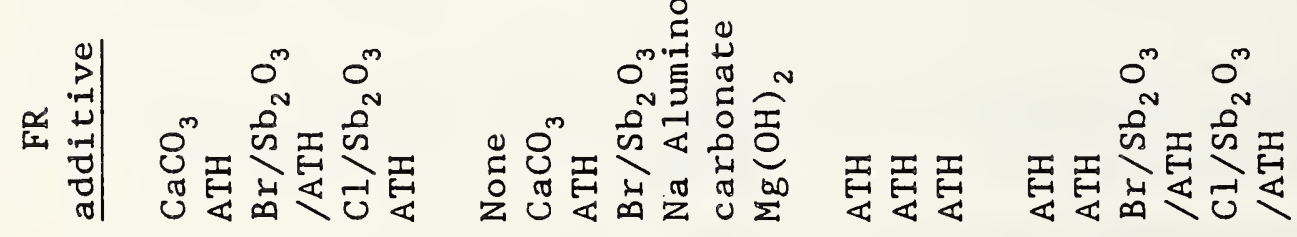

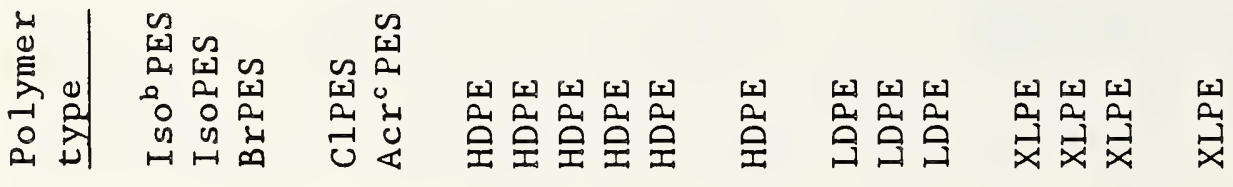

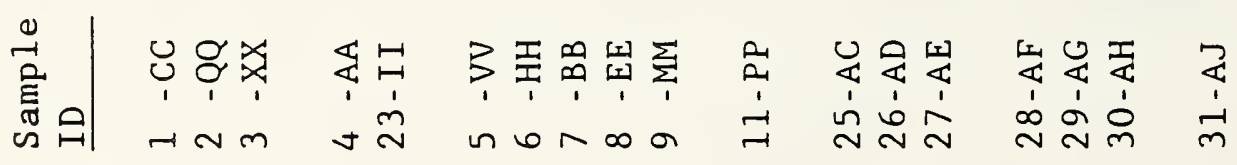




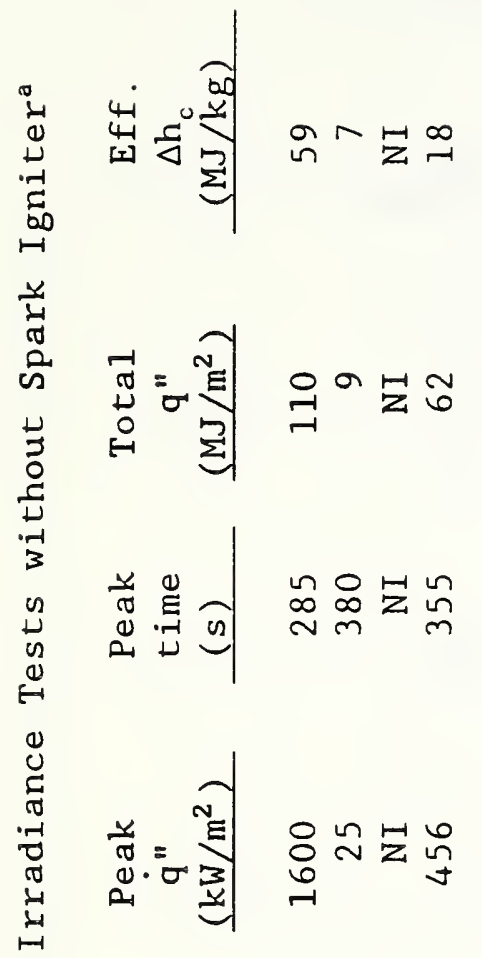

:

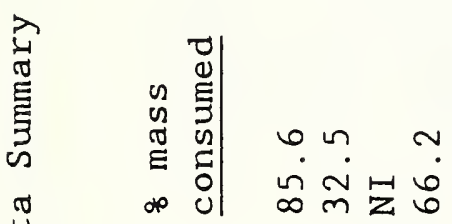

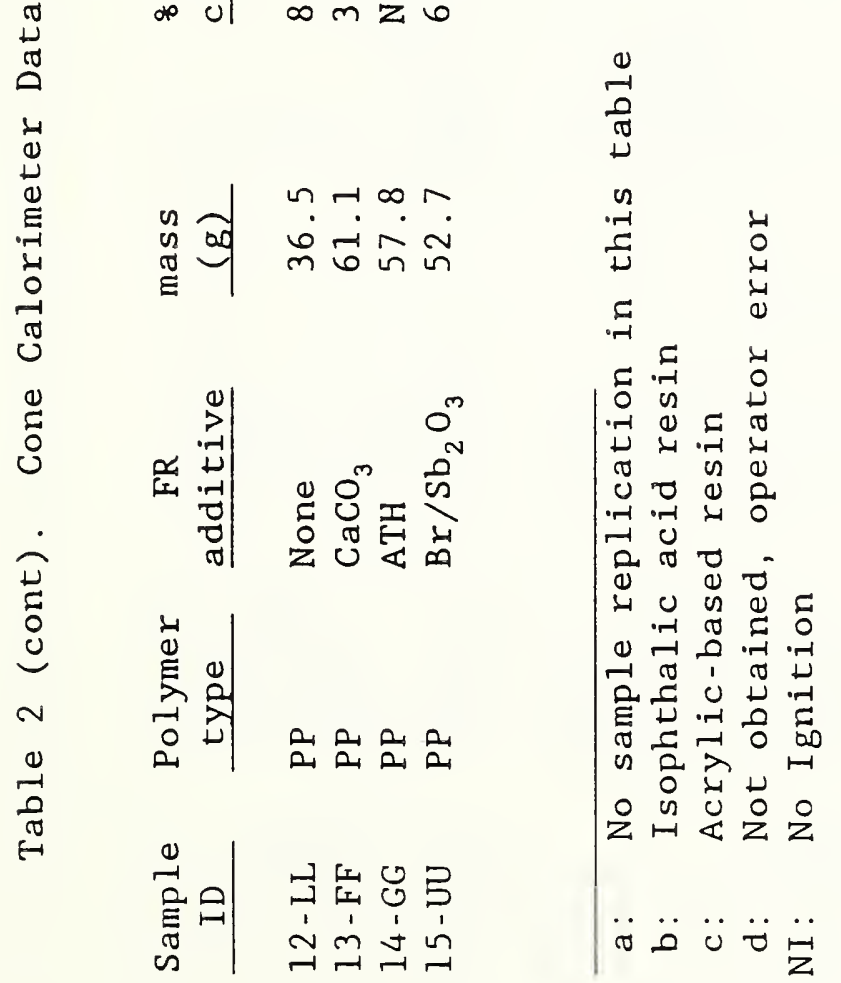


Table 3. Cone Calorimeter Data Summary -. Test Average Data at $30 \mathrm{~kW} / \mathrm{m}^{2}$ Irradiance without Spark Igniter ${ }^{a}$

\begin{tabular}{|c|c|c|c|c|c|}
\hline $\begin{array}{l}\text { Sample } \\
\text { ID }\end{array}$ & $\begin{array}{l}\text { Polymer } \\
\text { type } \\
\end{array}$ & $\begin{array}{c}F R \\
\text { additive }\end{array}$ & $\begin{array}{c}\mathrm{CO} \\
(\mathrm{kg} / \mathrm{kg}) \\
\end{array}$ & $\begin{array}{c}\mathrm{CO}_{2} \\
(\mathrm{~kg} / \mathrm{kg}) \\
\end{array}$ & $\begin{array}{c}\text { Smoke } \\
\left(\mathrm{m}^{2} / \mathrm{kg}\right)\end{array}$ \\
\hline $1-C C$ & Iso ${ }^{b}$ PES & $\mathrm{CaCO}_{3}$ & 0.041 & 1.782 & 523 \\
\hline $2-Q Q$ & IsoPES & ATH & $\mathrm{NI}$ & $\mathrm{NI}$ & NI \\
\hline $3-x x$ & BrPES & $\begin{array}{l}\mathrm{Br} / \mathrm{Sb}_{2} \mathrm{O}_{3} \\
/ \mathrm{ATH}\end{array}$ & $N I$ & NI & NI \\
\hline $4-A A$ & CIPES & $\mathrm{Cl} / \mathrm{Sb}_{2} \mathrm{O}_{3}$ & NI & NI & NI \\
\hline $23-I I$ & $A c r^{c}$ PES & ATH & $\mathrm{NI}$ & $\mathrm{NI}$ & $\mathrm{NI}$ \\
\hline $5-\mathrm{VV}$ & HDPE & None & 0.027 & 2.845 & 513 \\
\hline $6-\mathrm{HH}$ & HDPE & $\mathrm{CaCO}_{3}$ & 0.034 & 2.245 & 1087 \\
\hline $7-B B$ & HDPE & ATH & $\mathrm{NI}$ & NI & NI \\
\hline $8-E E$ & HDPE & $\mathrm{Br} / \mathrm{Sb}_{2} \mathrm{O}_{3}$ & 0.012 & 1.853 & 702 \\
\hline $9-M M$ & HDPE & $\begin{array}{l}\mathrm{Na} \text { Alumino- } \\
\text { carbonate }\end{array}$ & 0.014 & 2.061 & 212 \\
\hline $11-P P$ & HDPE & $\mathrm{Mg}(\mathrm{OH})_{2}$ & $\mathrm{NI}$ & NI & NI \\
\hline $25-A C$ & LDPE & ATH & 0.021 & 2.096 & 347 \\
\hline $26-A D$ & LDPE & ATH & 0.022 & 1.888 & 99 \\
\hline $27-A E$ & LDPE & ATH & NI & $\mathrm{NI}$ & NI \\
\hline $28-A F$ & XLPE & ATH & NI & NI & NI \\
\hline $29-A G$ & XLPE & ATH & $\mathrm{NI}$ & NI & NI \\
\hline $30-\mathrm{AH}$ & XLPE & $\begin{array}{l}\mathrm{Br} / \mathrm{Sb}_{2} \mathrm{O}_{3} \\
/ \mathrm{ATH}\end{array}$ & 0.155 & 0.644 & 1366 \\
\hline $31-\mathrm{AJ}$ & XLPE & $\begin{array}{l}\mathrm{Cl} / \mathrm{Sb}_{2} \mathrm{O}_{3} \\
/ \mathrm{ATH}\end{array}$ & $\mathrm{NI}$ & NI & NI \\
\hline $12-\mathrm{LL}$ & PP & None & 0.033 & 2.312 & 749 \\
\hline $13-F F$ & PP & $\mathrm{CaCO}_{3}$ & 0.029 & 0.196 & 607 \\
\hline $14-G G$ & PP & ATH & NI & $\mathrm{NI}$ & NI \\
\hline 15 - UU & PP & $\mathrm{Br} / \mathrm{Sb}_{2} \mathrm{O}_{3}$ & 0.151 & 0.696 & 1258 \\
\hline
\end{tabular}

\footnotetext{
a: No sample replication in this table

b: Isophthalic acid resin

c: Arylic-based resin

NI No ignition
} 


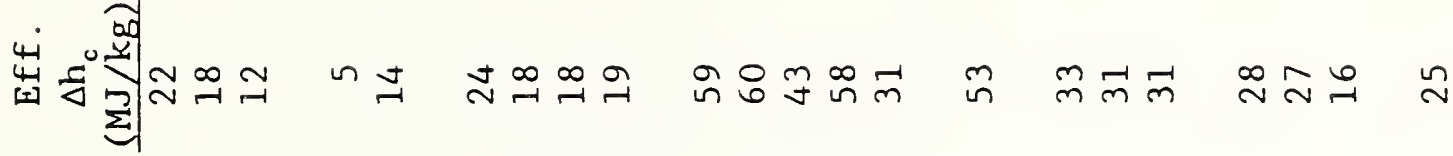

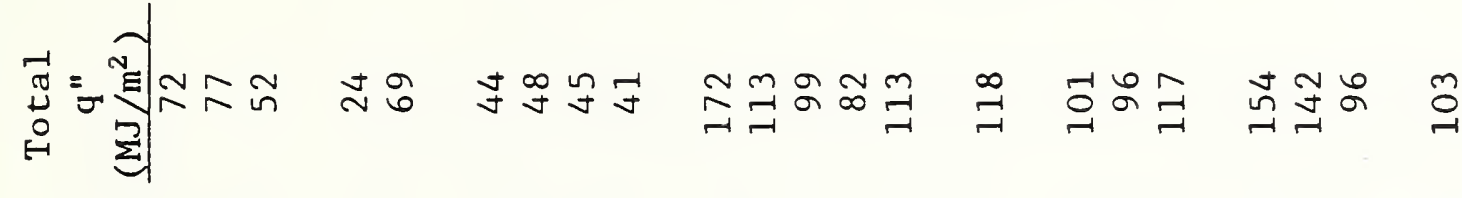

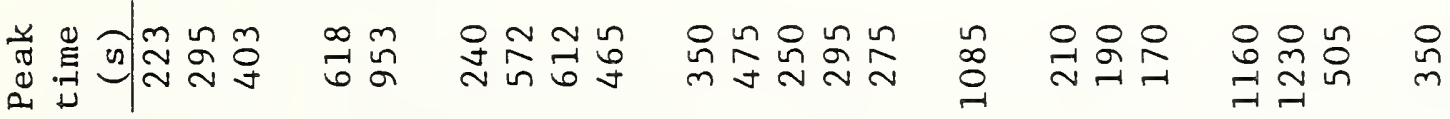

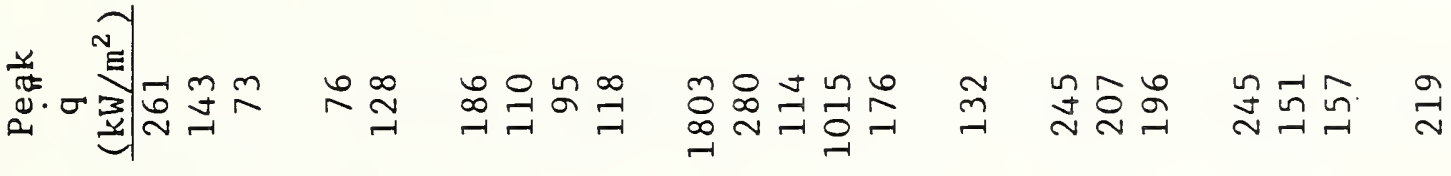

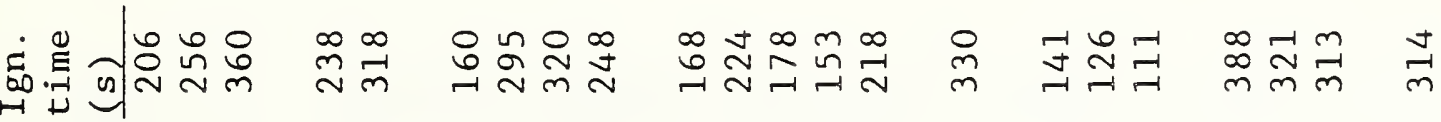

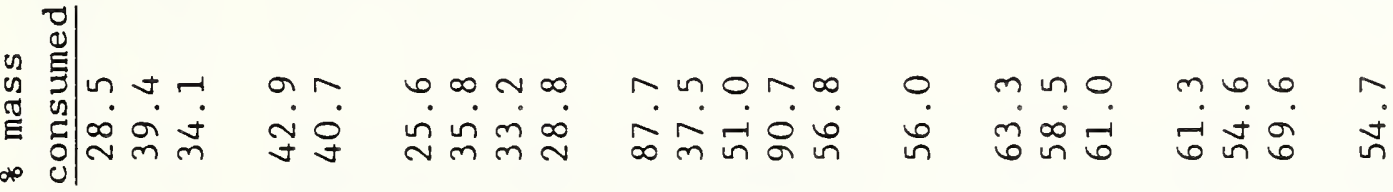

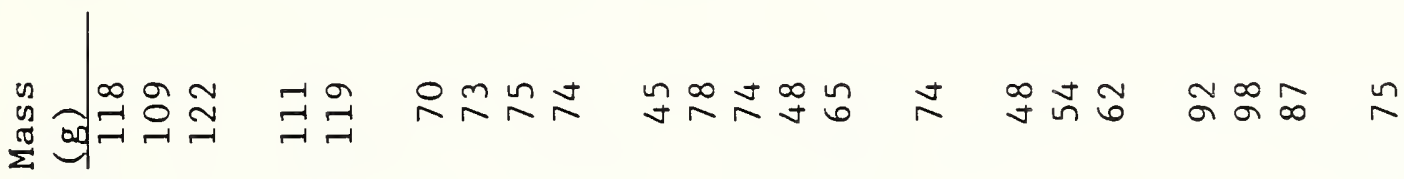

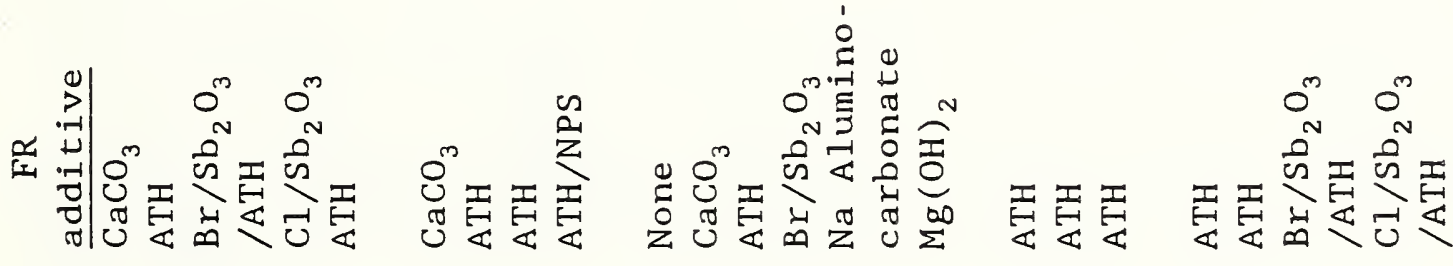

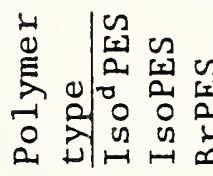

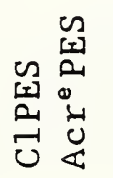

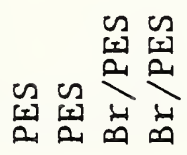

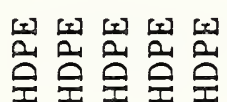

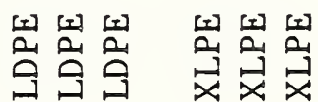
哲

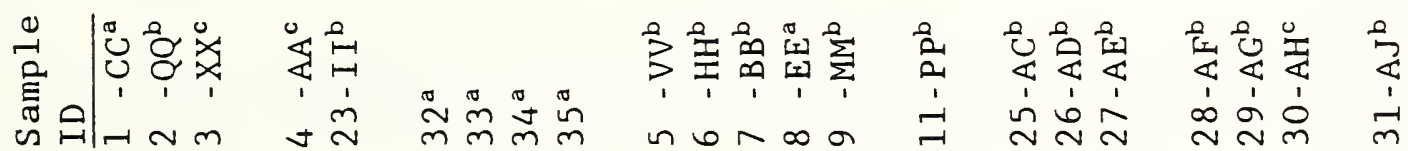


出

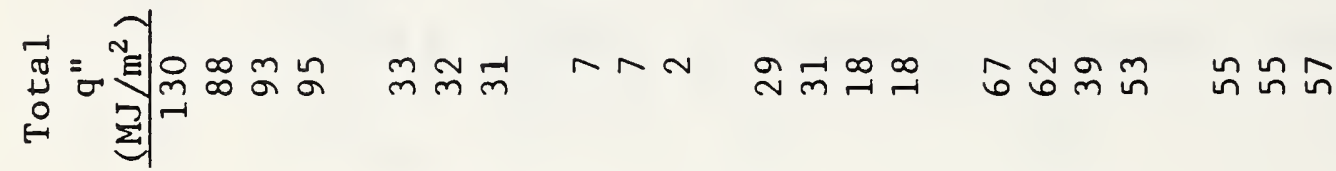

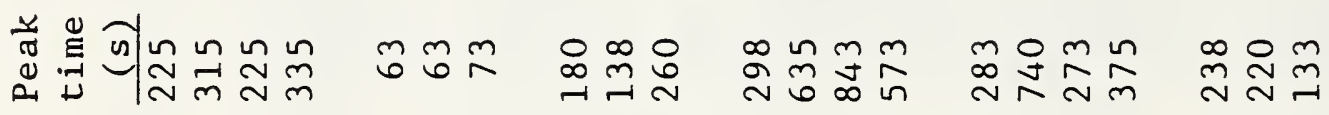

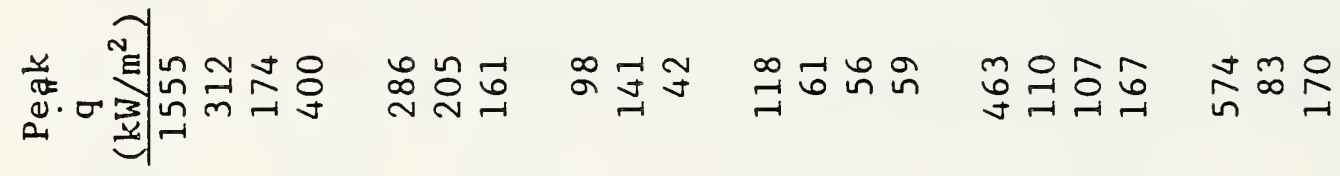

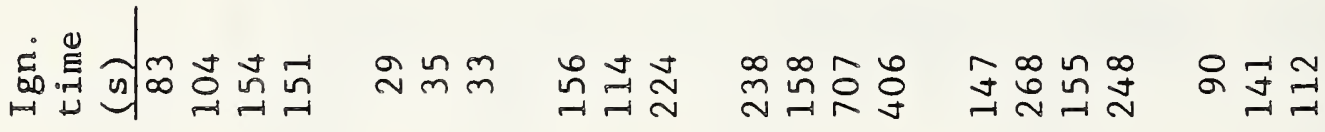

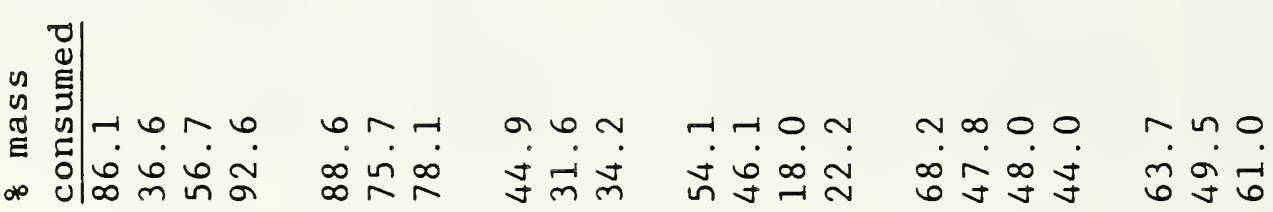

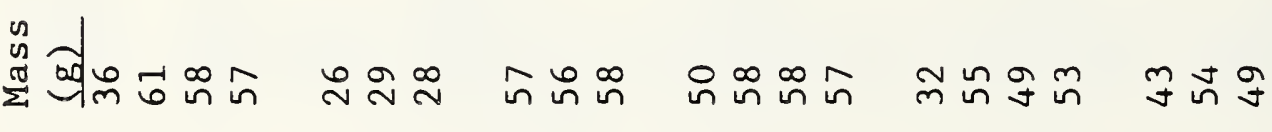

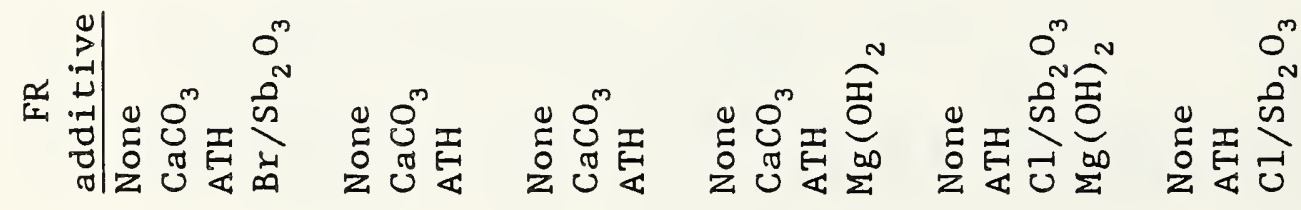

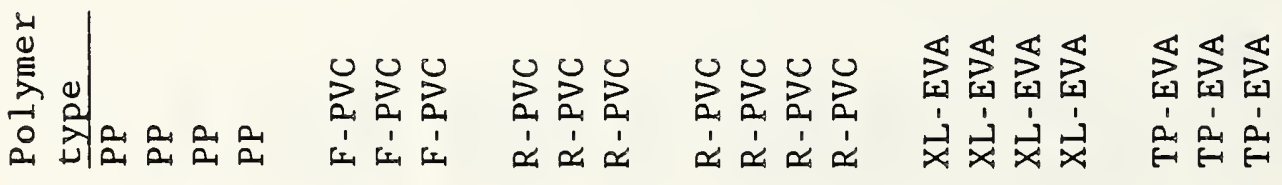

焉 


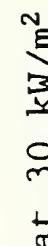

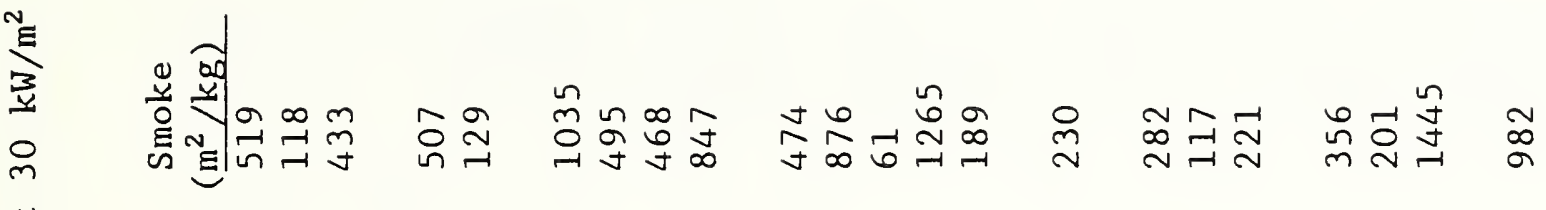

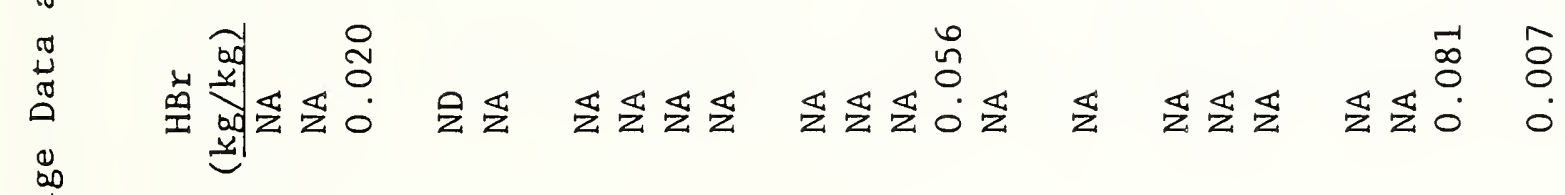

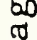

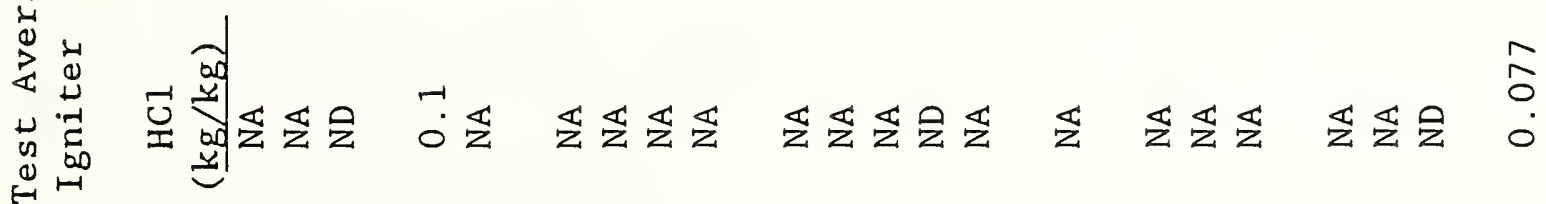
: 政 要

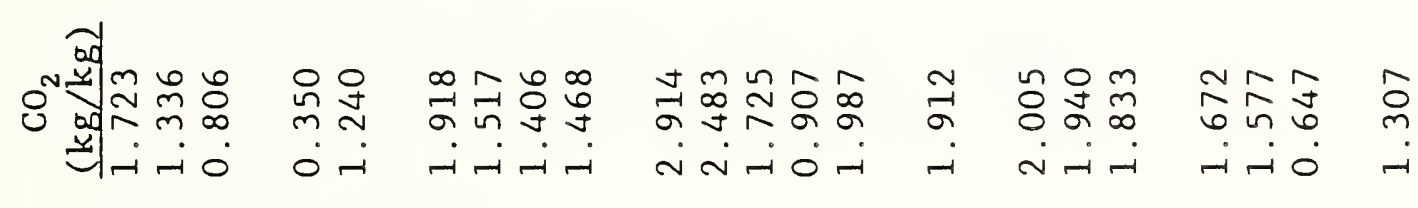

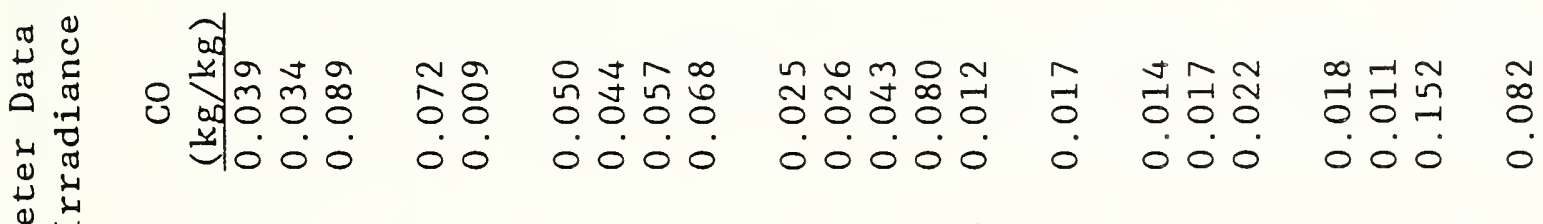

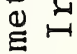
离

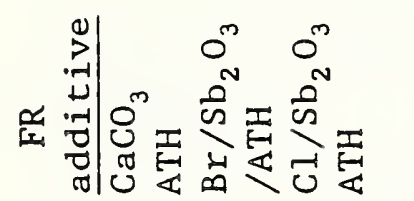

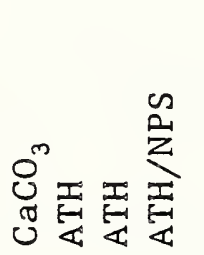

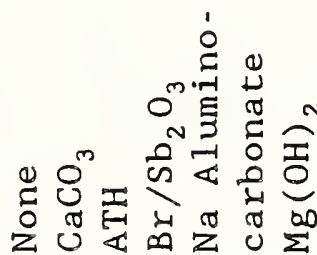

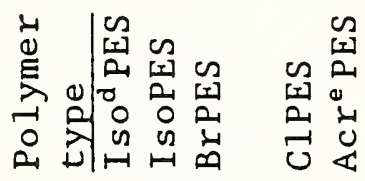

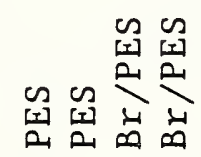

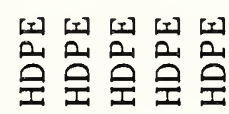
됨

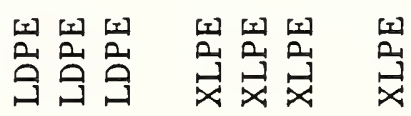

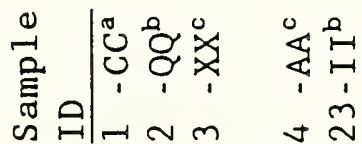

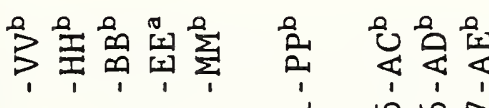

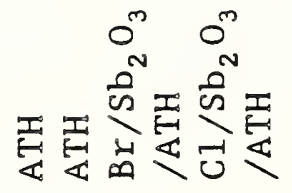
$\stackrel{0}{\infty}$

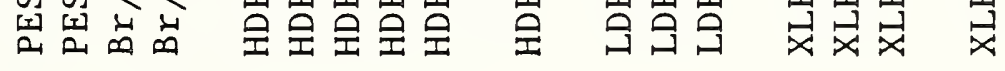

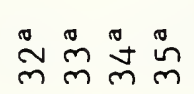
n $\stackrel{\sim}{\sim} \approx$

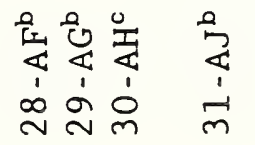




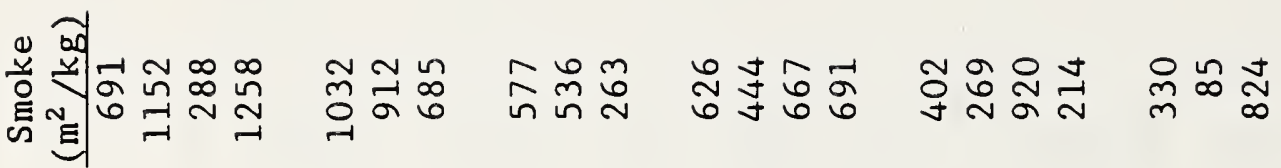

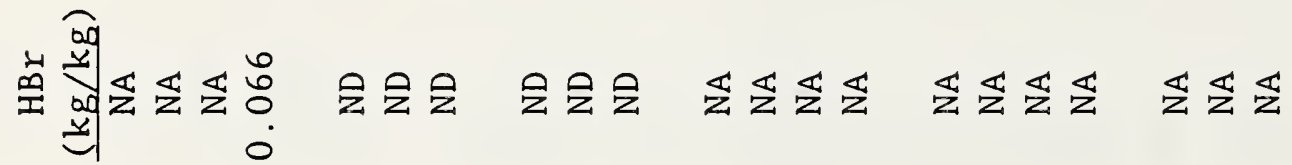

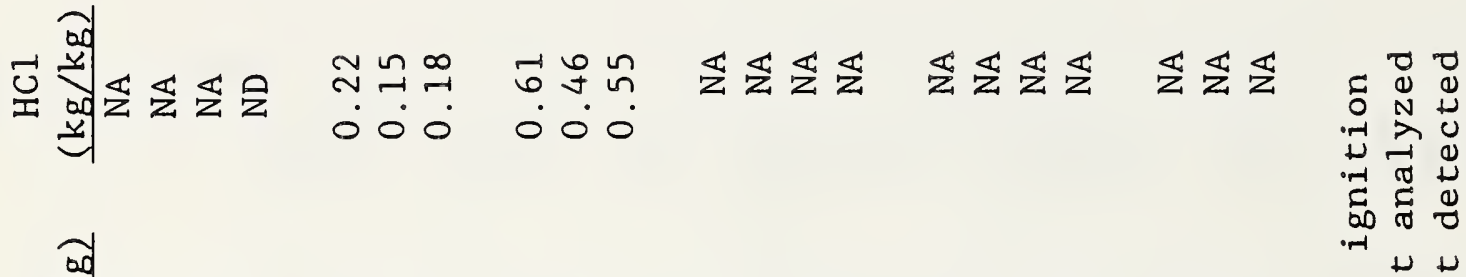

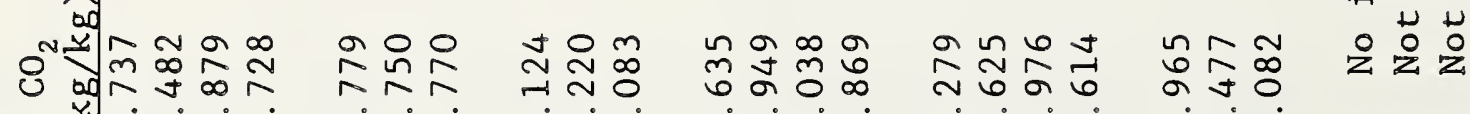

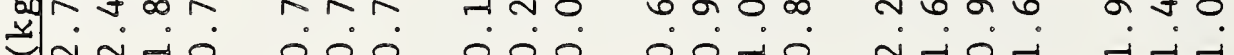

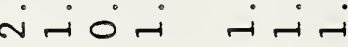

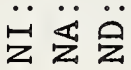

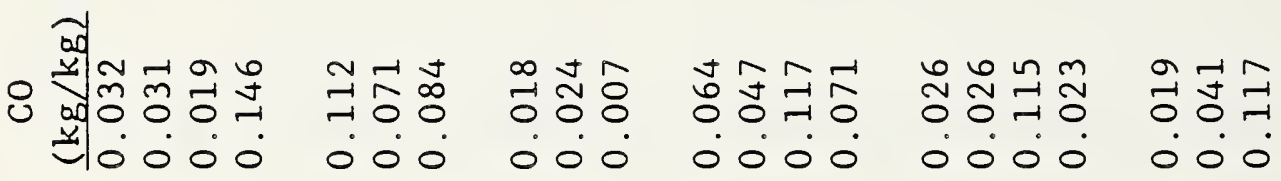

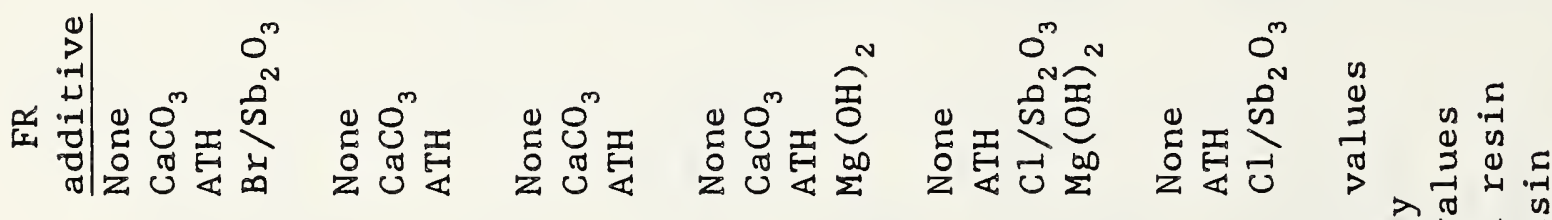

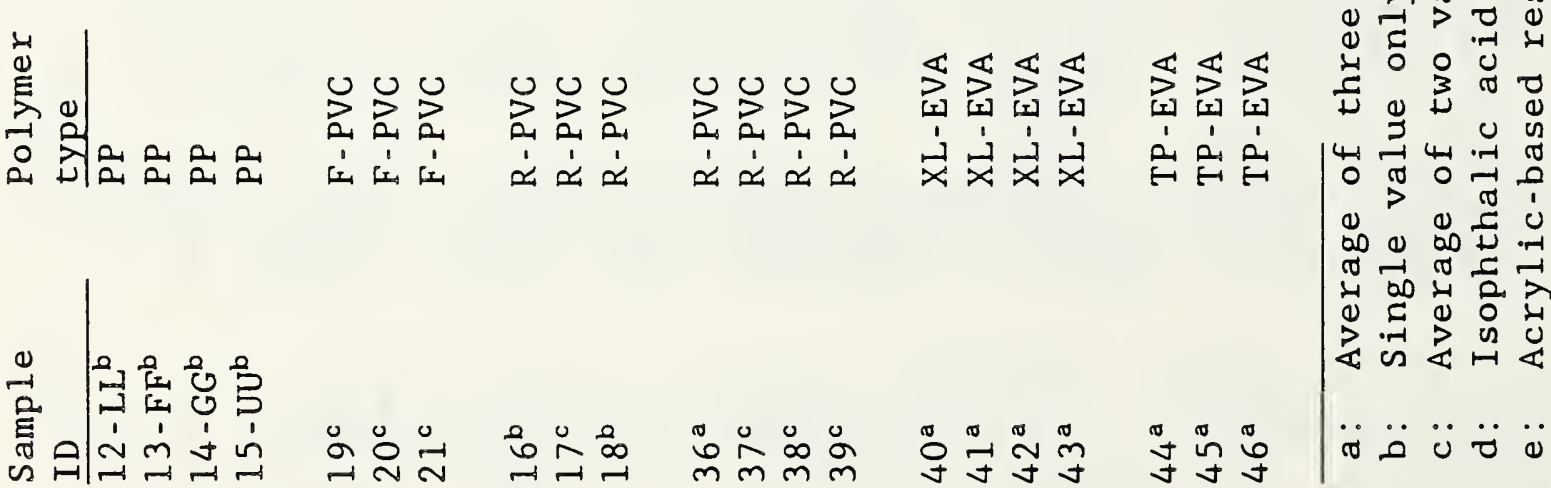




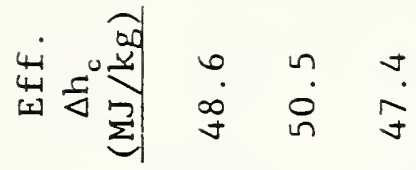

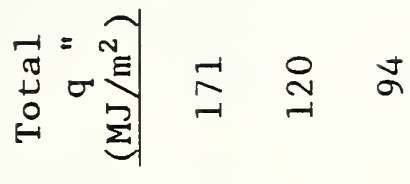

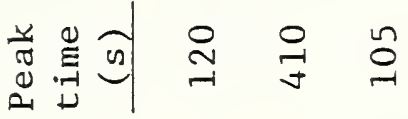

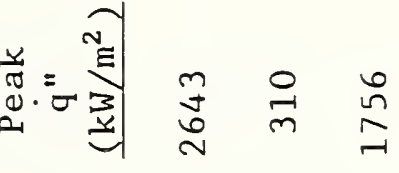

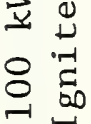

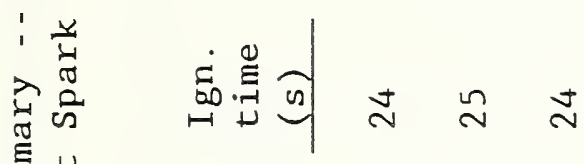

क

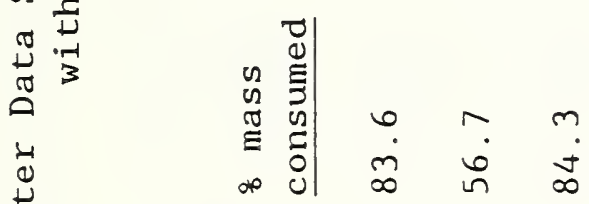

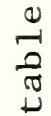

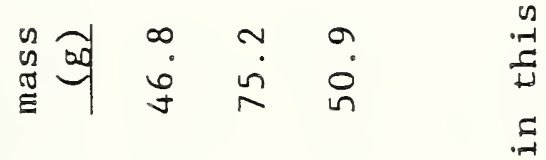

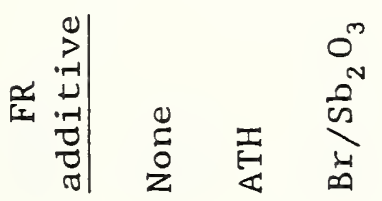

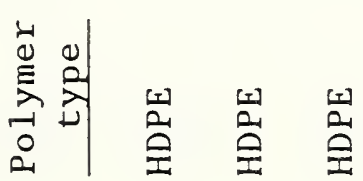

o

$\stackrel{\frac{\pi}{-1}}{\stackrel{0}{-1}}$

0
0
0
0
0
0
0
0
0
0
0
0
0
0
0
0
0
0
0 
Table 7. Cone Calorimeter Data Summary -- Test Average Data at $100 \mathrm{~kW} / \mathrm{m}^{2}$ Irradiance without Spark Igniter ${ }^{a}$

\begin{tabular}{|c|c|c|c|c|c|}
\hline $\begin{array}{c}\text { Sample } \\
\text { ID }\end{array}$ & $\begin{array}{c}\text { Polymer } \\
\text { type } \\
\end{array}$ & $\begin{array}{c}\mathrm{FR} \\
\text { additive }\end{array}$ & $\begin{array}{c}\mathrm{CO} \\
(\mathrm{kg} / \mathrm{kg}) \\
\end{array}$ & $\begin{array}{c}\mathrm{CO}_{2} \\
(\mathrm{~kg} / \mathrm{kg})\end{array}$ & $\begin{array}{c}\text { Smoke } \\
\left(\mathrm{m}^{2} / \mathrm{kg}\right)\end{array}$ \\
\hline $5-V V$ & HDPE & None & 0.029 & 3.345 & 315 \\
\hline $7-B B$ & HDPE & $\mathrm{ATH}$ & 0.017 & 1.802 & 521 \\
\hline $8-E E$ & HDPE & $\mathrm{Br} / \mathrm{Sb}_{2} \mathrm{O}_{3}$ & 0.031 & 1.075 & 722 \\
\hline
\end{tabular}

a: No sample replication in this table 


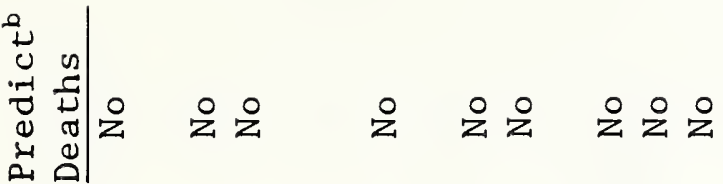

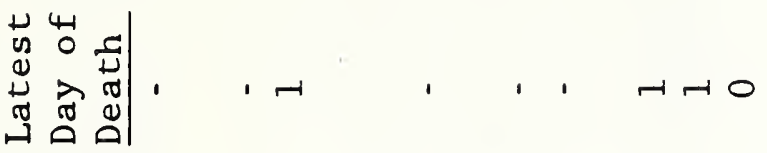

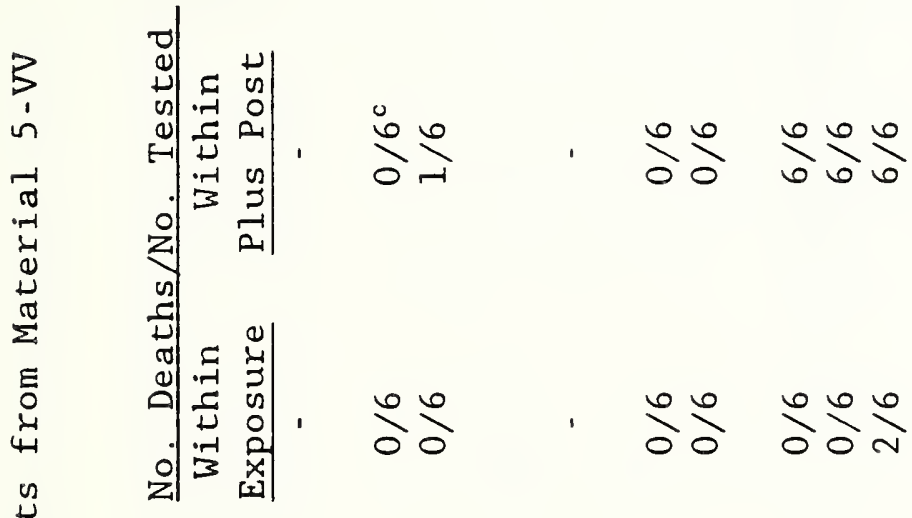

点

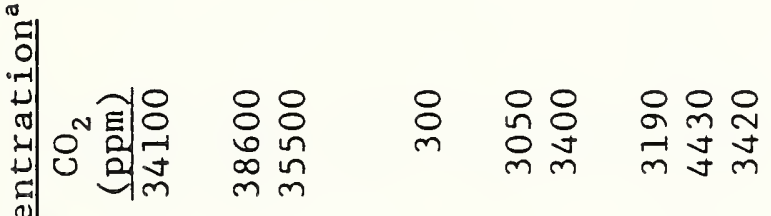

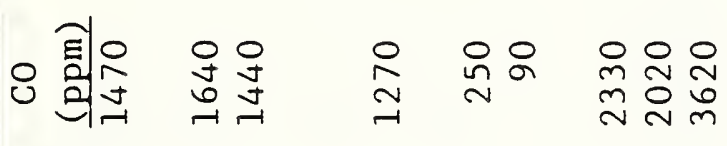

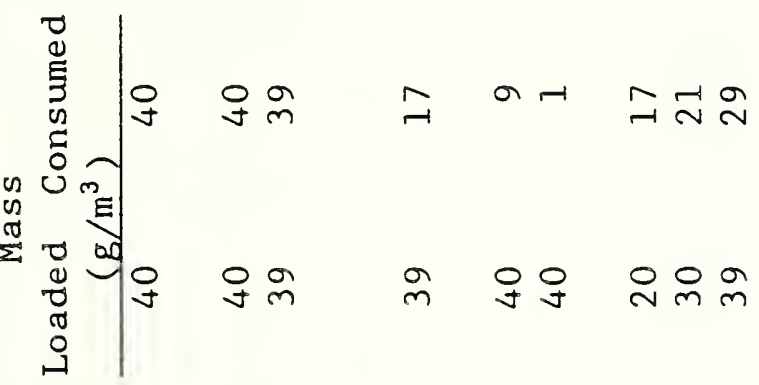

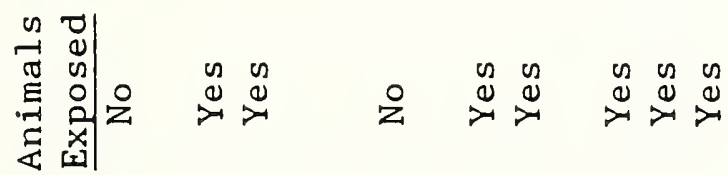

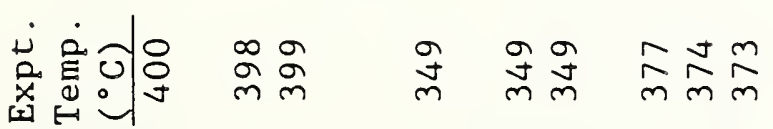

章师

碞

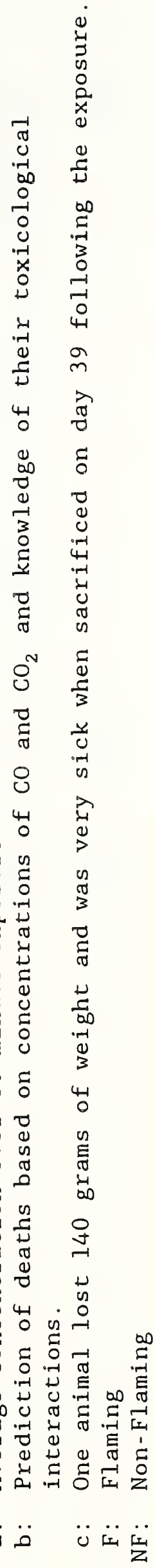




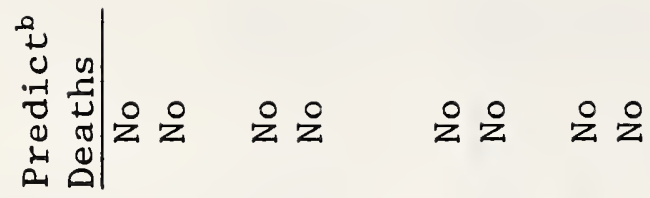

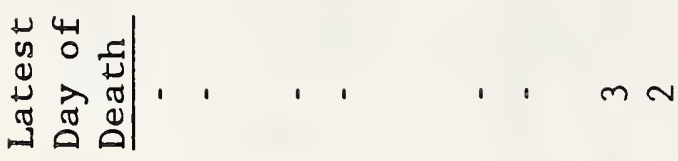

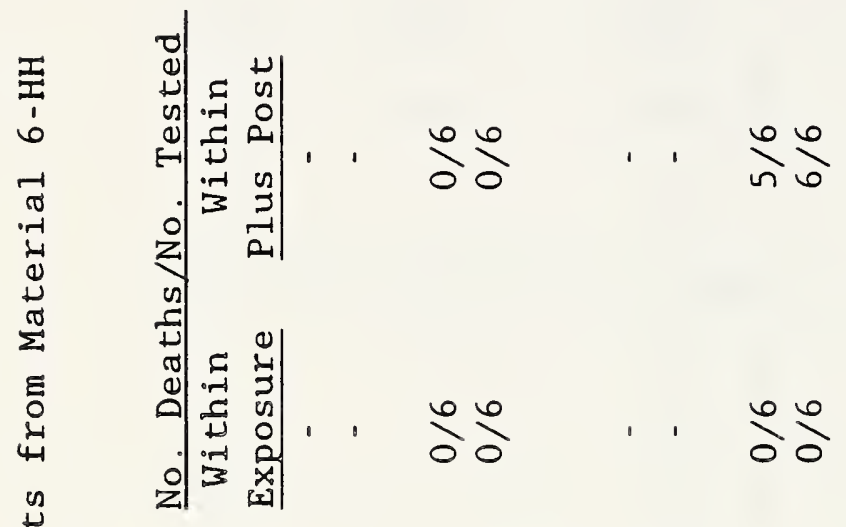

\begin{tabular}{c}
7 \\
0 \\
0 \\
0 \\
0 \\
0 \\
0 \\
0 \\
0 \\
-1 \\
0 \\
0 \\
\hline
\end{tabular}

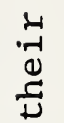

1
2
0
0
0
0

ปี

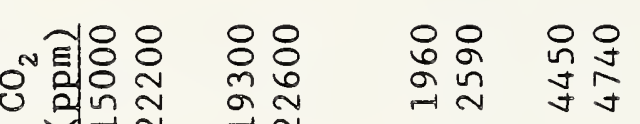

4

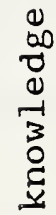

ชี

S

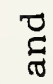

8

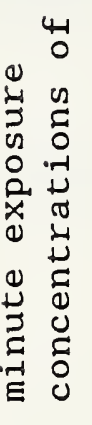

응

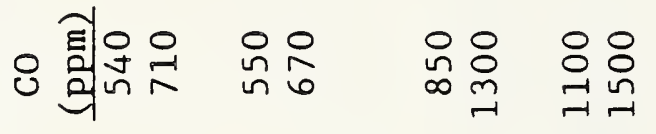

|

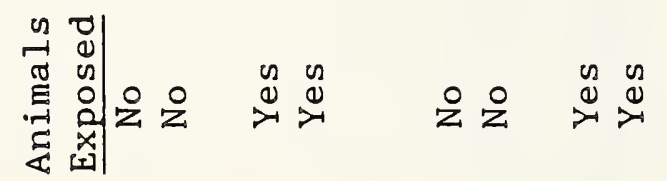

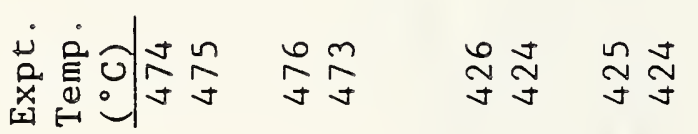

齐1 号

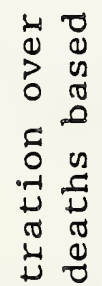

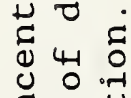

0 0 .

¿ :

(1) ป⿱一兀)

o $0, \Xi-1$

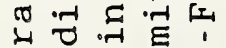

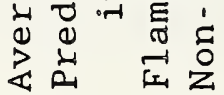

$\ddot{\sigma} \ddot{0} \ddot{\ddot{\Sigma}}$ 


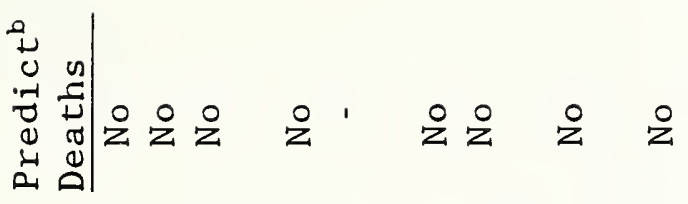

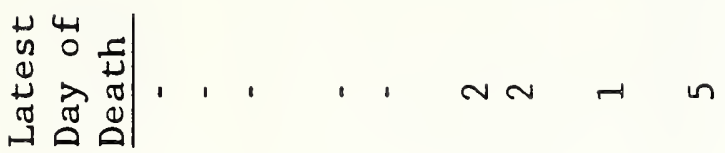

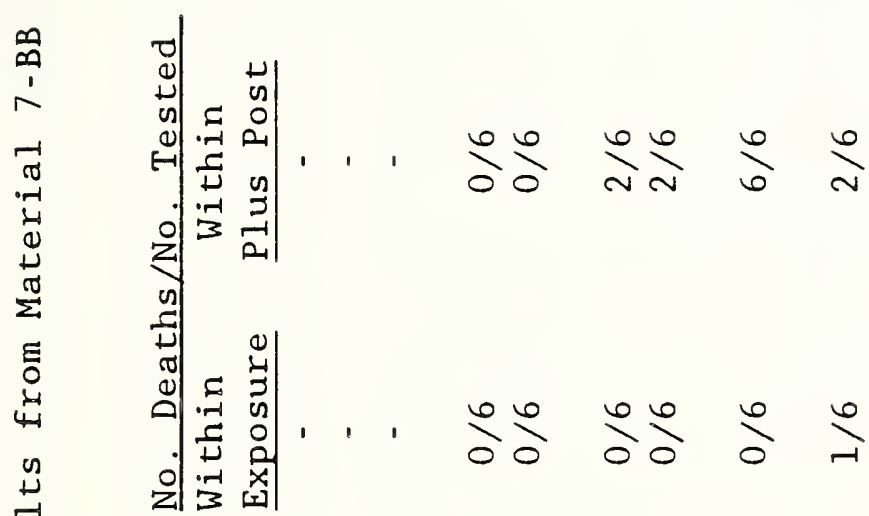

-1
0
$0-1$
0
0
0
0
-1
-7
0
0

吾

4

苾

ฮี

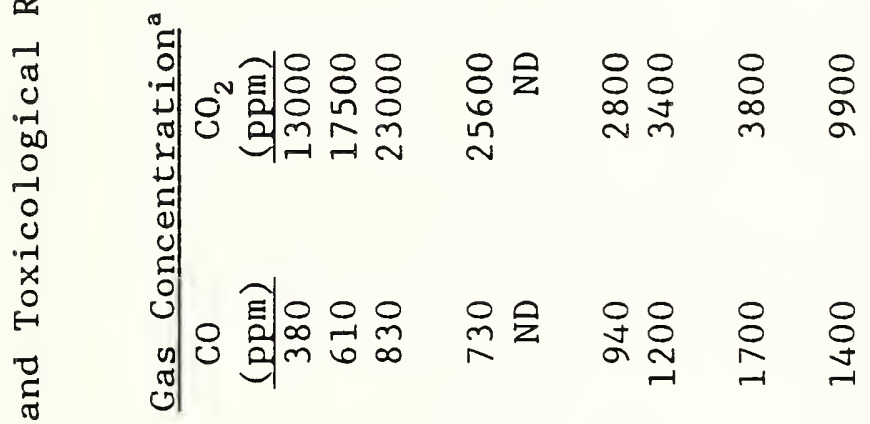

อ

先

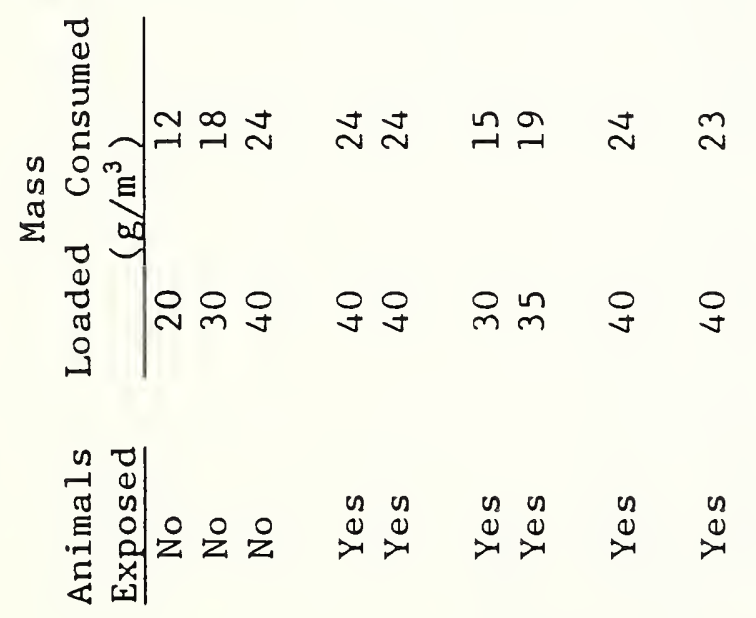

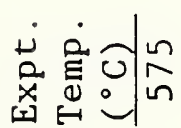

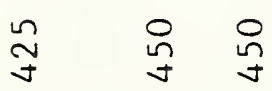

ฮ్ర

○

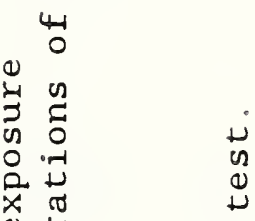



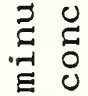

응

$\begin{array}{ll}4 & 0 \\ 0 & 0 \\ 0 & 0 \\ 0 & 0\end{array}$

○

$\stackrel{1}{\circ}$

$\frac{1}{\pi}$

용

${ }_{\pi}^{+\infty}$

幽

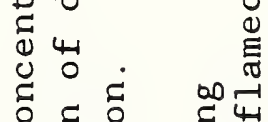

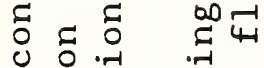

० 0 ป艹

$\infty 0 \pi \approx-1$

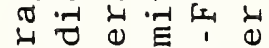

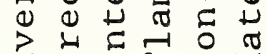

突|

空

1
1
岸

$\ddot{\sigma} \ddot{0} \ddot{1} \ddot{1} \ddot{2}$ z 


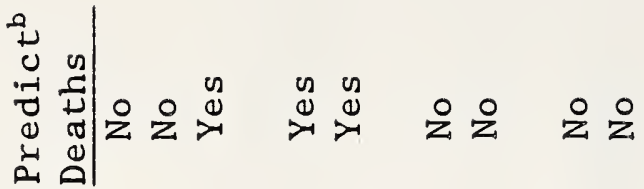

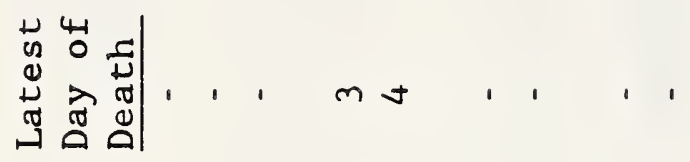

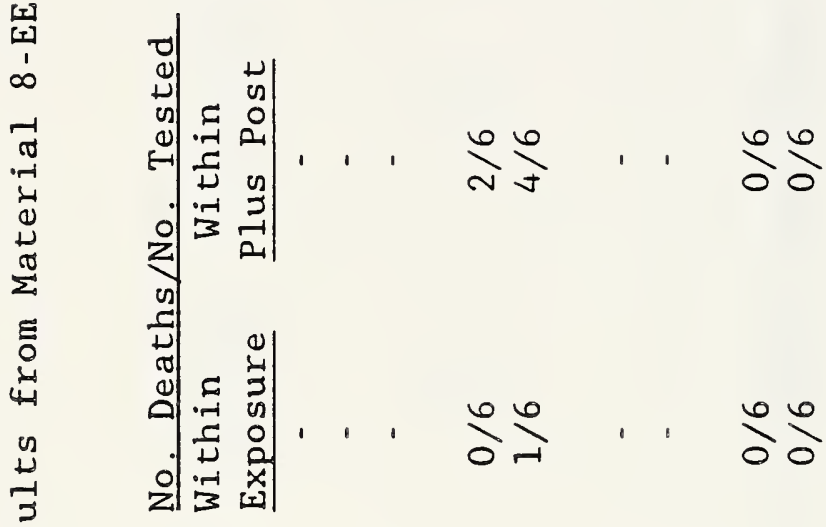

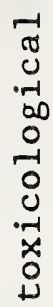

$\frac{11}{21}$

4

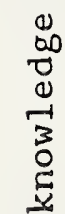

ซ్ర

8̊

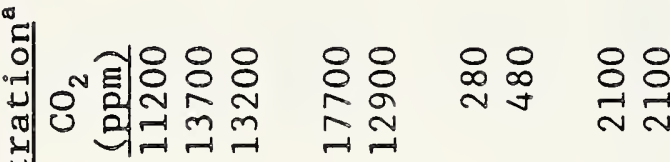

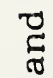

8

ن

$\underset{0}{01}$

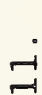

$\stackrel{0}{\frac{0}{\pi}}$

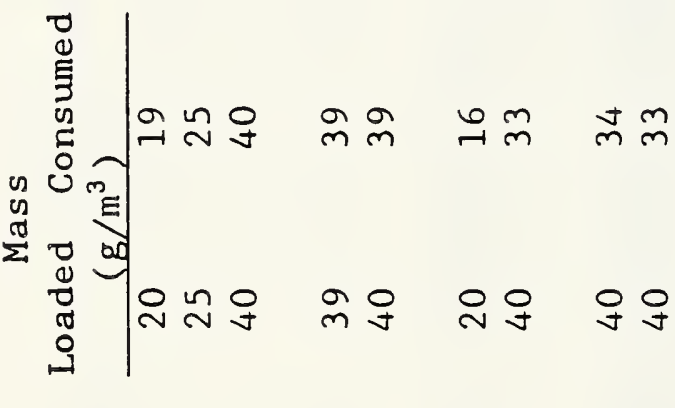

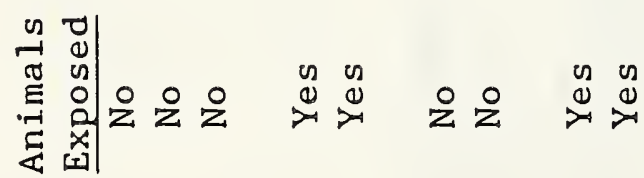

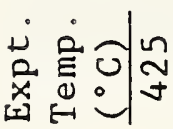

$\stackrel{n}{n}$

ํํำ

点

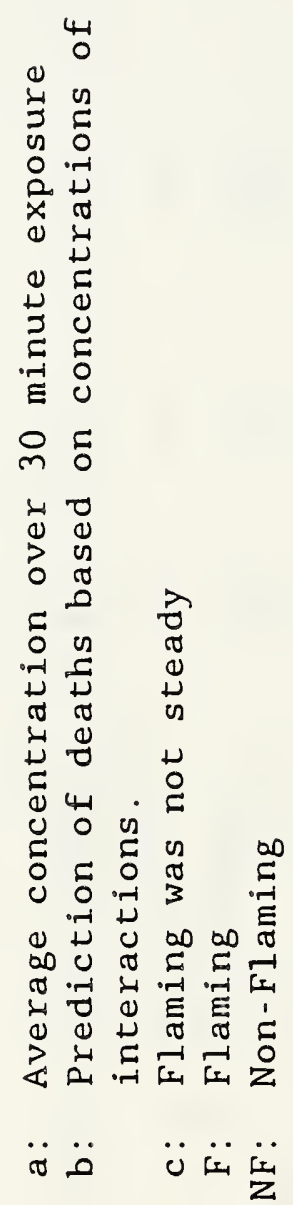




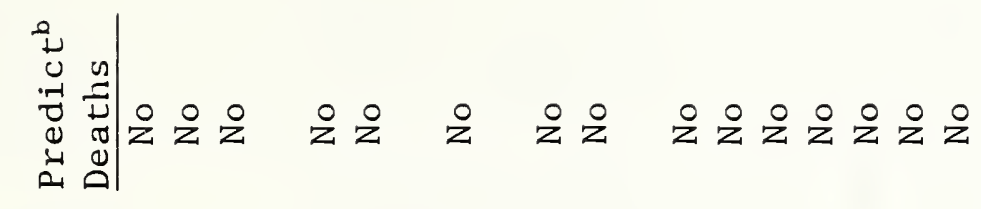

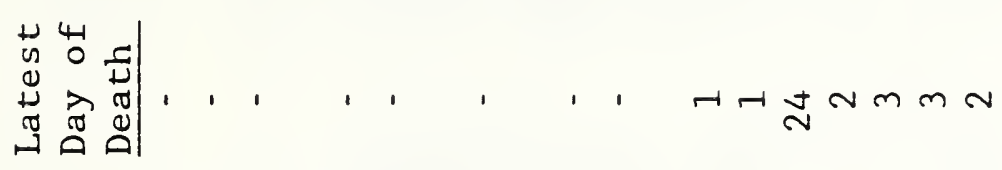

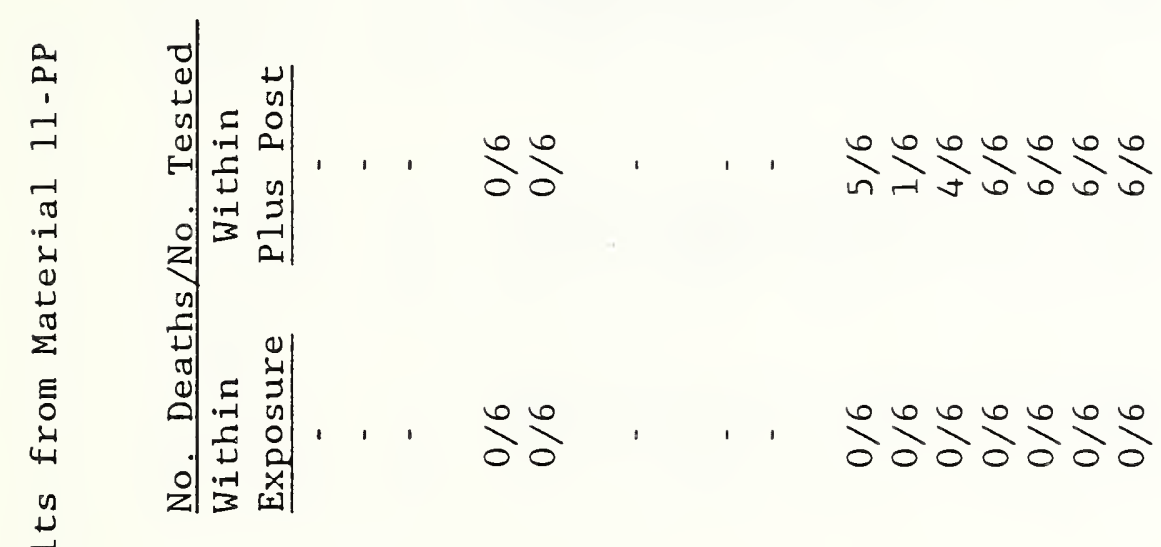

7
0
0
00
0
0
0
0
01
$x$
0
0

$\frac{\sqrt[n]{1}}{\frac{1}{2}}$

4

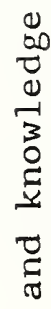

๑)

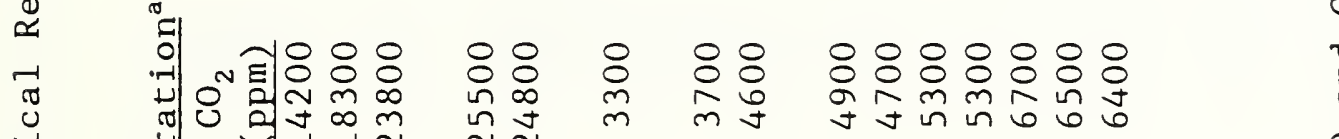

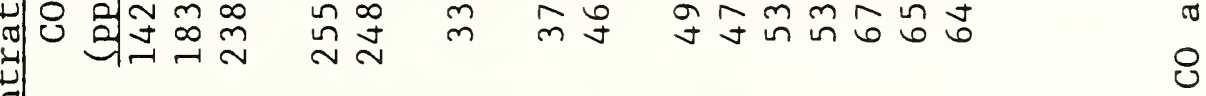

苞

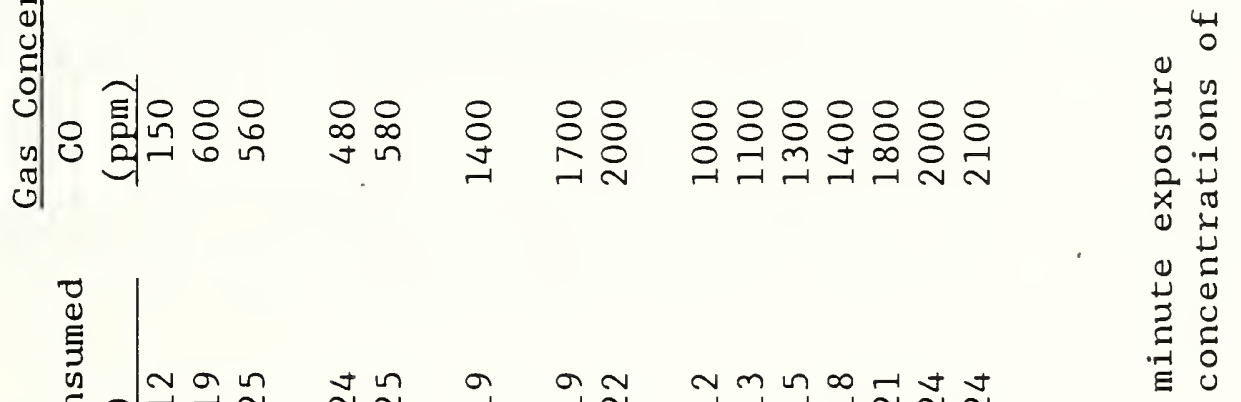

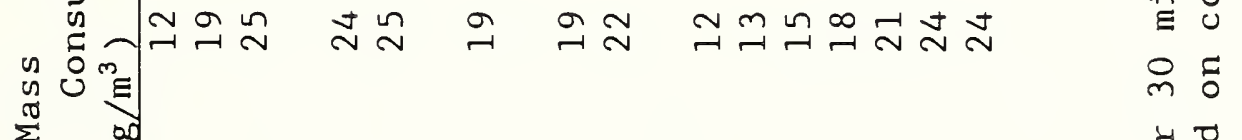

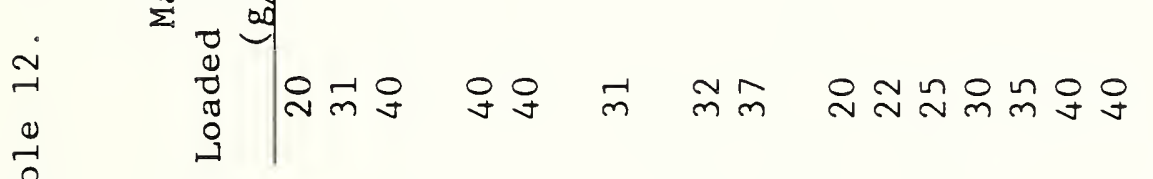

-10
0
0
0
0
0
0

$\overbrace{0}^{0}$

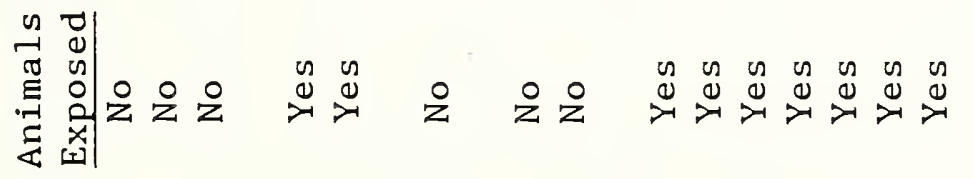

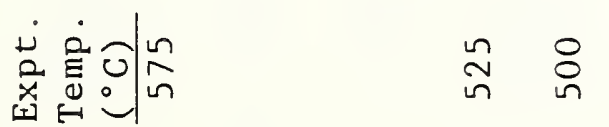

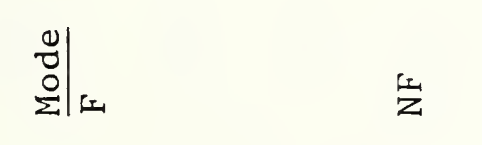

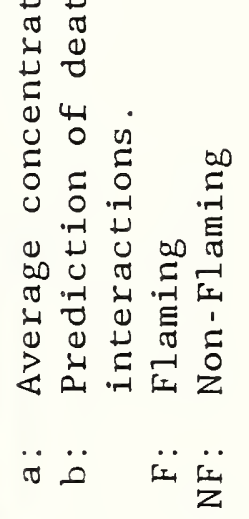




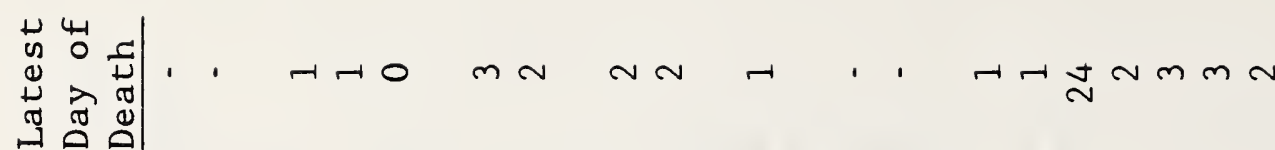

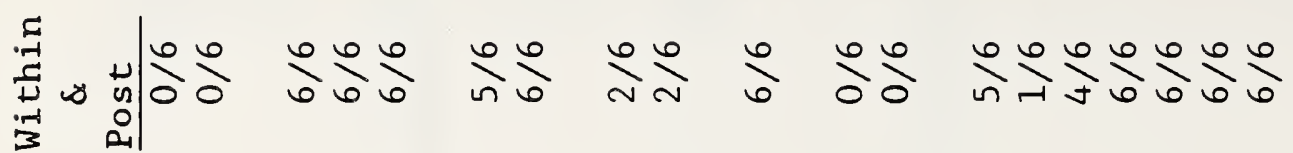

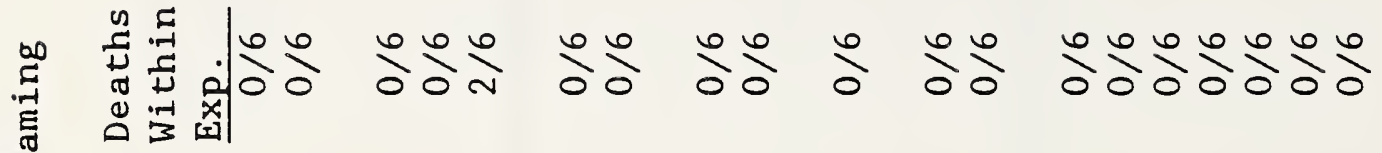

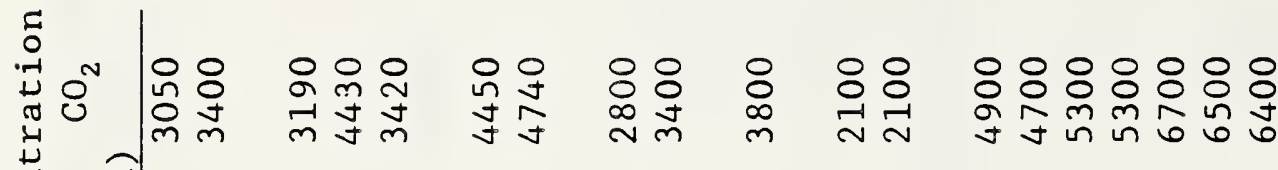

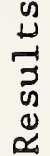

(ี) ह

¿

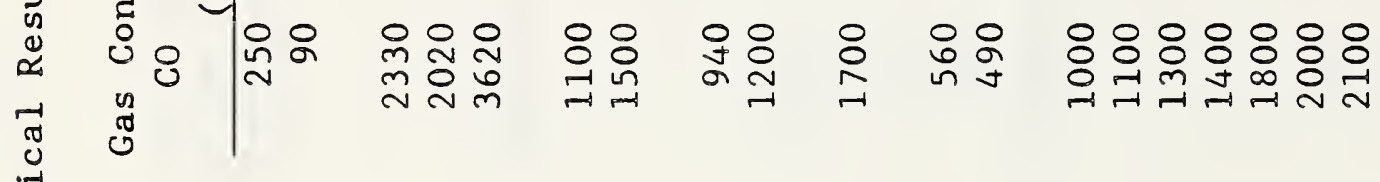

ه

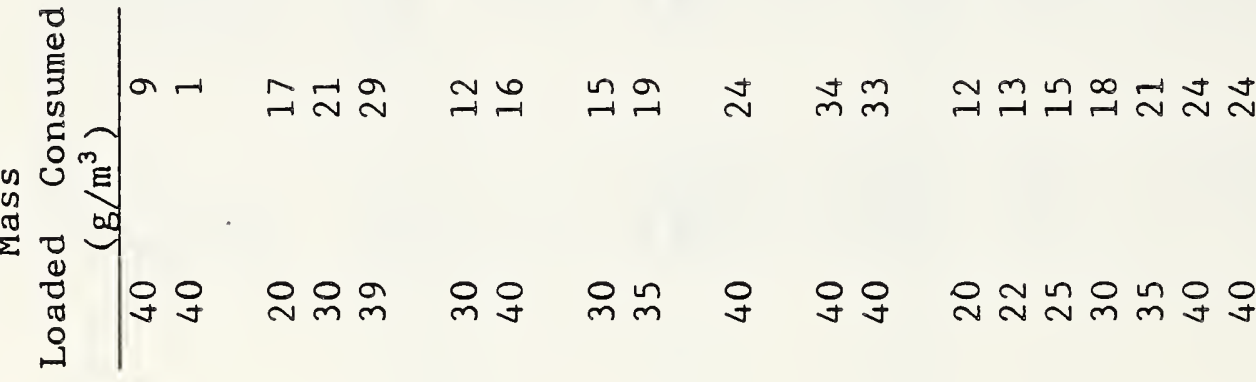

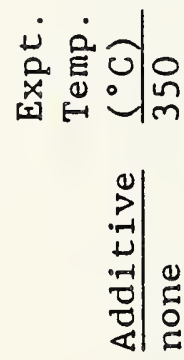

$\stackrel{n}{n}$

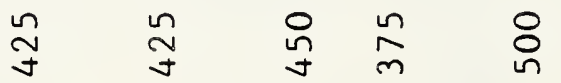

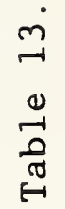

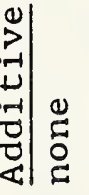

$\bigcup_{0}^{m} \quad$ 工्ञ

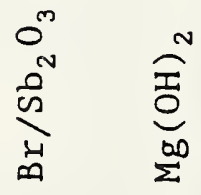

年

武 武

일 뇜

$\underset{0}{0} \mid \begin{aligned} & 3 \\ & 0\end{aligned}$

$\begin{array}{ll}\text { I } & \frac{m}{1} \\ 0 & n\end{array}$

秃 


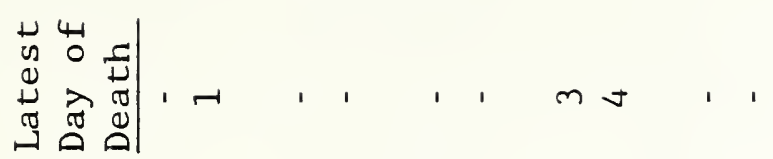

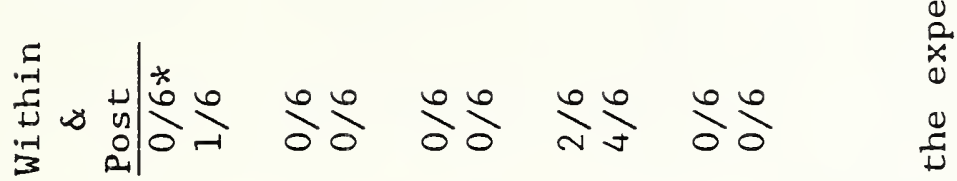

常

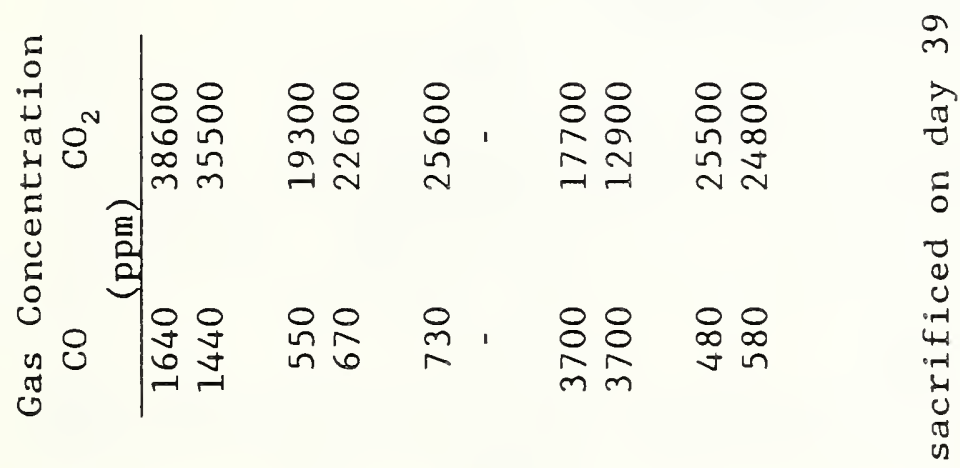

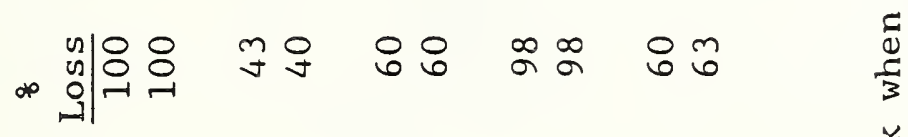

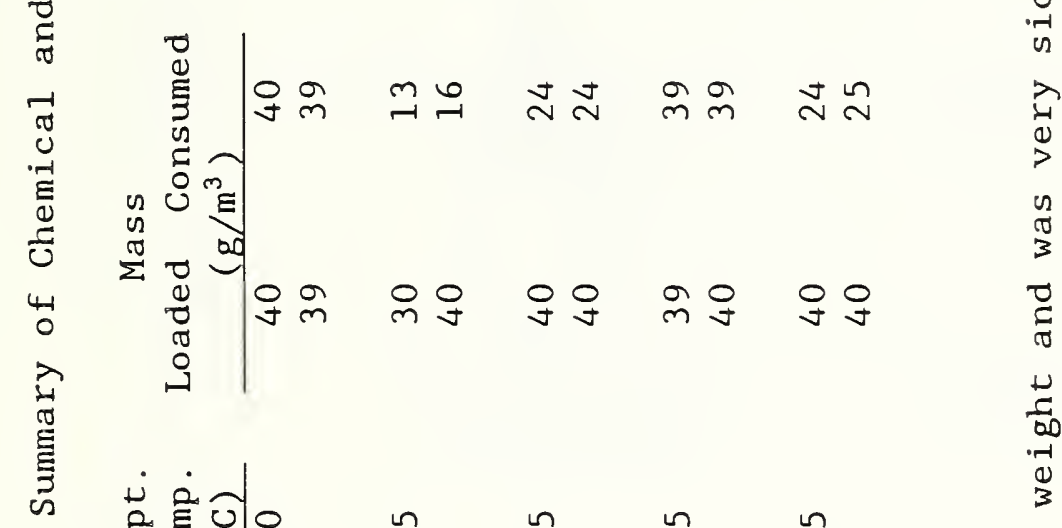

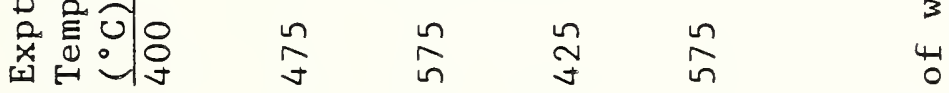

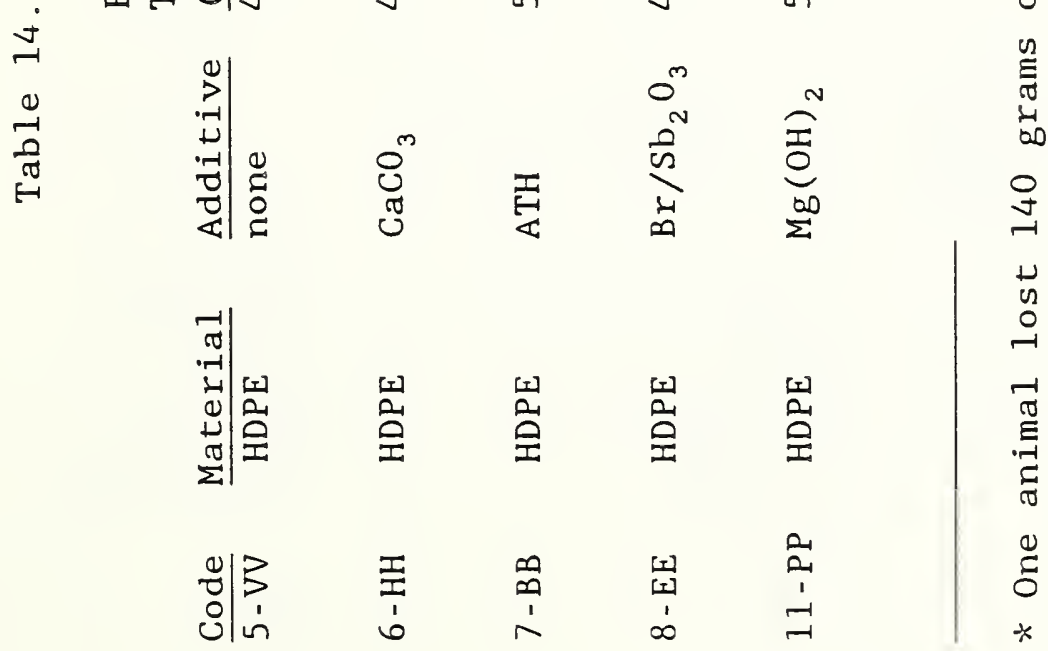




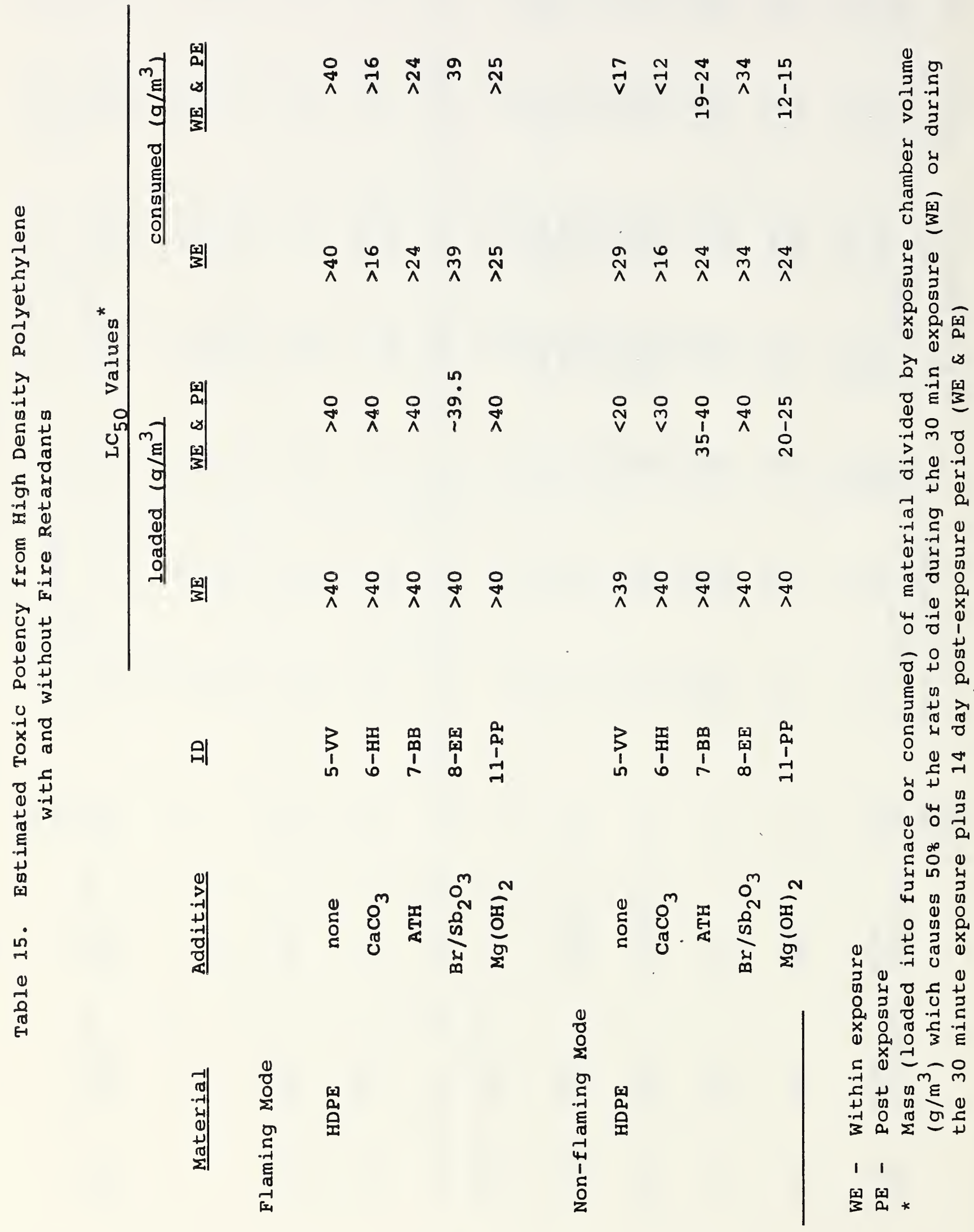




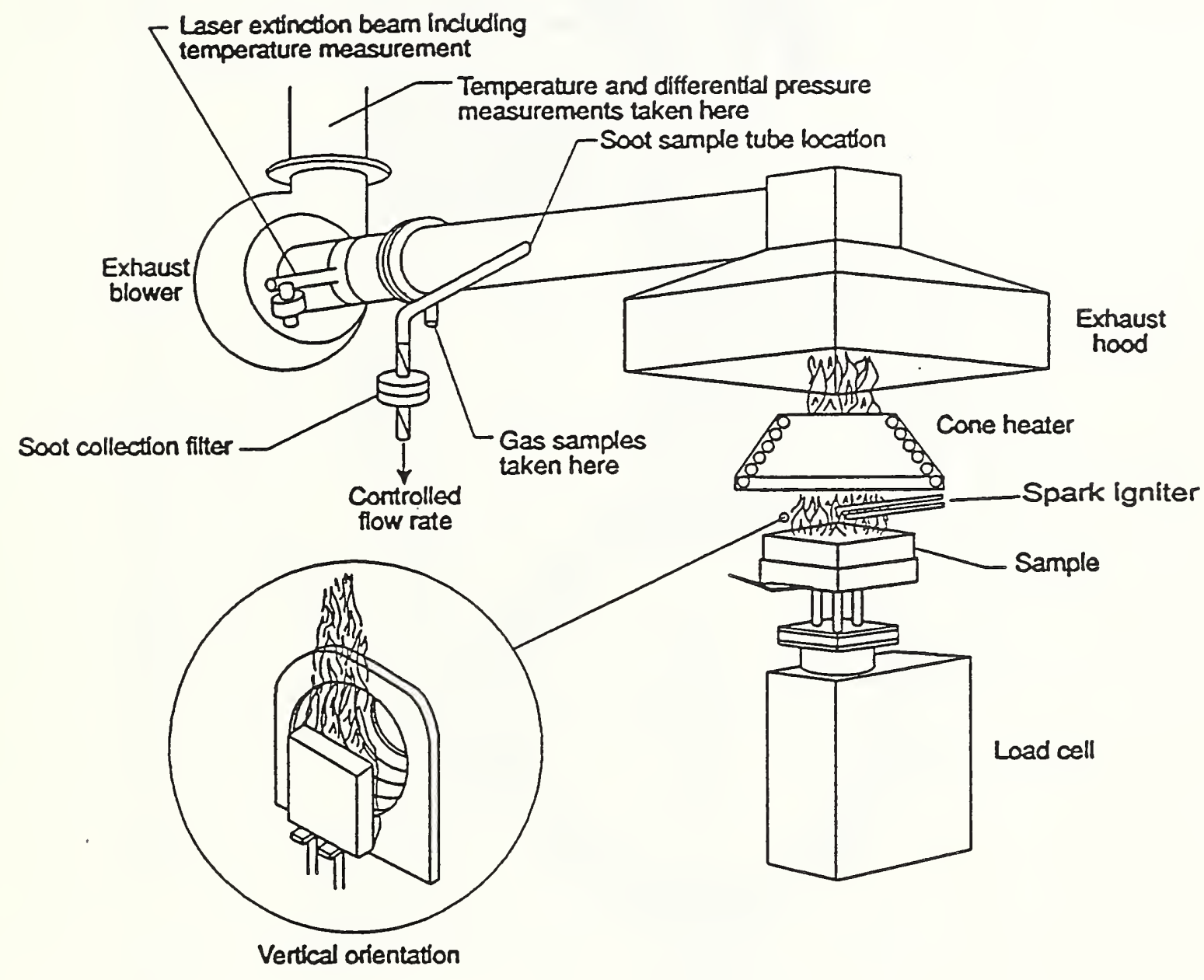

Figure 1. Conceptual View of the Cone Calorimeter 


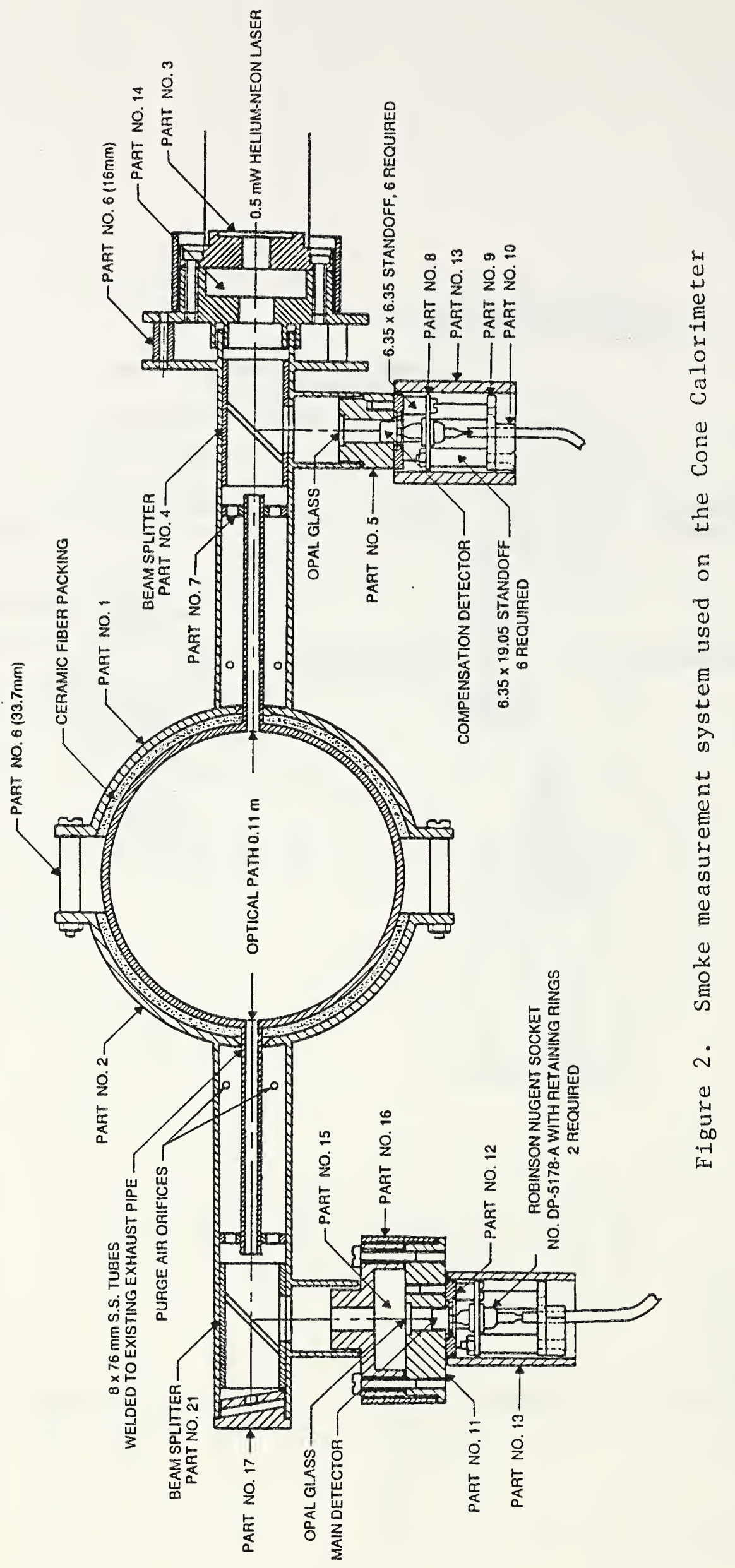




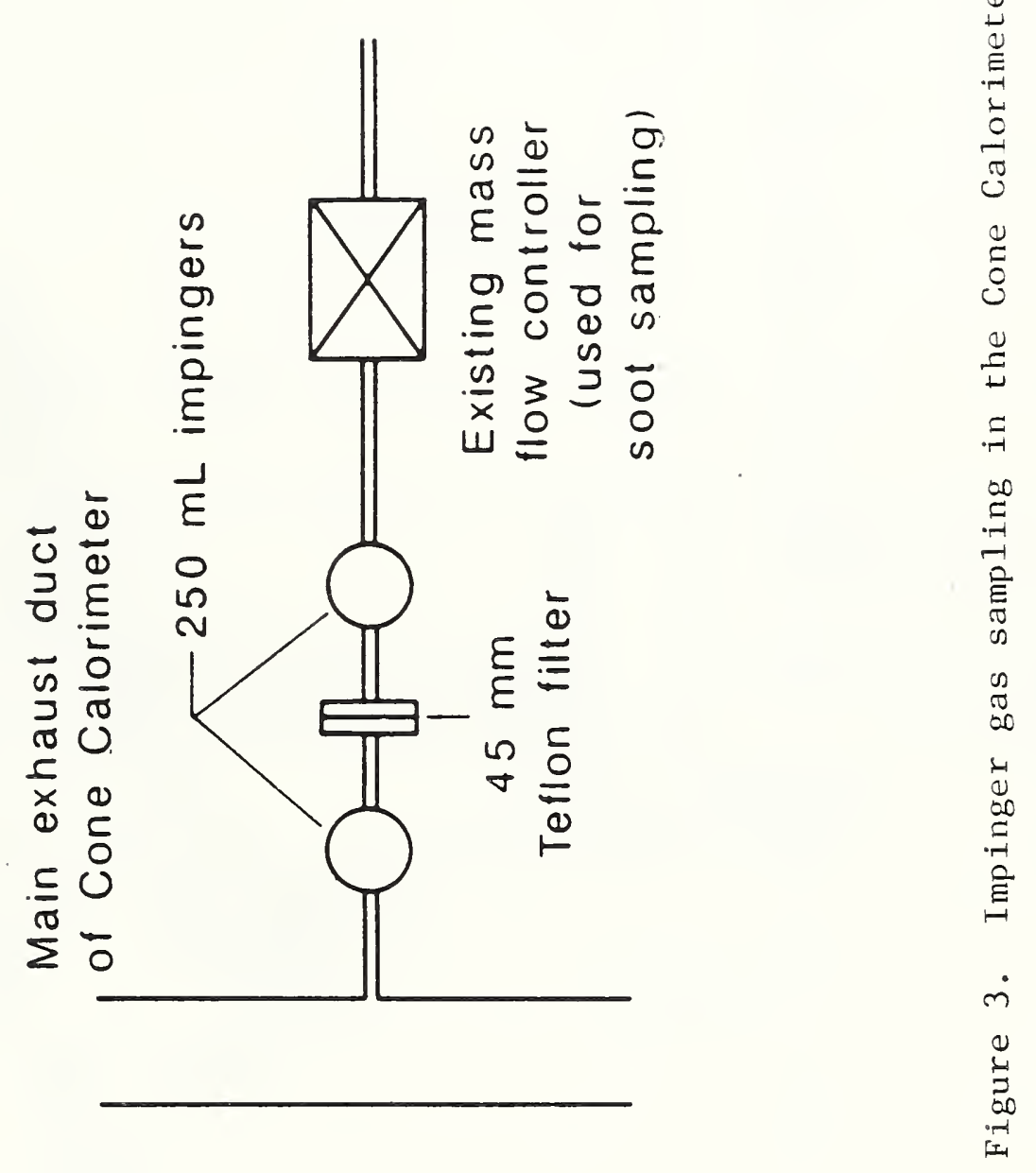




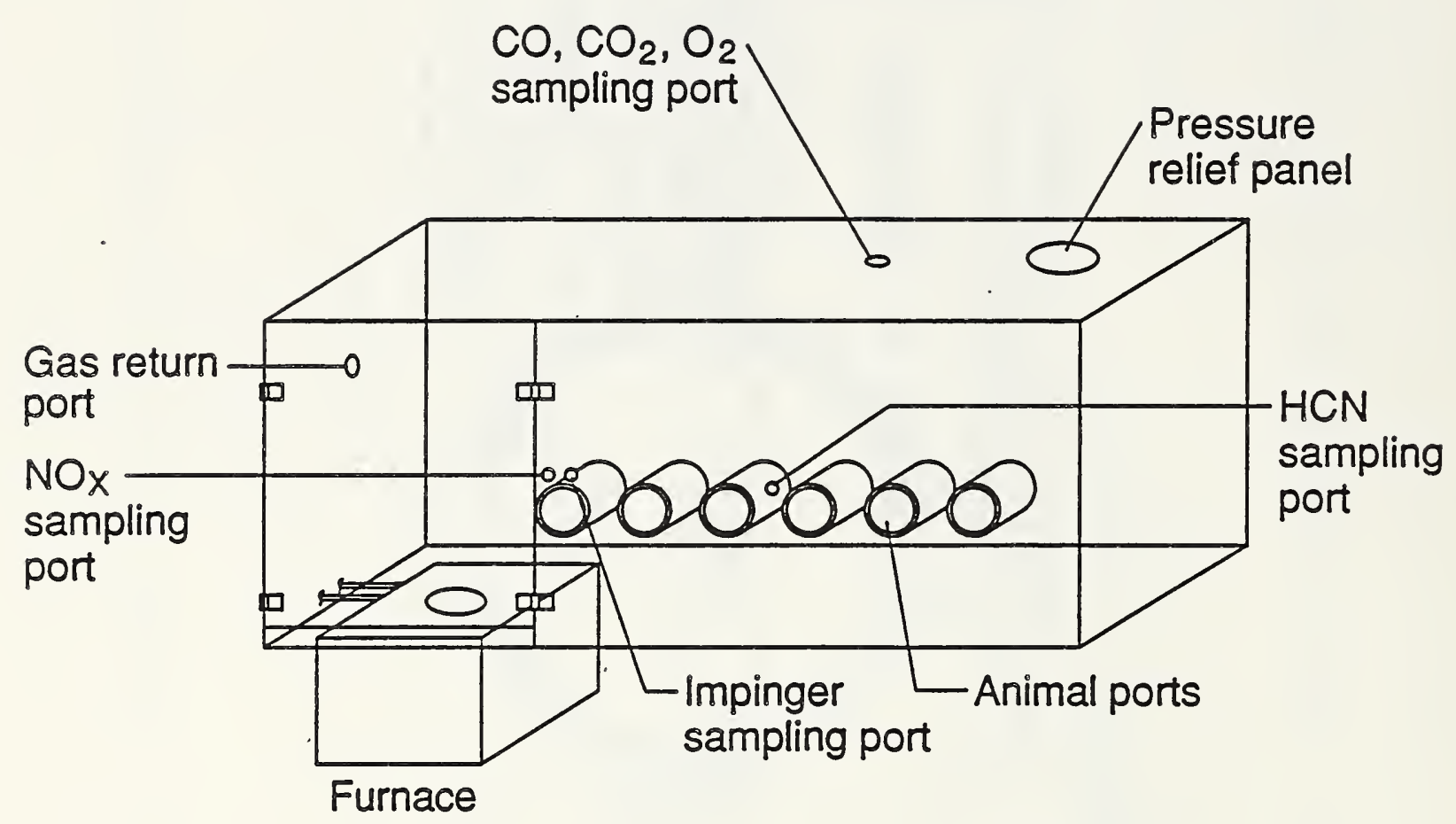

Figure 4. Animal Exposure System 


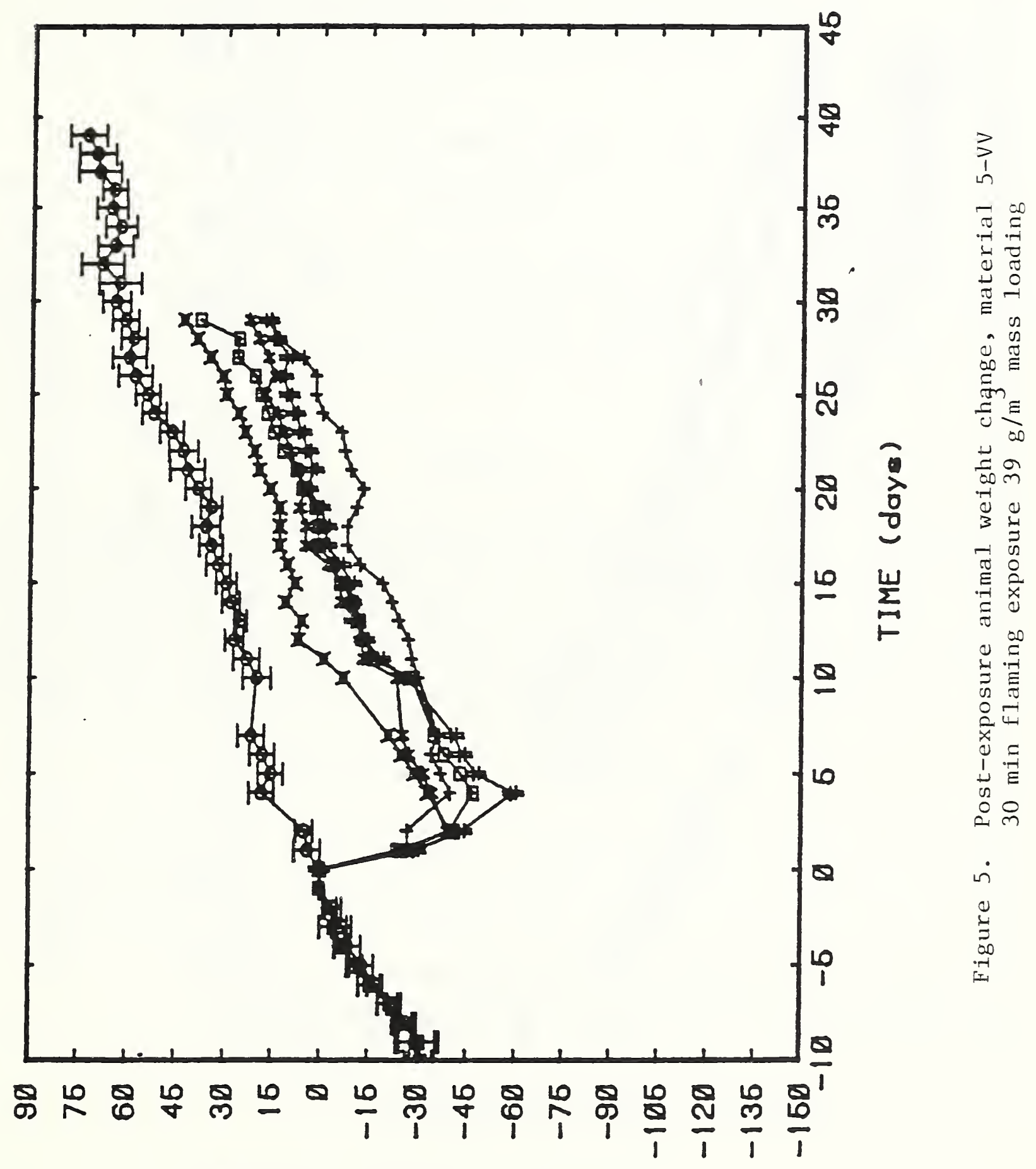

(вسD 


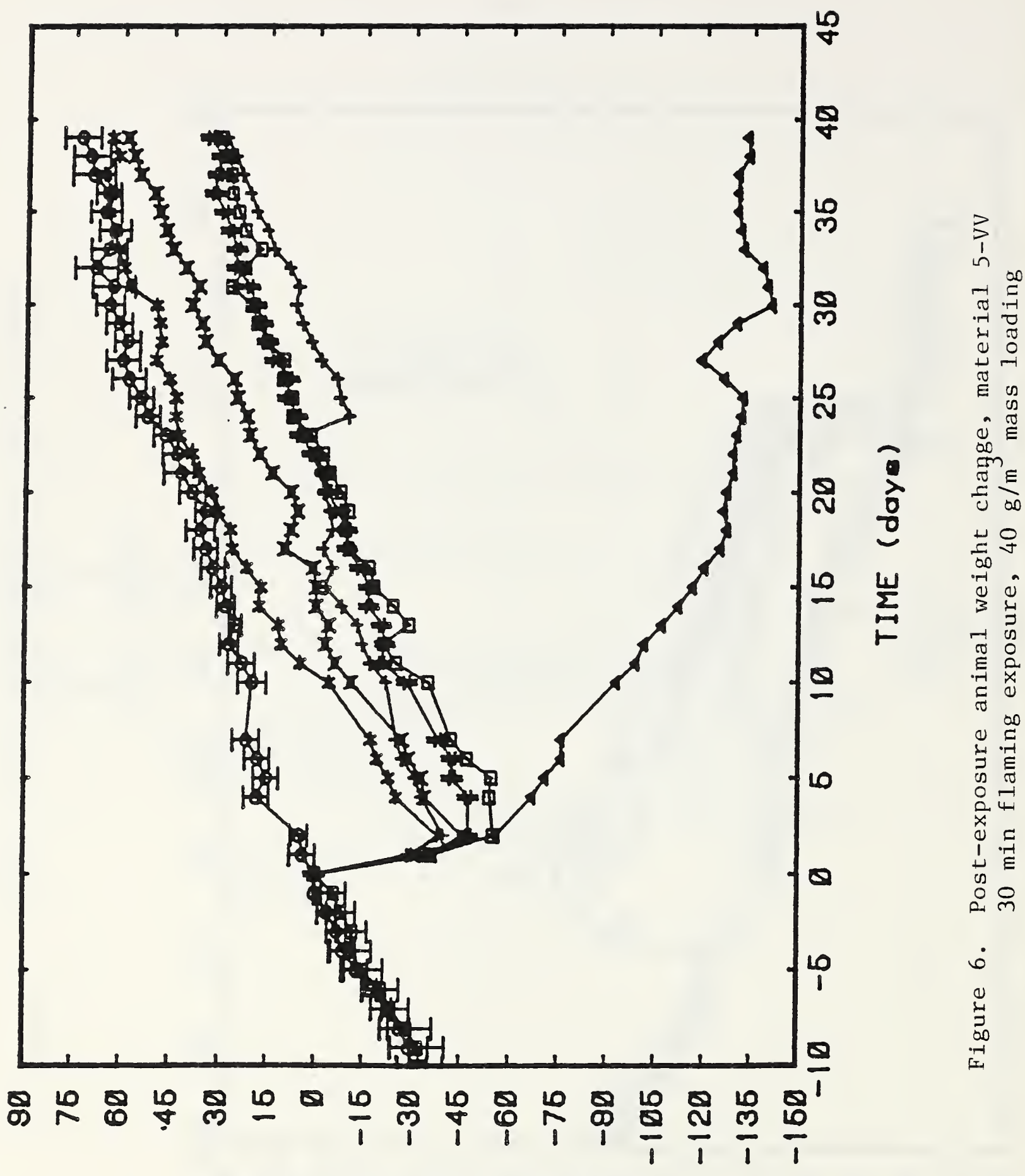

( WDدB) LHOIJM NI JONYHO 


\section{APPENDIX A. ION CHROMATOGRAPHY PROCEDURE}

\section{Apparatus}

A commercially available ion chromatograph (Waters Model ILC-1 Ion/Liquid Chromatograph) equipped with a Waters 430 Total Conductivity Detector was used to analyze for $\mathrm{Br}^{-}$and $\mathrm{Cl}^{-}$. An anion column (ICPAK-A or ICPAK-A HR) preceded by an Anion Guard-Pak Precolumn Module, all commercially available from Waters, was used. Chromatograms were recorded on a Spectra-Physics Model SP 4270 Integrator.

\section{$\underline{\text { Reagents }}$}

Al1 chemicals used in this work were of reagent grade quality. The water used was conditioned to $18.3 \mathrm{M} \Omega-\mathrm{cm}$ and passed through a $0.45 \mu \mathrm{m}$ nominal porosity filter. Initially, the eluent for the ion chromatograph was $5 \mathrm{mM} \mathrm{KOH}$; later in the study, the eluent was modified to $95 \% 5 \mathrm{mM} \mathrm{KOH} / 5 \%$ acetonitrile. Stock solutions of $\mathrm{Br}^{-}$and $\mathrm{Cl}^{-}$, nominally $1000 \mathrm{ppm}$, were prepared by dissolving $0.1489 \mathrm{~g}$ of $\mathrm{KBr}$ and $0.2100 \mathrm{~g}$ of $\mathrm{KCl}$, respectively, in $100 \mathrm{~mL}$ of the eluents described above. Calibration solutions of 1.0 to $5.0 \mathrm{ppm}$ for $\mathrm{Br}^{-}$and $\mathrm{Cl}^{-}$were prepared by serial dilution of the stock solutions with the eluents.

\section{Chromatographic Procedure}

The eluent flow rate was $1.0 \mathrm{~mL} / \mathrm{min}$. The sample loop had a volume of $100 \mu \mathrm{L}$. Unknowns were diluted 1:10 with eluent. Samples and standards were loaded into the loop using a syringe and a $0.45 \mu \mathrm{m}$ syringe filter. The sample loop was rinsed with $\mathrm{ca}$. $1 \mathrm{~mL}$ of the analyte solution before the sample was injected onto the column. 



\begin{tabular}{|c|c|c|}
\hline \multirow[t]{4}{*}{$\begin{array}{l}\text { NIST:-114A } \\
\text { (REV. 3-89) }\end{array}$} & \multirow{3}{*}{$\begin{array}{l}\text { U.S. DEPARTMENT OF COMMERCE } \\
\text { NATIONAL INSTITUTE OF STANDARDS AND TECHNOLOGY } \\
\text { BIBLIOGRAPHIC DATA SHEET }\end{array}$} & $\begin{array}{l}\text { 1. PUBUCATION OR REPORT NUMBER } \\
\text { NISTIR } 4649\end{array}$ \\
\hline & & 2. PERFORMING ORGANIZATION REPORT NUMBER \\
\hline & & \\
\hline & & October 1991 \\
\hline
\end{tabular}

4. TITLE AND SUBTITLE

Data for Fire Hazard Assessment of Selected Non-halogenated and Halogenated Fire Retardants; Report of Test FR 3983

5. AUTHOR(S) Richard H. Harris, Jr., Vytenis Babrauskas, Barbara C. Levin, Maya Paabo

6. PERFORMINO OROANIZATION (IF JOINT OR OTHER THAN NIST, SEE INSTRUCTIONS)

U.S. DEPARTMENT OF COMMERCE

NATIONAL INSTITUTE OF STANDARDS AND TECHNOLOGY

GAITHERSBURG, MD 20899

\section{CONTRACT/GRANT NUMBER \\ 8. TYPE OF REPORT AND PERIOD COVERED}

9. SPONSORING ORGANIZATION NAME AND COMPLETE ADDRESS (STREET, CITY, STATE, ZIP)

J.M. Huber CORporation/Solem Division
H. HATION

4940 Peachtree Industrial Blvd.

Norcross, Georgia 30071

Aluminum Company of America

Route 780,7 th Street road

Alcoa Center, Pennsylvania 15069

10. SUPPLEMENTARY NOTES

DOCUMENT DESCRIBES A COMPUTER PROGRAM; SF-185, FIPS SOFTWARE SUMMARY, IS ATTACHED.

11. ABSTRACT (A 2OO-WORD OR LESS FACTUAL SUMMARY OF MOST SIGNIFICANT INFORMATION. IF DOCUMENT INCLUDES A SIGNIFICANT BIBLOGRAPHY OR UTERATURE SURVEY, MENTION IT HERE.)

Five plastic materials, with and without fire retardants, were studied to compare the fire hazards of non-halogenated fire retardant additives with halogenated flame retardants. The plastic materials were identified by the sponsors as unsaturated polyesters, thermoplastic high density, low density and cross-linked low density polyethylenes, polypropylene, flexible and rigid poly(vinyl chlorides), and cross-linked and thermoplastic ethylene-vinyl acetate copolymers. The non-halogenated fire retardants tested were aluminum hydroxide $\left(\mathrm{Al}(\mathrm{OH})_{3}\right)$, also known as alumina trihydrate (ATH), sodium alumino-carbonate, and magnesium hydroxide. The halogenated flame retardants were chlorine or bromine/antimony oxides. The plastics were studied using the Cone Calorimeter and the cup furnace smoke toxicity method (high density polyethylene only). The Cone Calorimeter provided data on mass consumed, time to ignition, peak rate and peak time of heat release, total heat released, effective heat of combustion, average yields of $\mathrm{CO}, \mathrm{CO}_{2}, \mathrm{HCl}$, and $\mathrm{HBr}$, and average smoke obscuration. The concentrations of toxic gases generated in the cup furnace smoke toxicity method were used to predict the toxic potency of the mixed thermal decomposition products. The data from the Cone Calorimeter indicate that the non-halogenated fire retardants were, in most of the tested plastic formulations, more effective than the halogenated flame retardants in increasing the time to ignition. The non-halogenated fire retardants were also more effective in reducing the mass consumed, peak rate of heat release, total heat released, and effective heat of combustion, and in reducing the amount of smoke produced. The use of halogenated flame retardants increased smoke production and $\mathrm{CO}$ yields and, additionally, produced the known acid gases and toxic irritants, $\mathrm{HCl}$ and $\mathrm{HBr}$, in measurable quantities. The chemical analytical dats for the high density polyethylene samples decomposed via the cup furnace smoke toxicity method in the non-flaming mode indicated that the levels of $\mathrm{CO}$ and $\mathrm{CO}_{2}$ were insufficient to cause death of the test animals (rats), but deaths did occur with all samples except the one containing the halogenated flame retardant. In the flaming mode deaths occurred during exposure to the combustion products from the non-fire retarded control and from the halogenated sample; only in the latter case were the CO and $\mathrm{CO}_{2}$ concentrations high enough to cause the within exposure deaths. These toxicity results are unusual, but do not indicate a need for concern, since the $\mathrm{LC}_{50}$ values are in the range typical of many common materials.

12. KEY WORDS (6 TO 12 ENTRIES; ALPHABETICAL ORDER; CAPITALZE ONLY PROPER NAMES; AND SEPARATE KEY WORDS BY SEMICOLONS)

Cone calorimeters; flame retardant treatments; halogenated compounds; plastics; polyethylenes; polypropylene; polyvinyl chloride; toxic hazards; toxicity.

FOR OFFICIAL DISTRIBUTION. DO NOT RELEASE TO NATIONAL TECHNICAL INFORMATION SERVICE (NTIS).

ORDER FROM SUPERINTENDENT OF DOCUMENTS, U.S. GOVERNMENT PRINTING OFFICE, WASHINGTON, DC 20402.

ORDER FROM NATIONAL TECHNICAL INFORMATION SERVICE (NTIS), SPRINGFIELD, VA 22161.

55

15. PRICE

A0 4 

